\title{
Mechanical vs. Electronic Strain: Oval-Shaped Alkynyl-Pt(II)-Phosphine Macrocycles
}

Jan Plutnar, ${ }^{a}$ Cecile Givelet, ${ }^{a, b}$ Cyprien Lemouchi, ${ }^{a, b}$ Jana Jaklová Dytrtová, ${ }^{a, c}$ Ivana Císařová, ${ }^{d}$ Simon J. Teat ${ }^{e}$ and Josef Michl ${ }^{a, b *}$

[a] Institute of Organic Chemistry and Biochemistry, Academy of Sciences of the Czech Republic, Flemingovo nám. 2, 16610 Prague 6, Czech Republic

[b] Department of Chemistry, University of Colorado, Boulder, CO 80309-0215, United States

[c] Department of Physiology and Biochemistry, Faculty of Physical Education and Sport, Charles University, José Martího 269/31, 16252 Prague 6, Czech Republic

[d] Department of Inorganic Chemistry, Faculty of Science, Charles University in Prague, Hlavova 2030, 12843 Prague 2, Czech Republic

[e] Advanced Light Source, Berkeley Laboratory, 1 Cyclotron Road, Berkeley, California, 94720, United States 
Mechanical vs. Electronic Strain: Oval-Shaped Alkynyl-Pt(II)-Phosphine Macrocycles Jan Plutnar, Cecile Givelet, Cyprien Lemouchi, Jana Jaklová Dytrtová, Ivana Císařová, Simon J. Teat and Josef Michl

Table of content

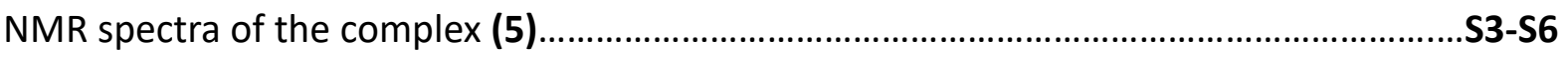

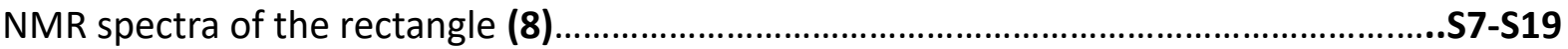

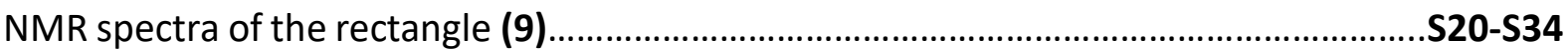

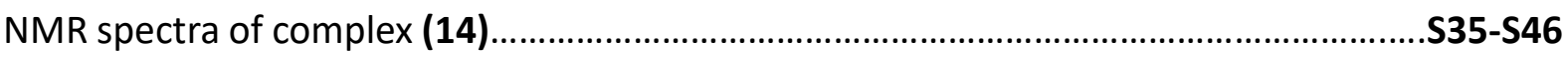

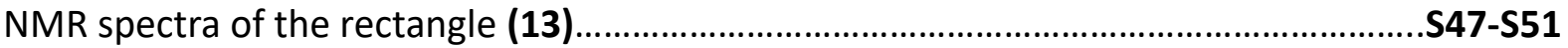

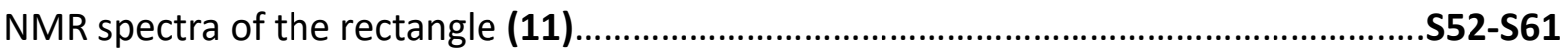

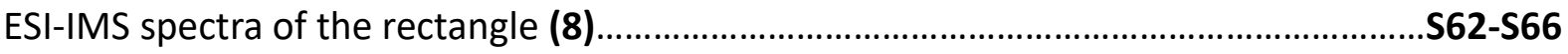

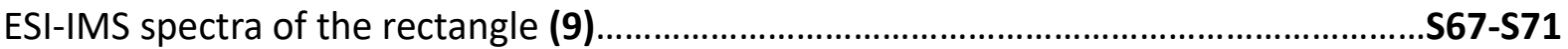

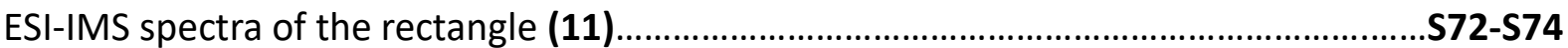

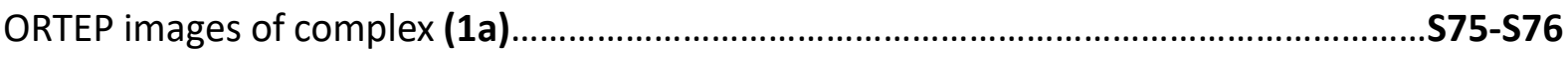

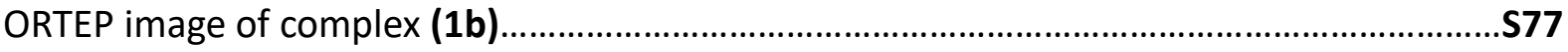

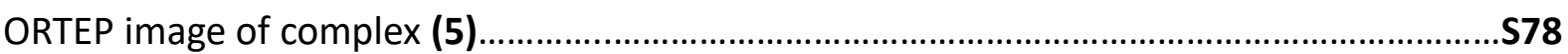

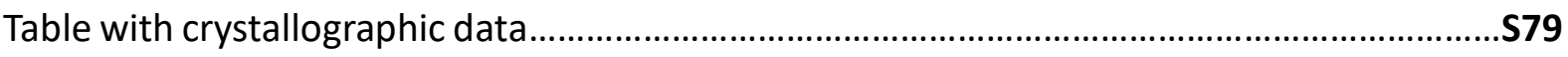

Syntheses and characterization of the model compounds.................................................S80-84 


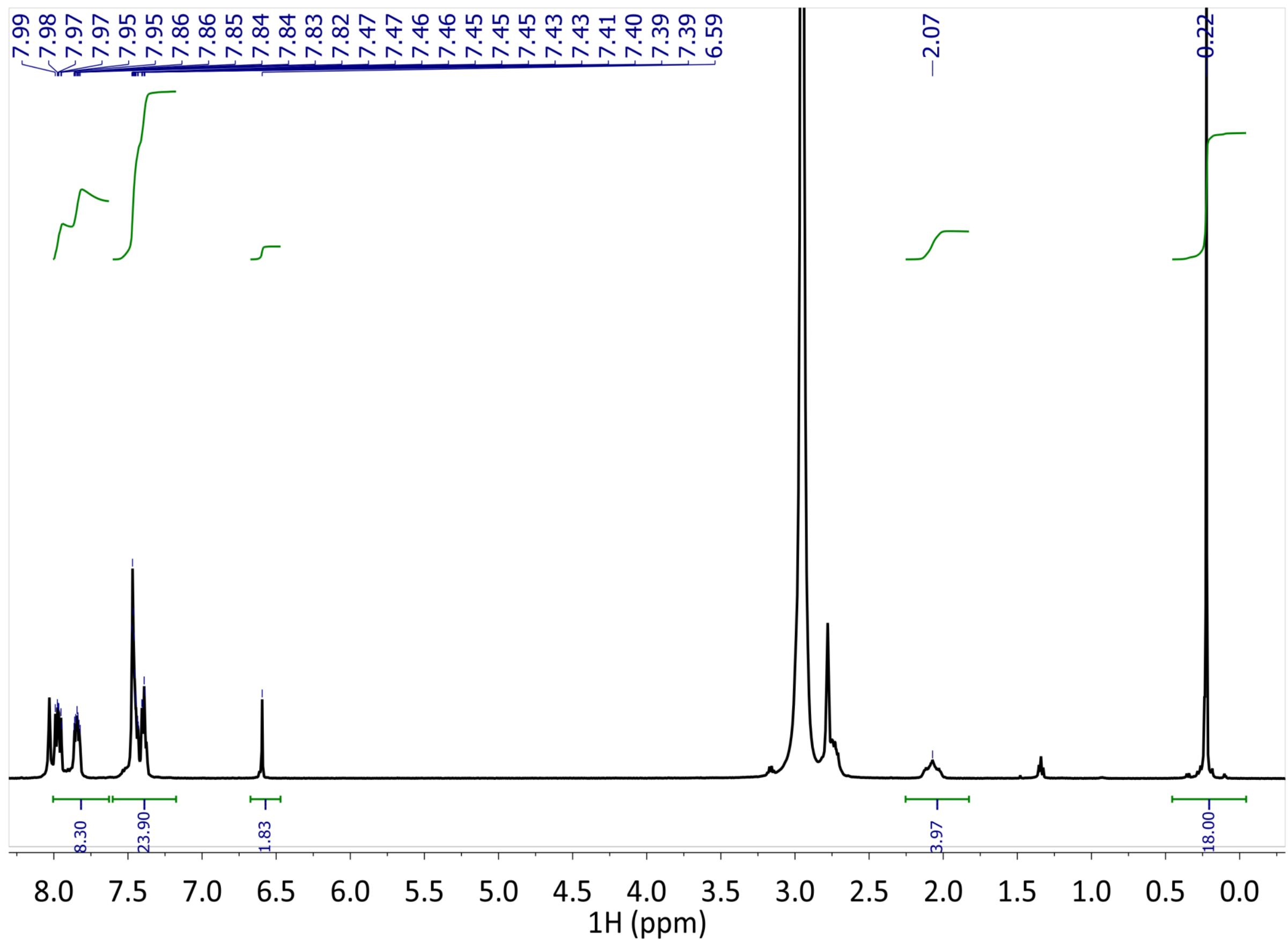

Figure S1. The ${ }^{1} H$ NMR spectrum of complex (5). 


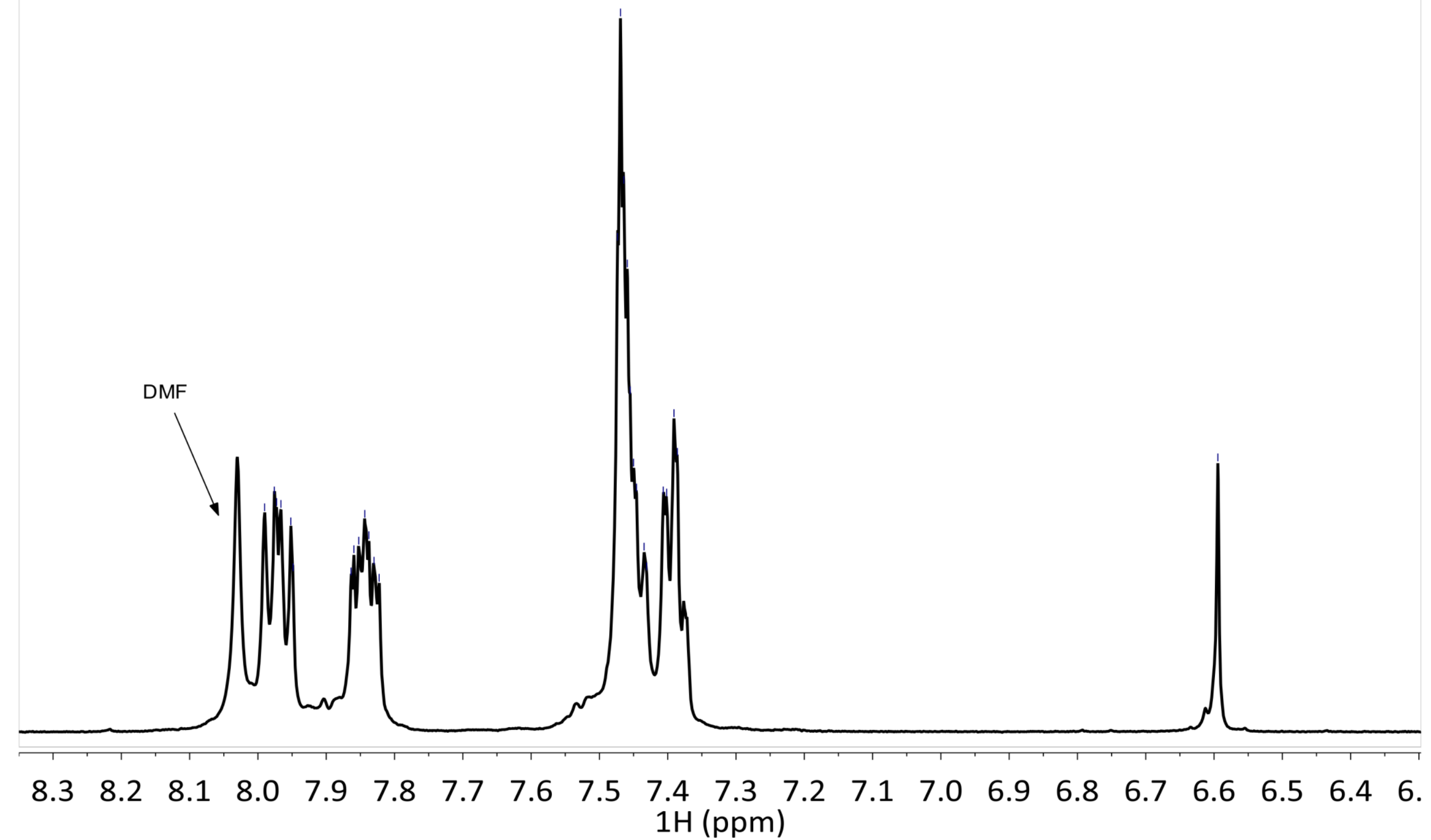

Figure S2. The aromatic region of the ${ }^{1} \mathrm{H}$ NMR spectrum of complex (5). 


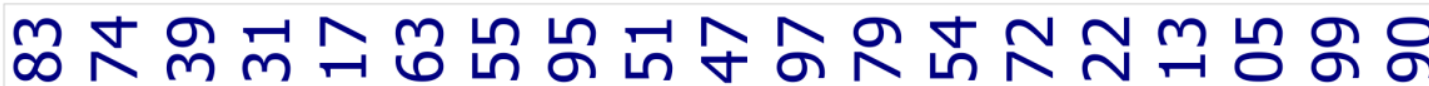
"ं $m m m m m m m m m m m m m m n n m m n$

$$
\begin{aligned}
& \infty \text { ॠ } \\
& \text { ज } \\
& \square
\end{aligned}
$$

丈 $m$ ก H $\infty_{1}^{\infty} \infty N_{=1}^{\infty}$

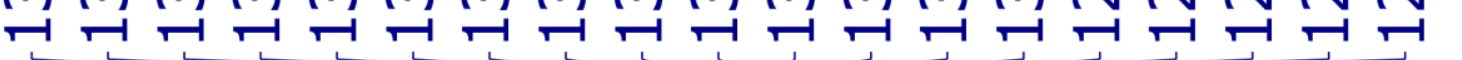

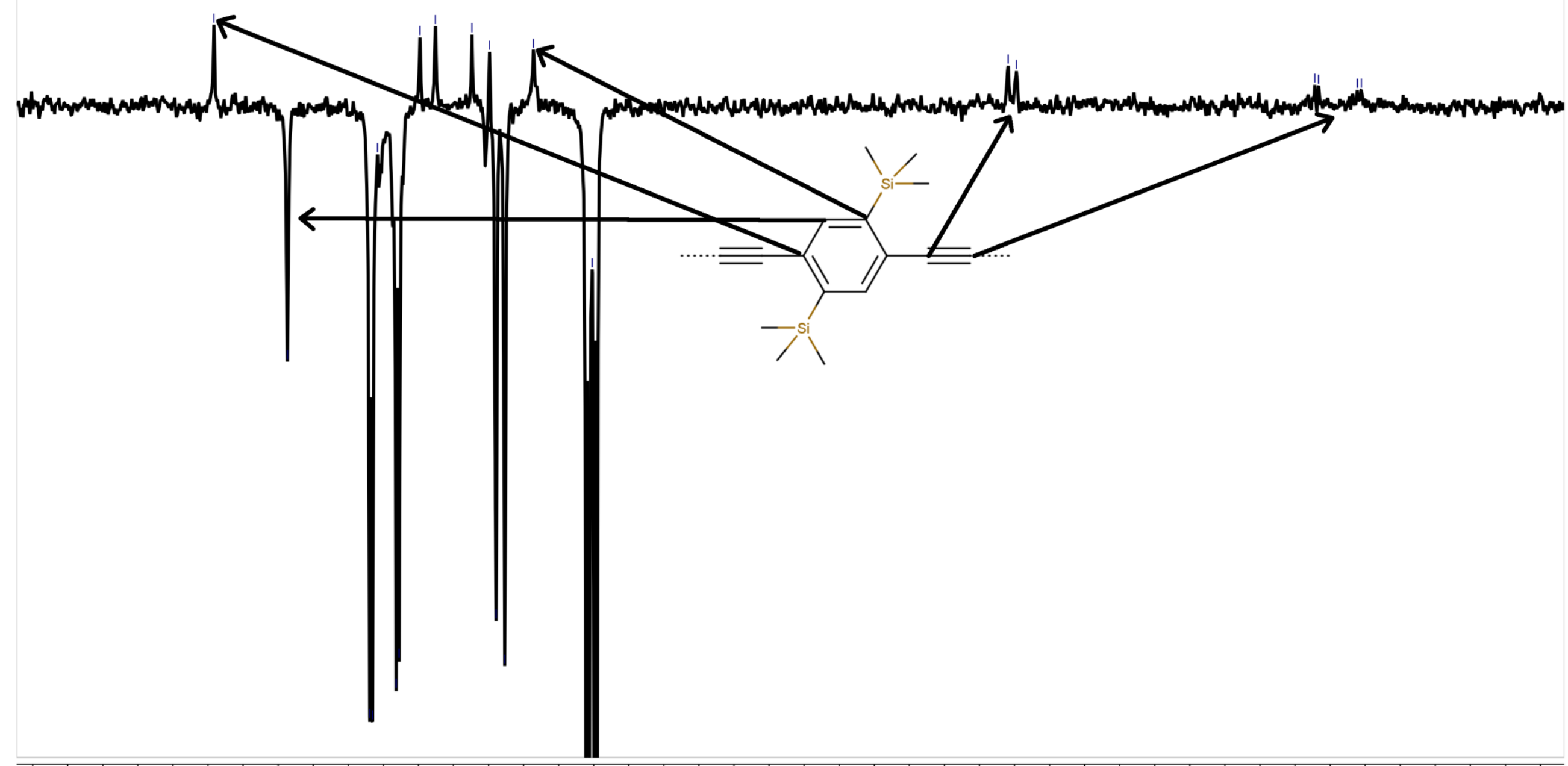

144142140138136134132130128126124122120118116114112110108106104102 $13 \mathrm{C}(\mathrm{ppm})$

Figure S3. The aromatic region of the APT spectrum of complex (5). 


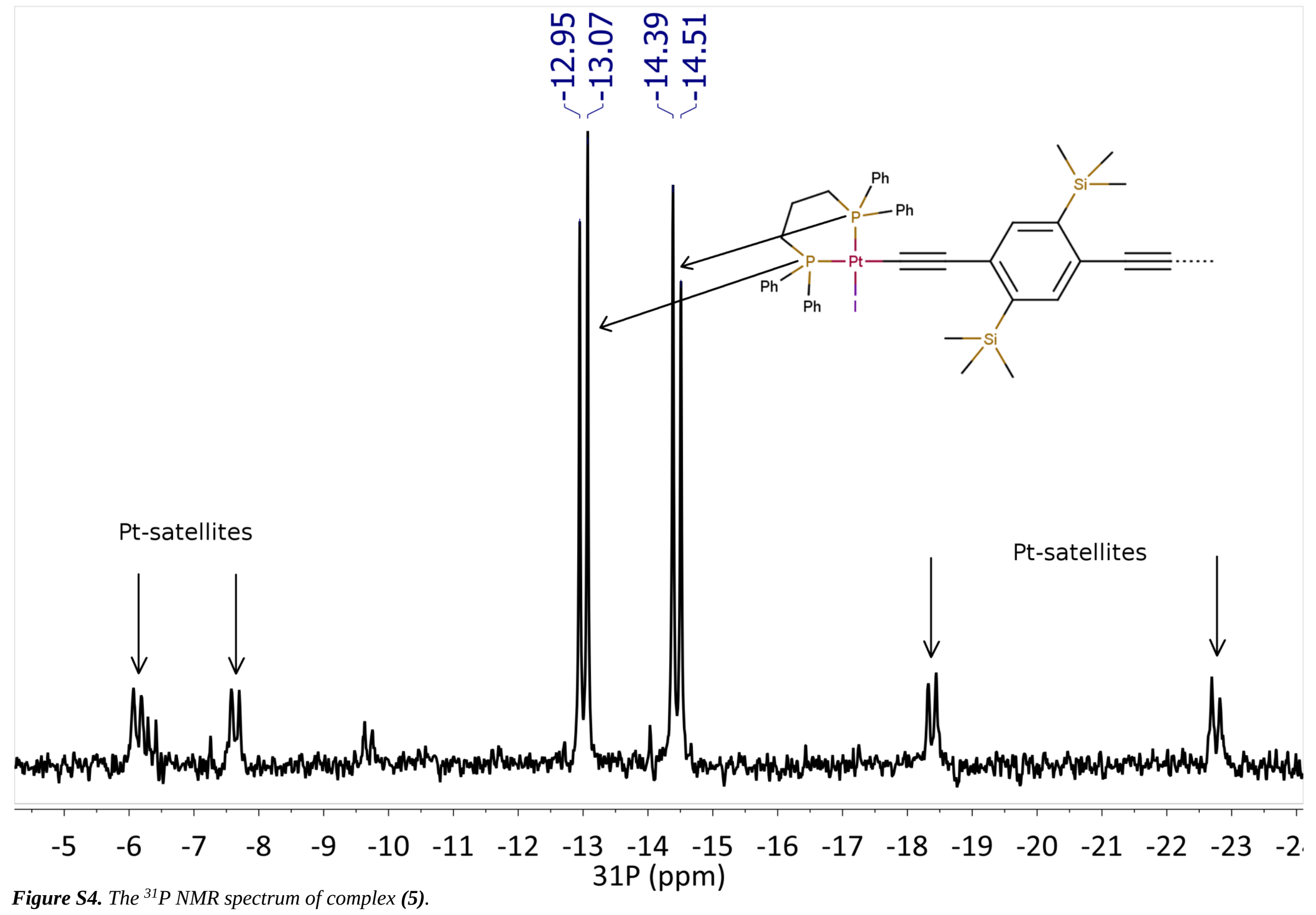

Figure S4. The ${ }^{31} P$ NMR spectrum of complex (5). 


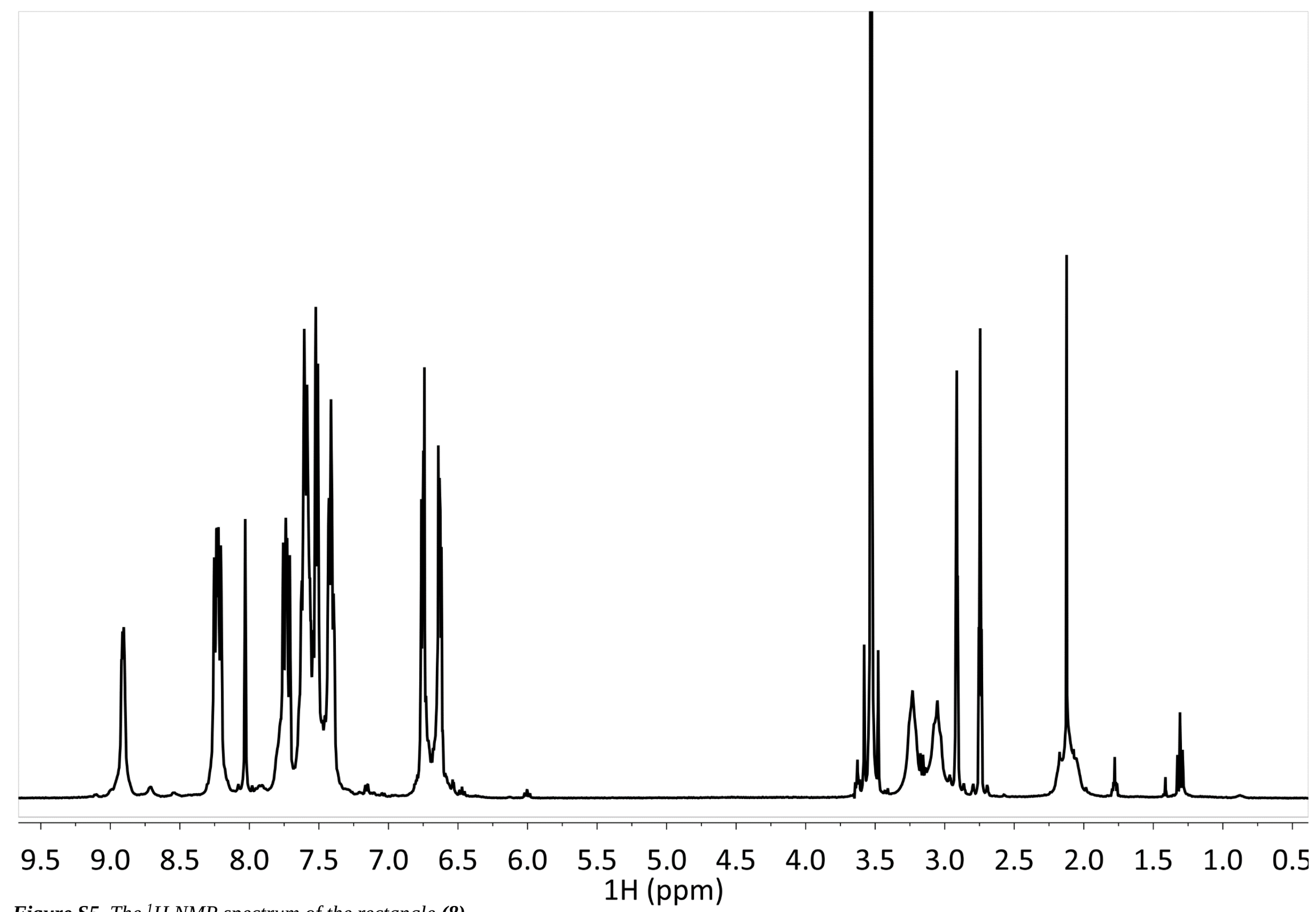

Figure S5. The ${ }^{1} H$ NMR spectrum of the rectangle (8). 


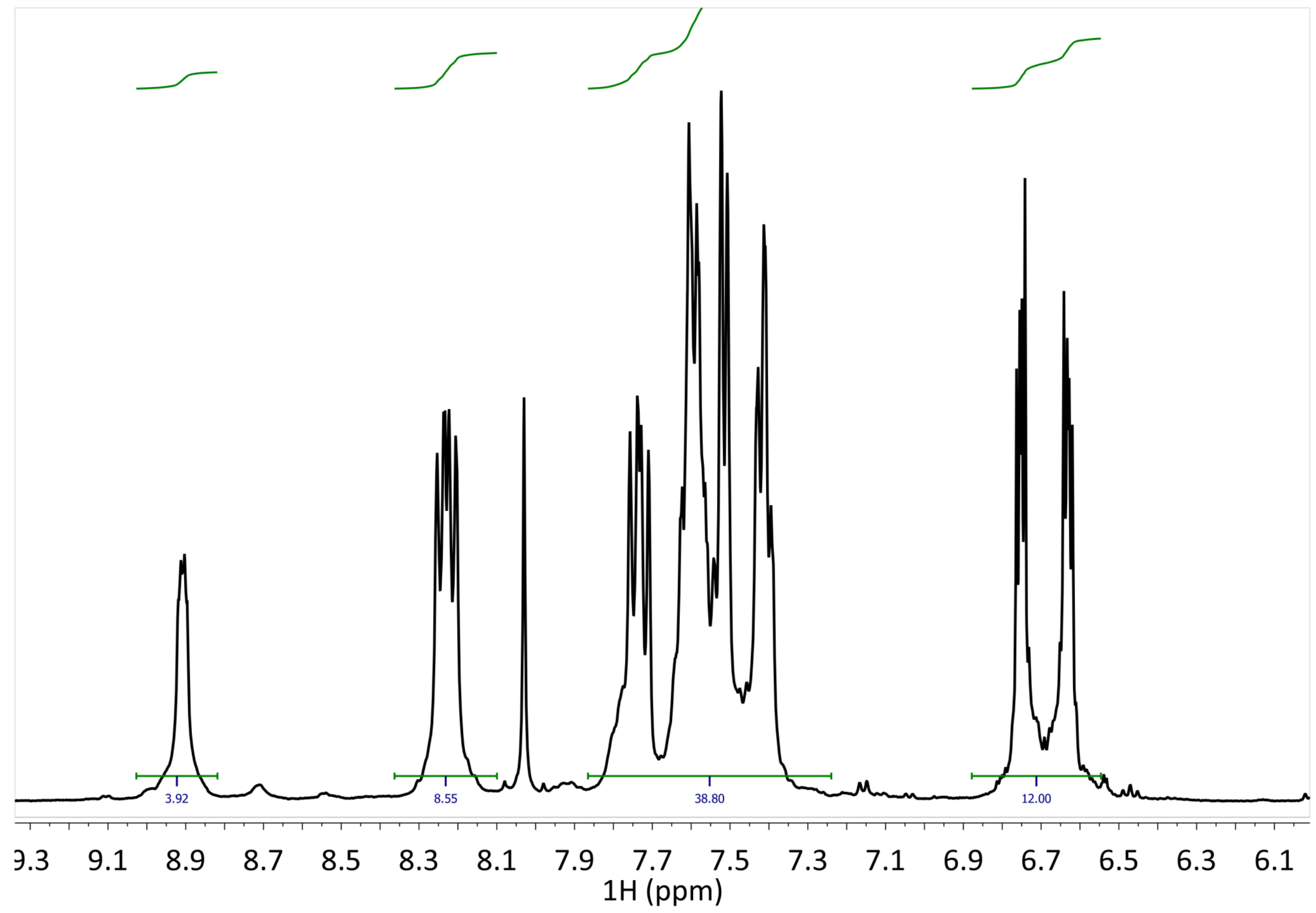

Figure S6. The aromatic region of the ${ }^{1} \mathrm{H}$ NMR spectrum of the rectangle (8). 


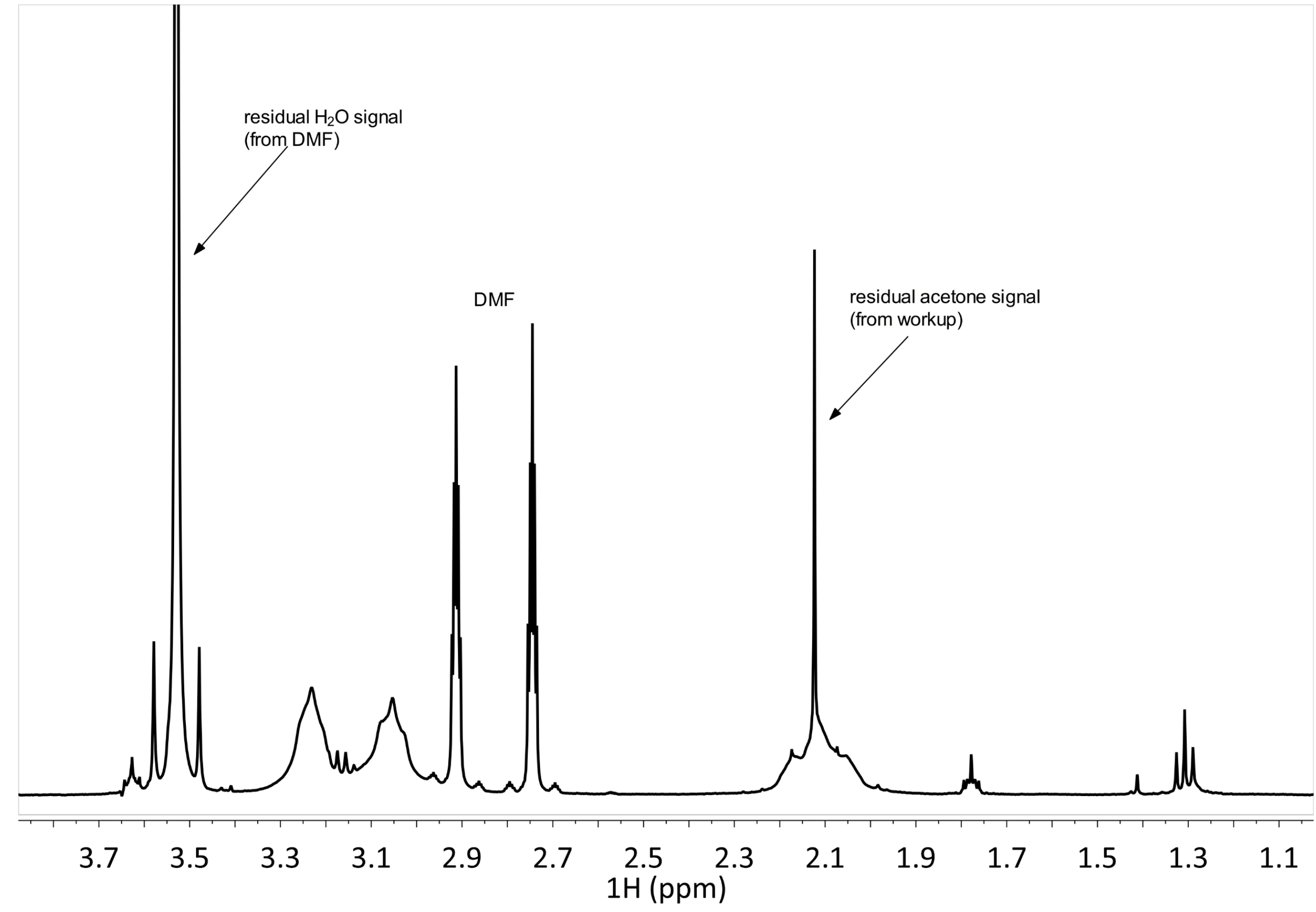

Figure S7. The aliphatic region of the ${ }^{1} \mathrm{H}$ NMR spectrum of the rectangle (8). 


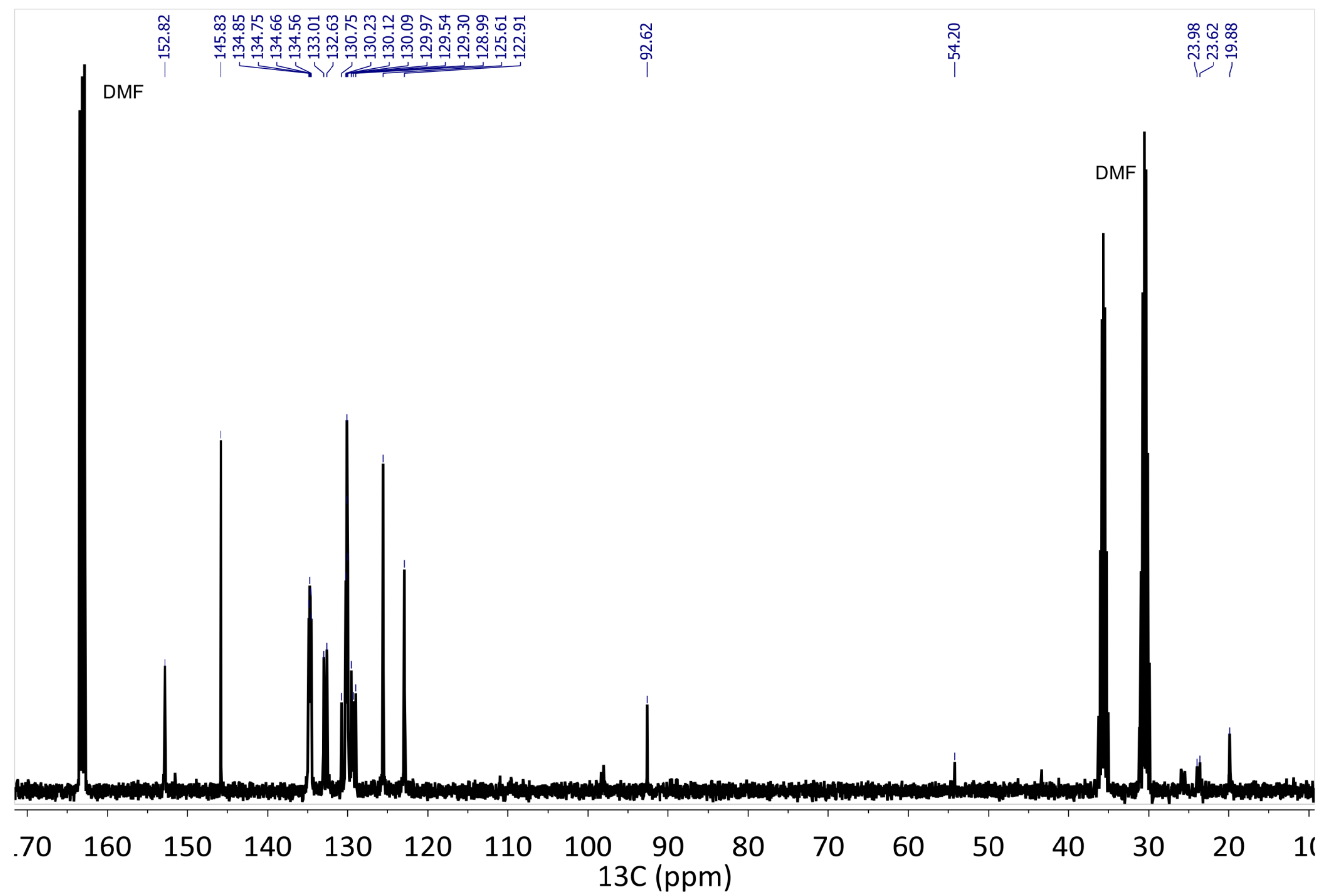

Figure S8. The ${ }^{13} \mathrm{C}$ NMR spectrum of the rectangle (8). 

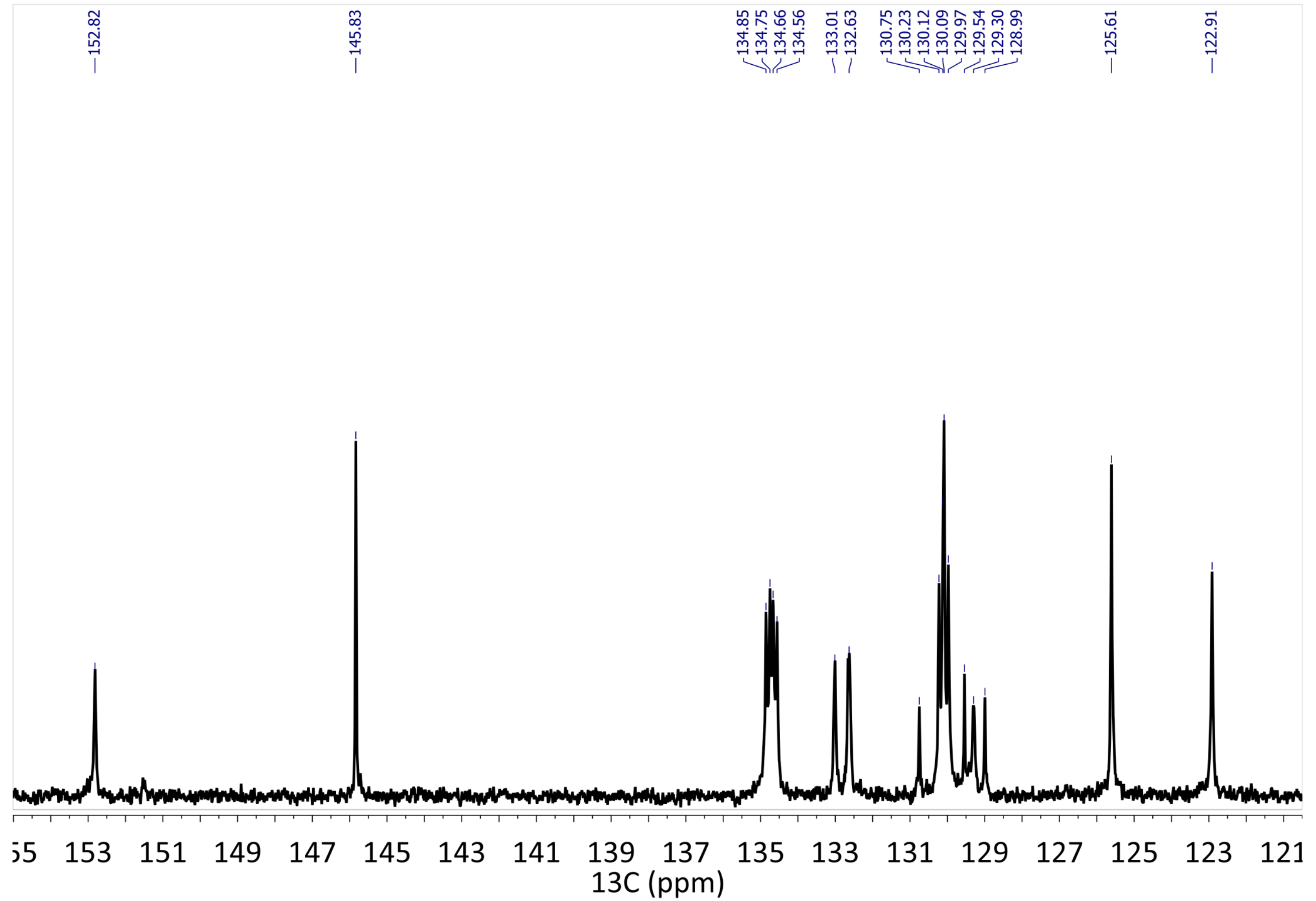

Figure S9. The aromatic region of the ${ }^{13} C$ NMR spectrum of rectangle (8). 


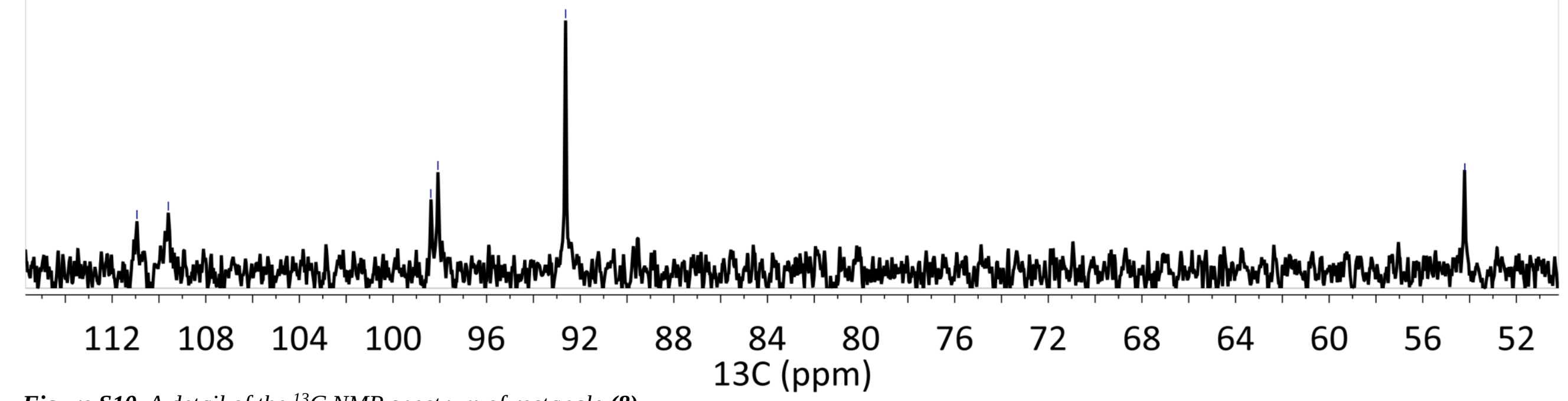
Figure S10. A detail of the ${ }^{13} C$ NMR spectrum of rectangle (8). 


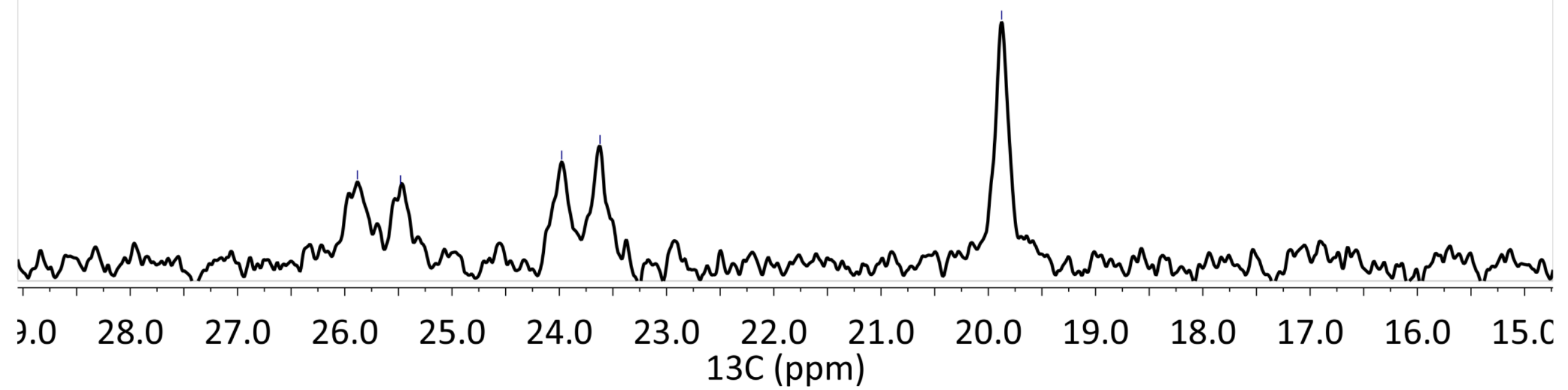

Figure S11. The aliphatic region of the ${ }^{13} C$ NMR spectrum of rectangle (8). 


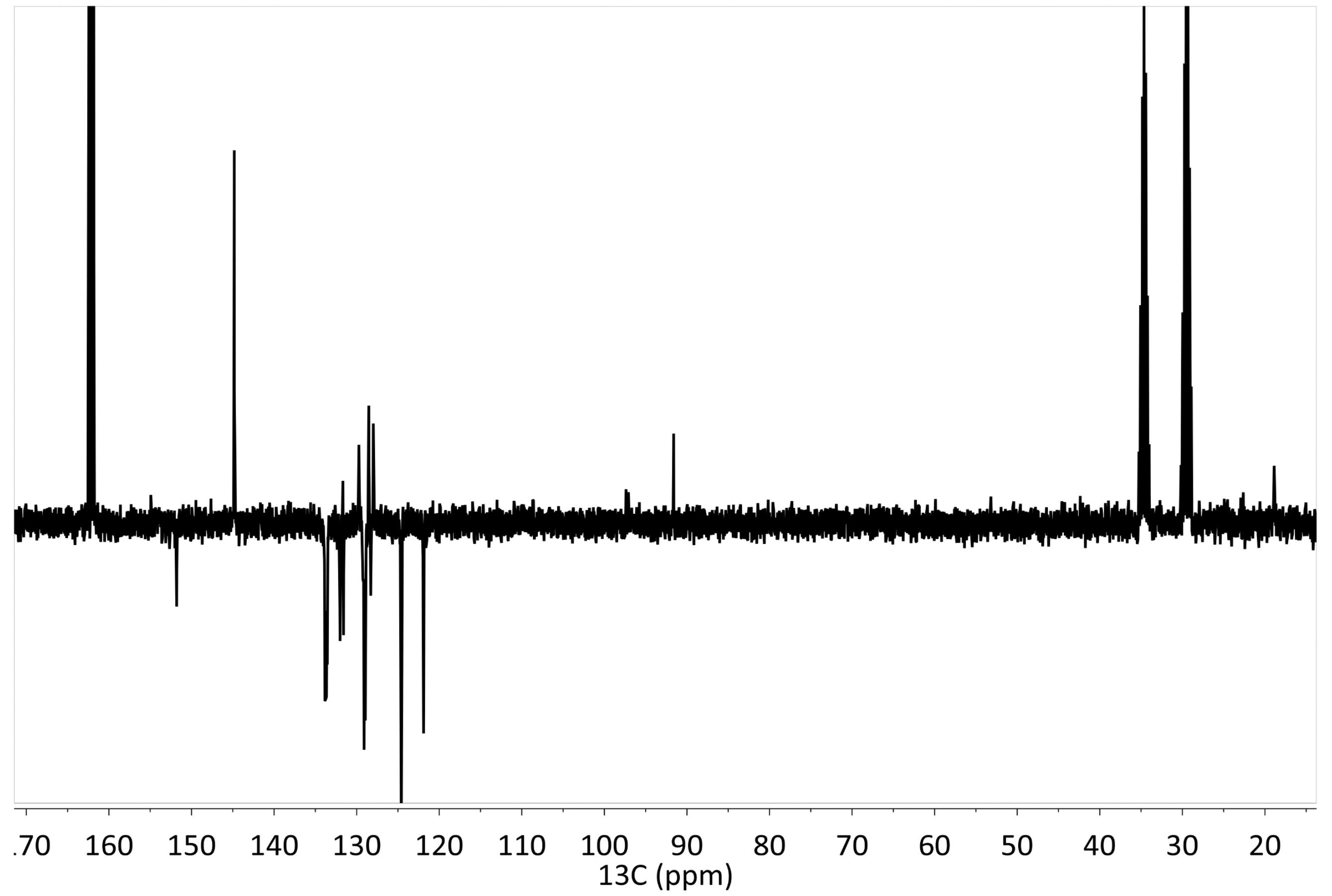

Figure S12. The APT NMR spectrum of the rectangle (8). 


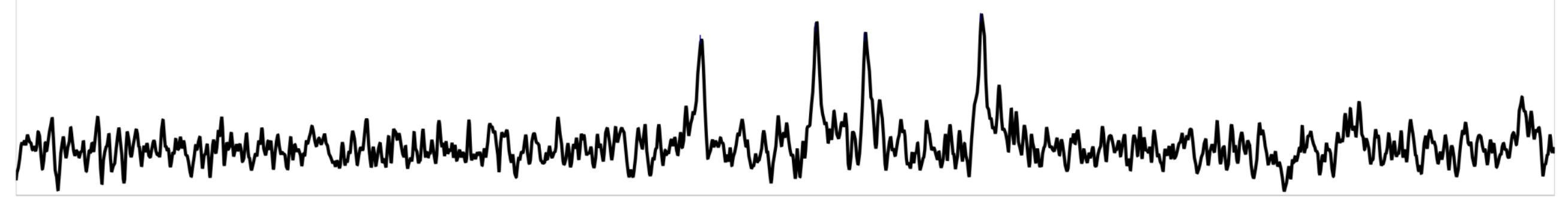
$\begin{array}{llllllllllll}4360 & -4400 & -4440 & -4480 & -4520 & -4560 & -4600 & -4640 & -4680 & -4720 & -4760 & -480(\end{array}$ Figure S13. The ${ }^{195} \mathrm{Pt}$ NMR spectrum of the rectangle (8). $\quad$ 195Pt $(\mathrm{ppm})$ 


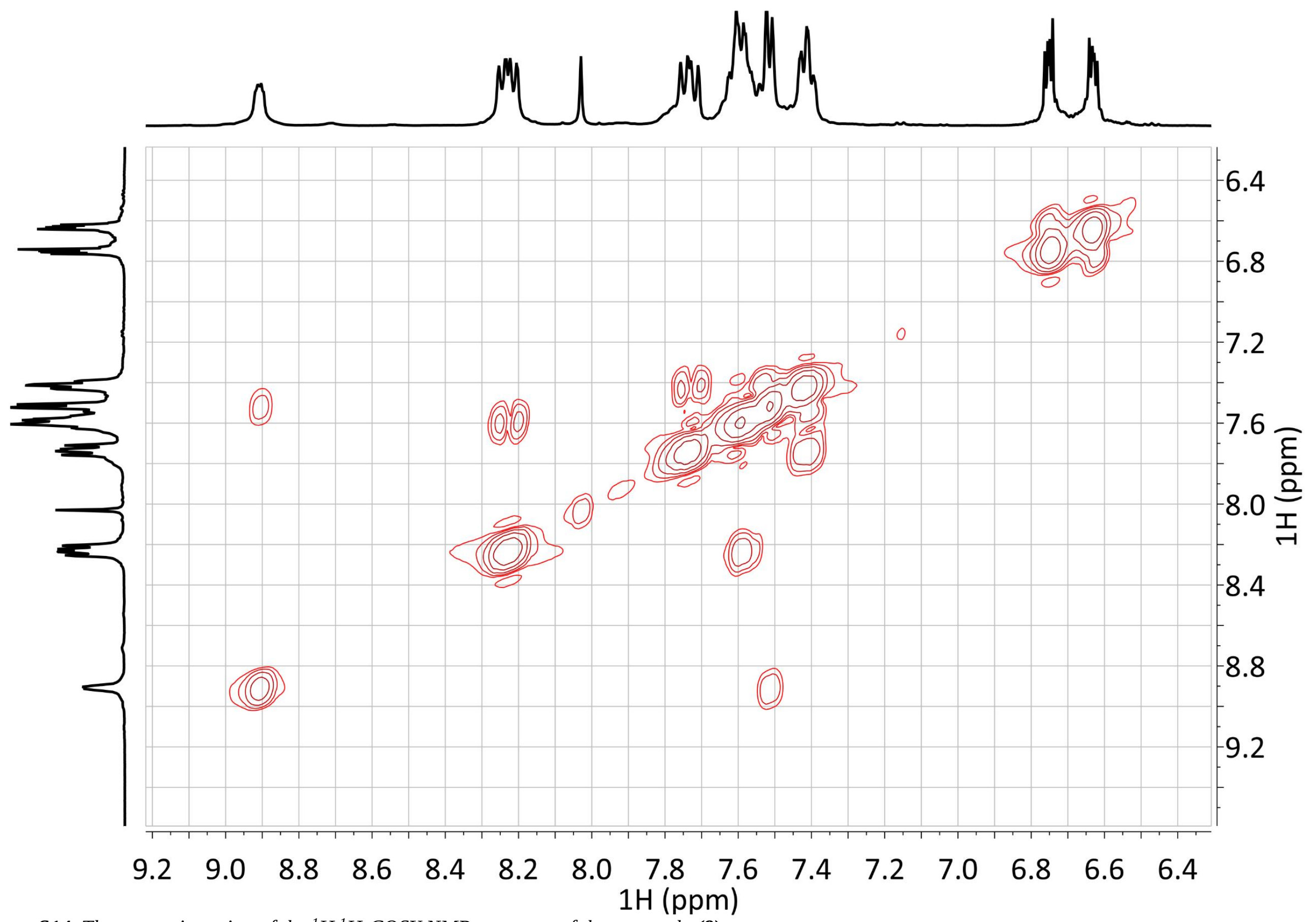

Figure S14. The aromatic region of the ${ }^{1} \mathrm{H},{ }^{1} \mathrm{H}$-COSY NMR spectrum of the rectangle (8). 


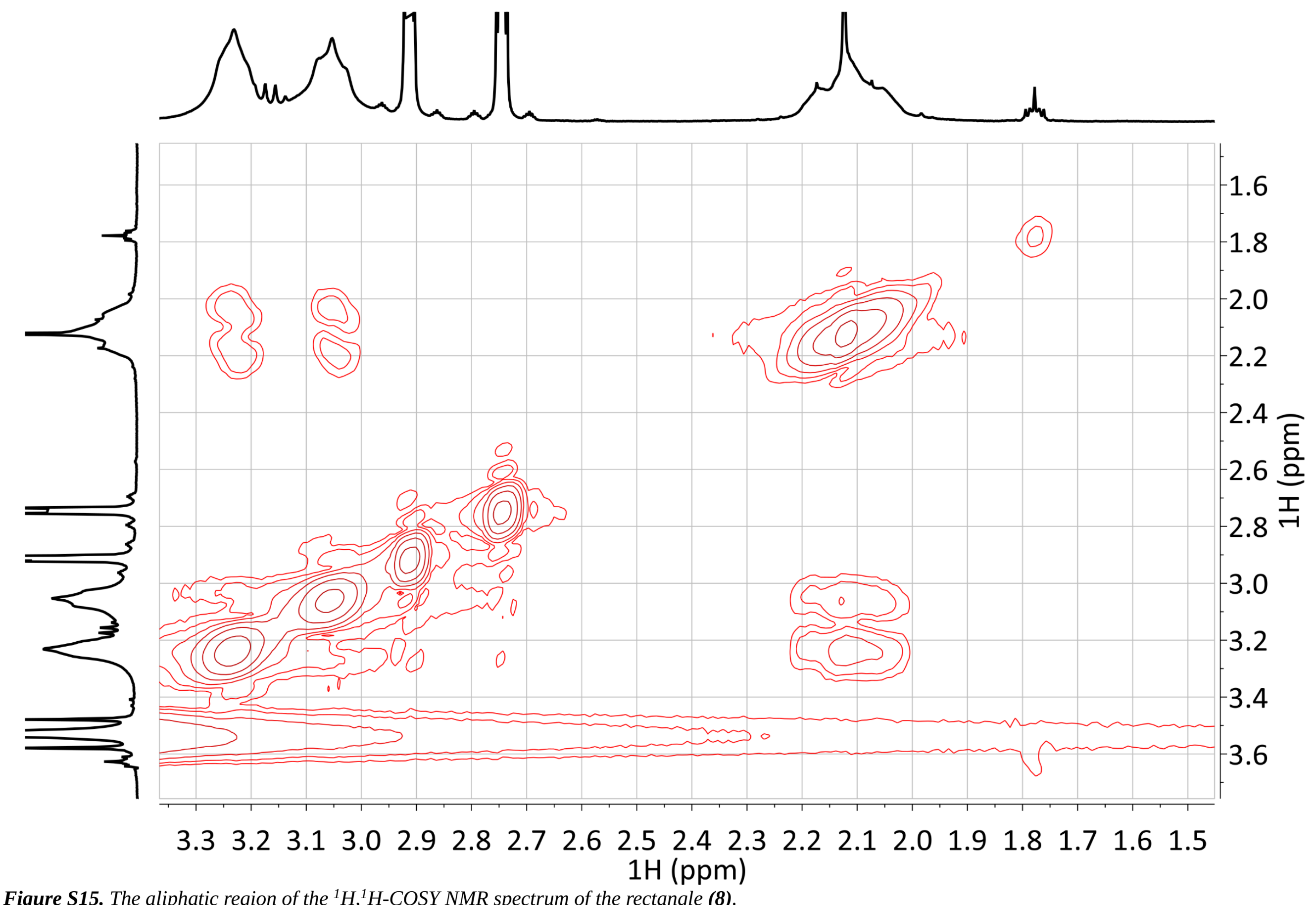

Figure S15. The aliphatic region of the ${ }^{1} \mathrm{H},{ }^{1} \mathrm{H}$-COSY NMR spectrum of the rectangle (8). 


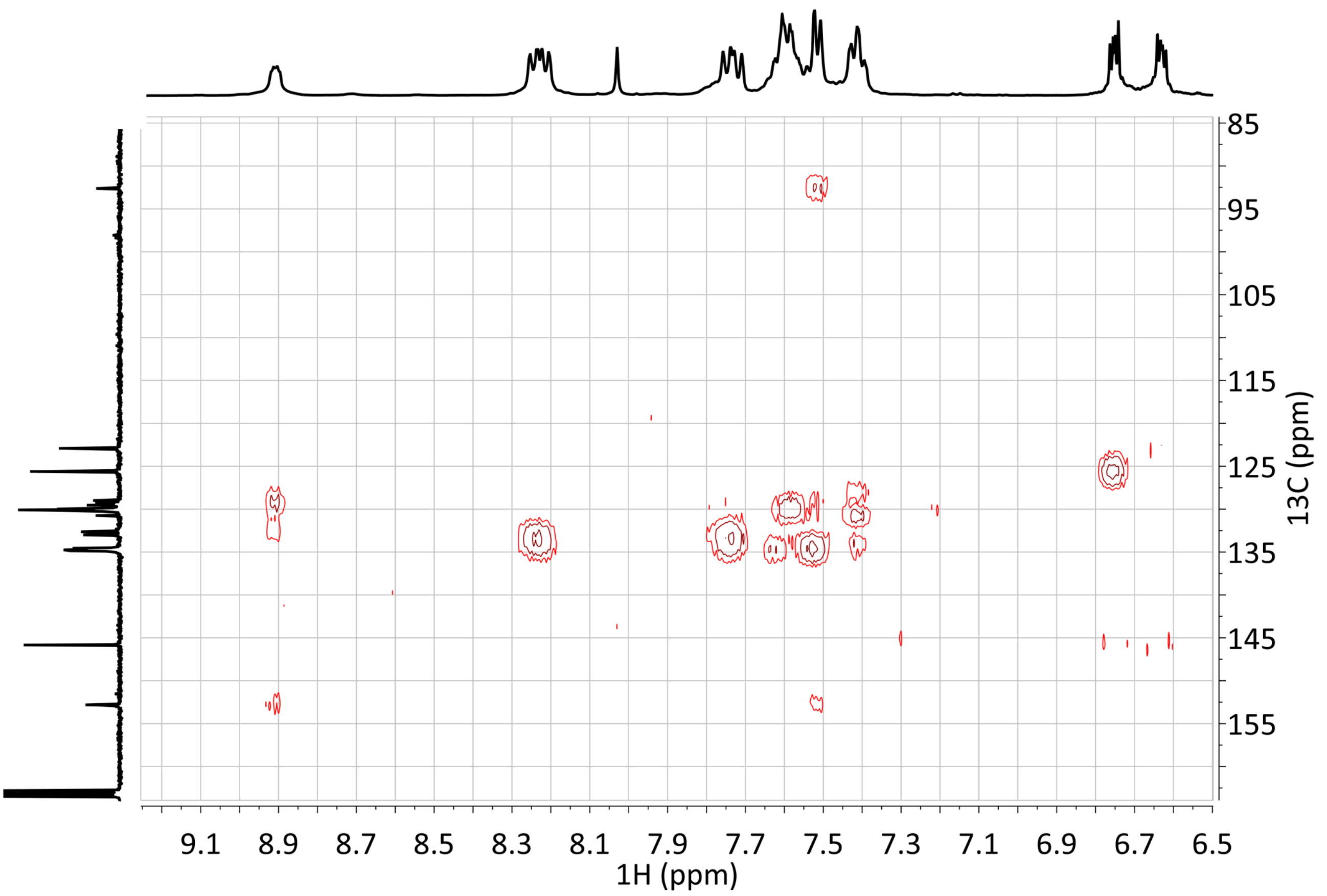

Figure S16. A detail of the HMBC NMR spectrum of the rectangle (8). 


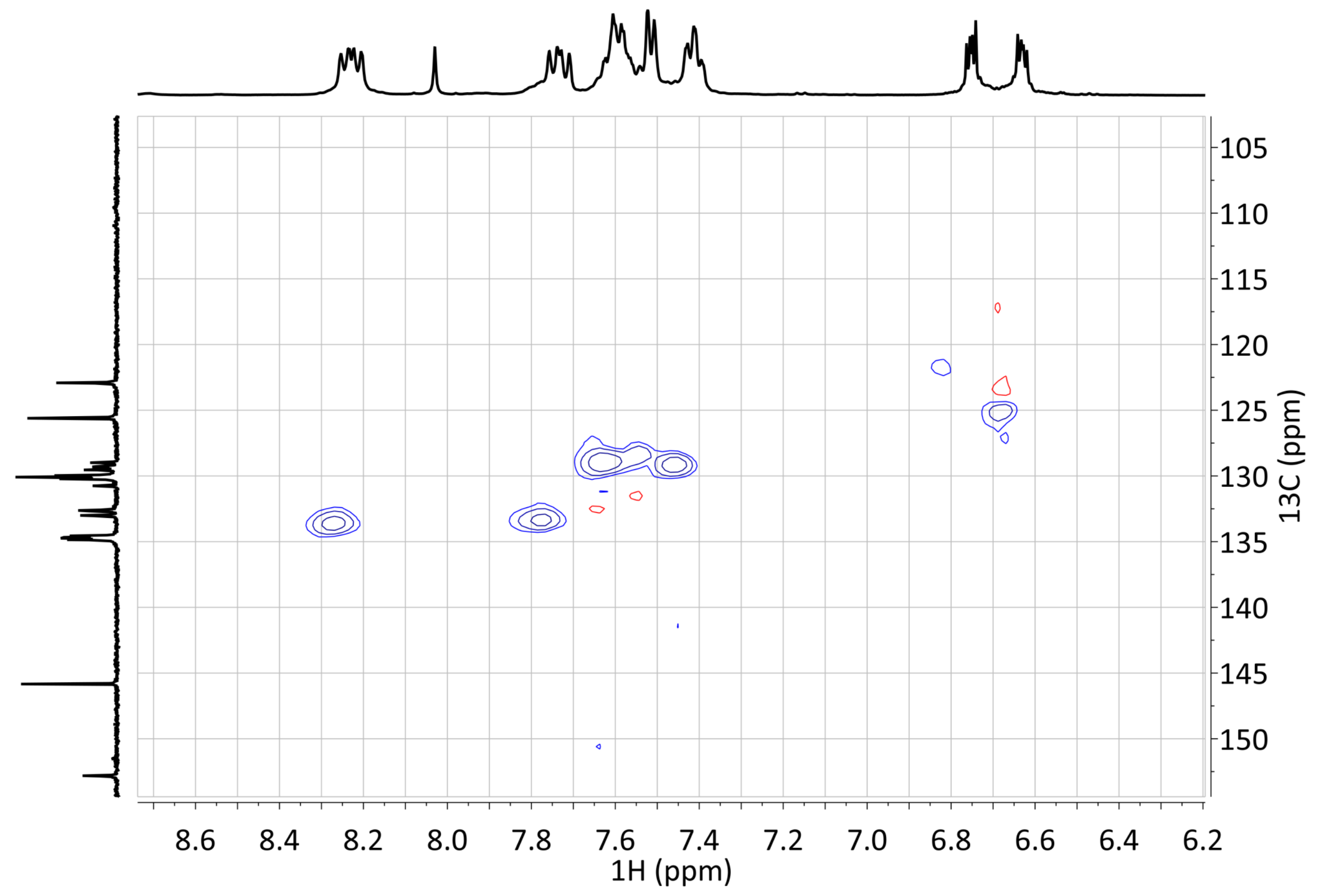

Figure S17. A detail of the HSQC NMR spectrum of the rectangle (8). 


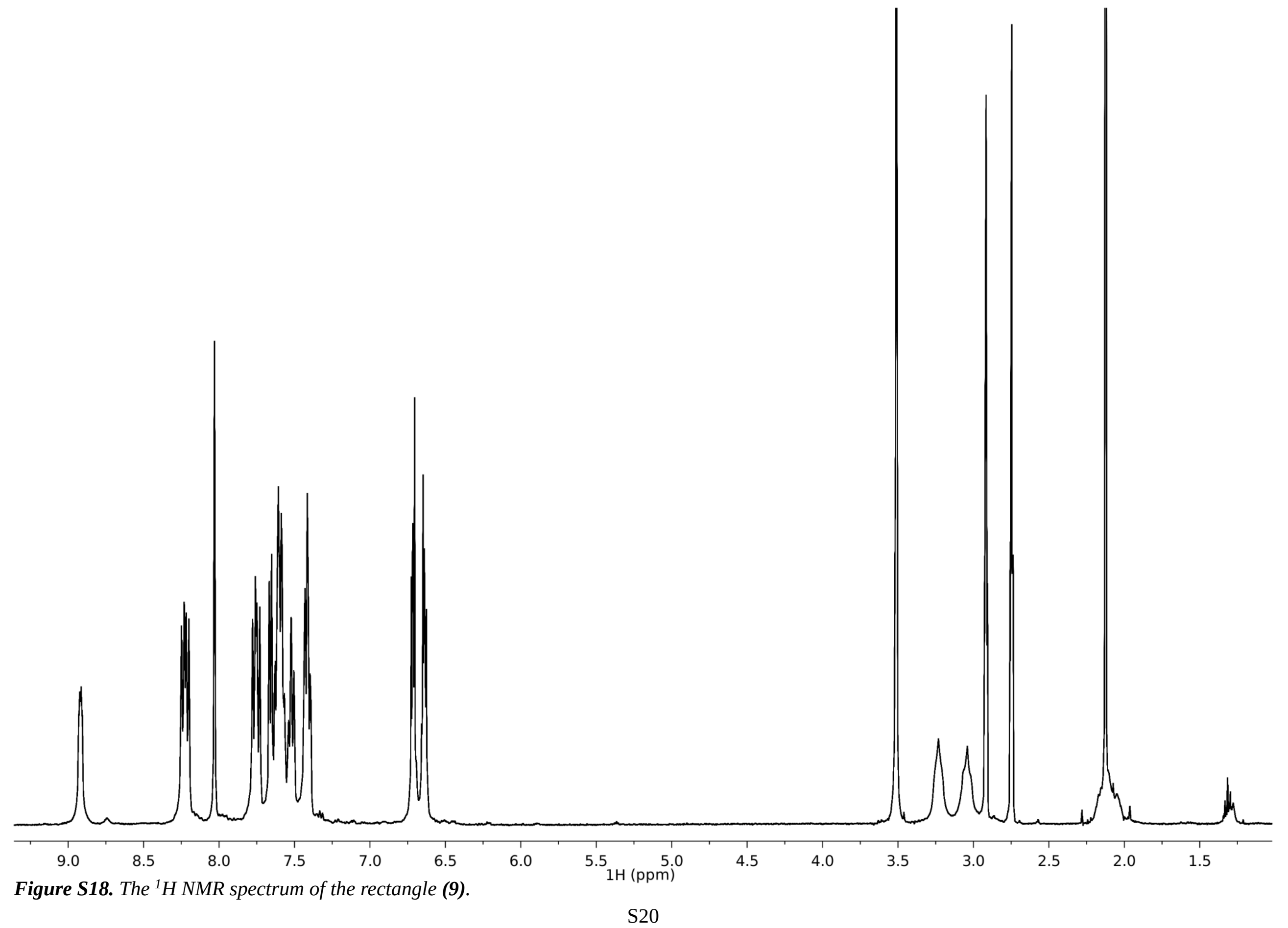




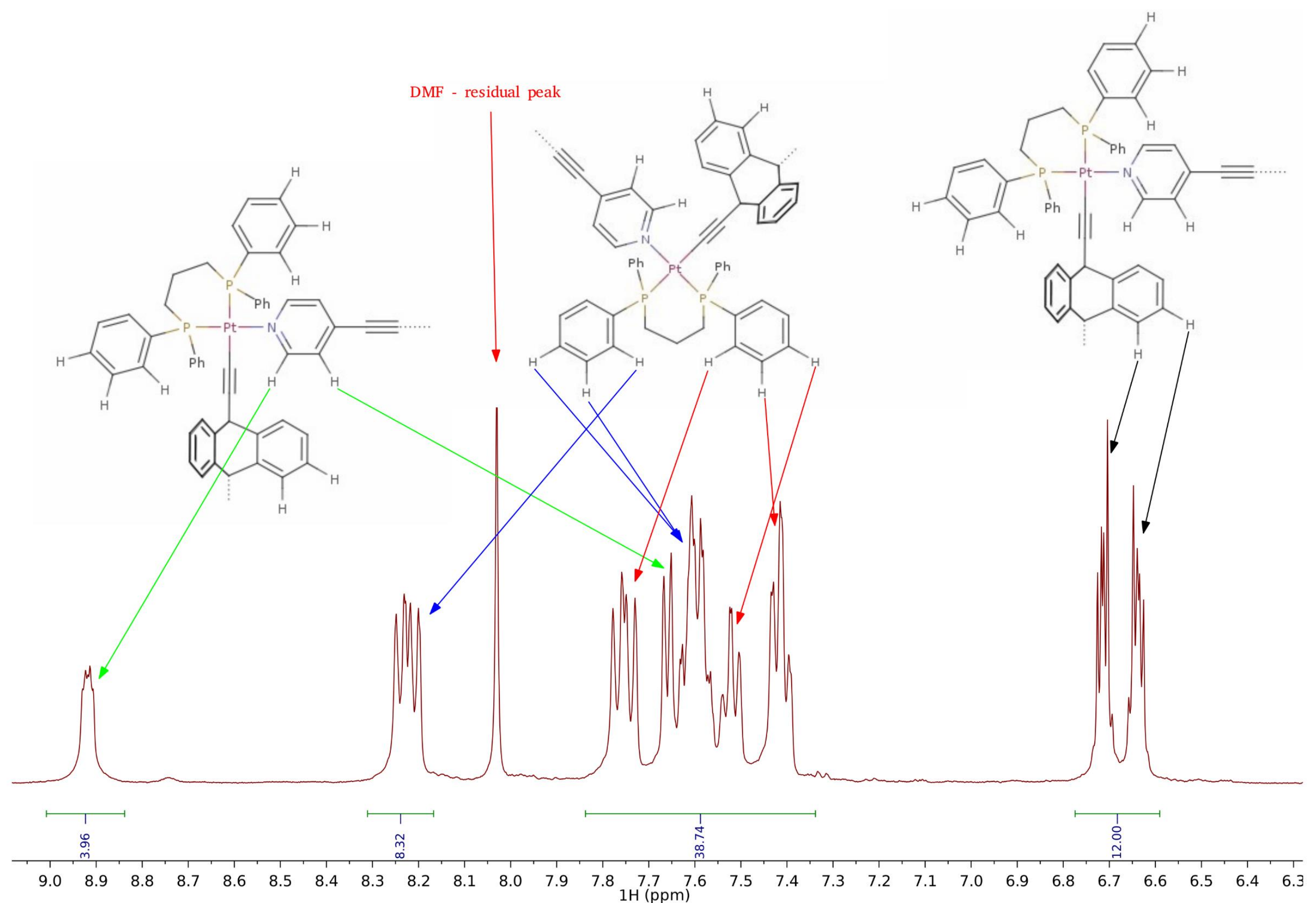

Figure S19. The aromatic region of the ${ }^{1} \mathrm{H} N \mathrm{NR}$ spectrum of the rectangle (9). 


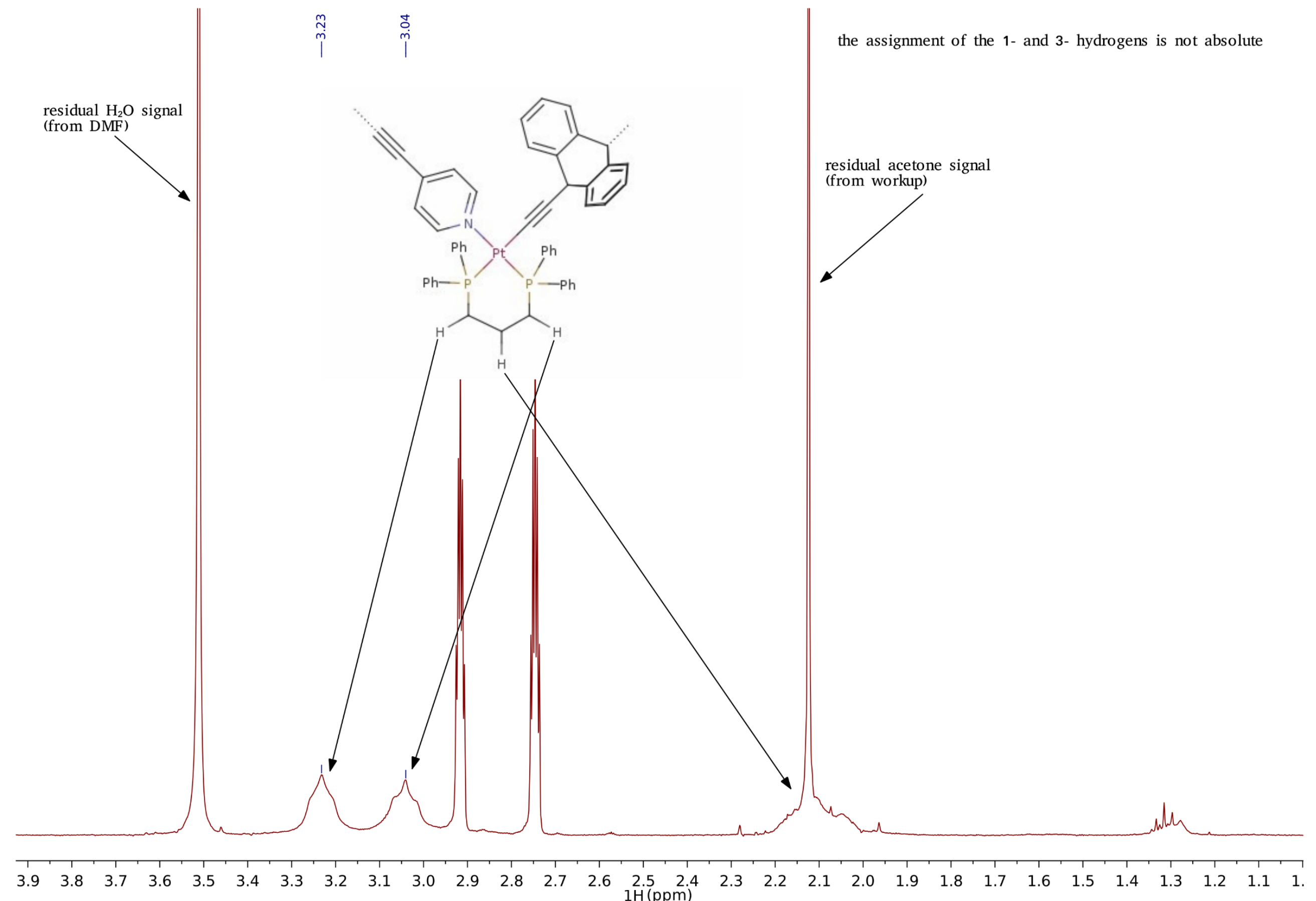

Figure S20. The aliphatic region of the ${ }^{1} \mathrm{H}$ NMR rectangle (9). 


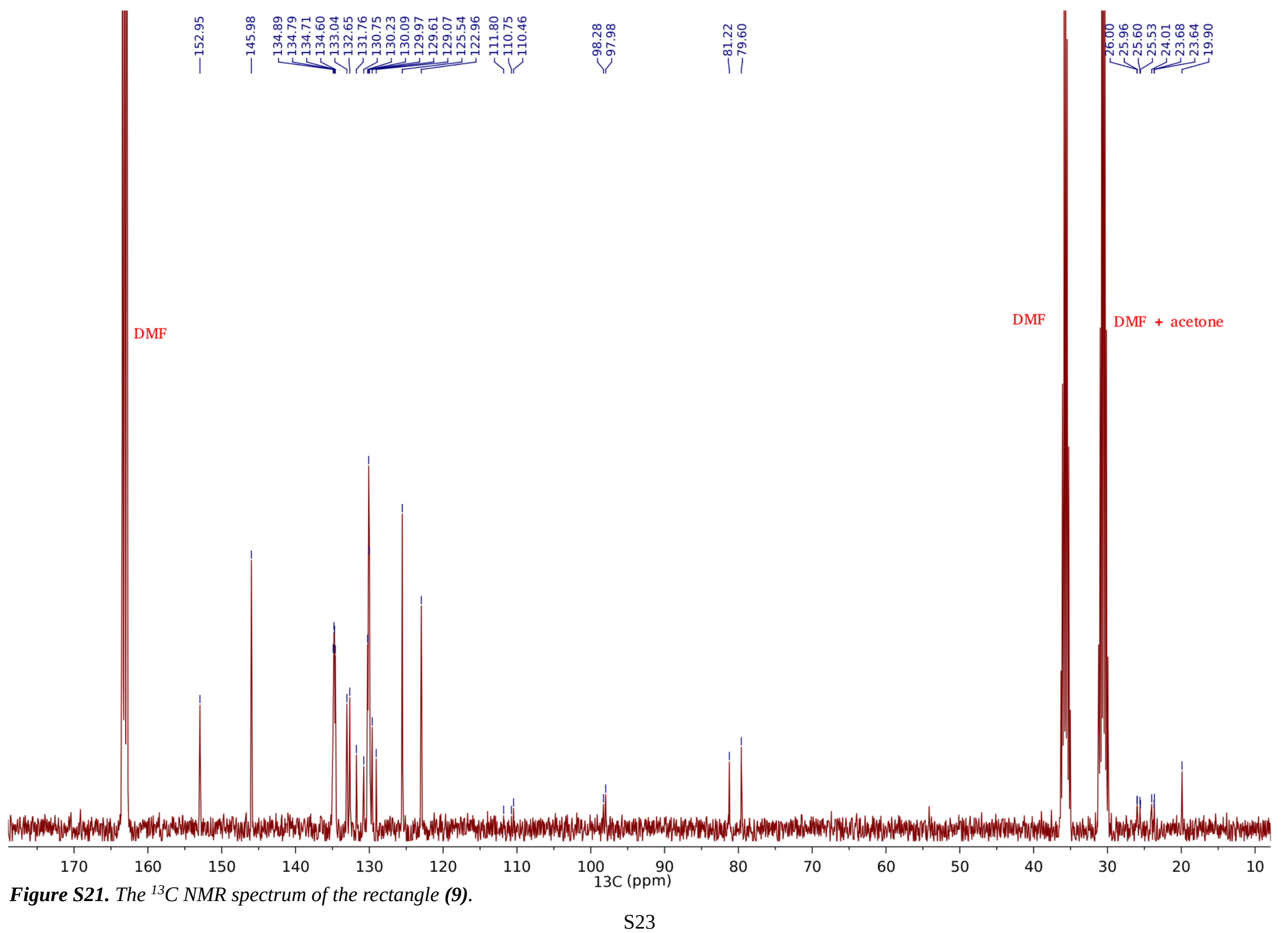




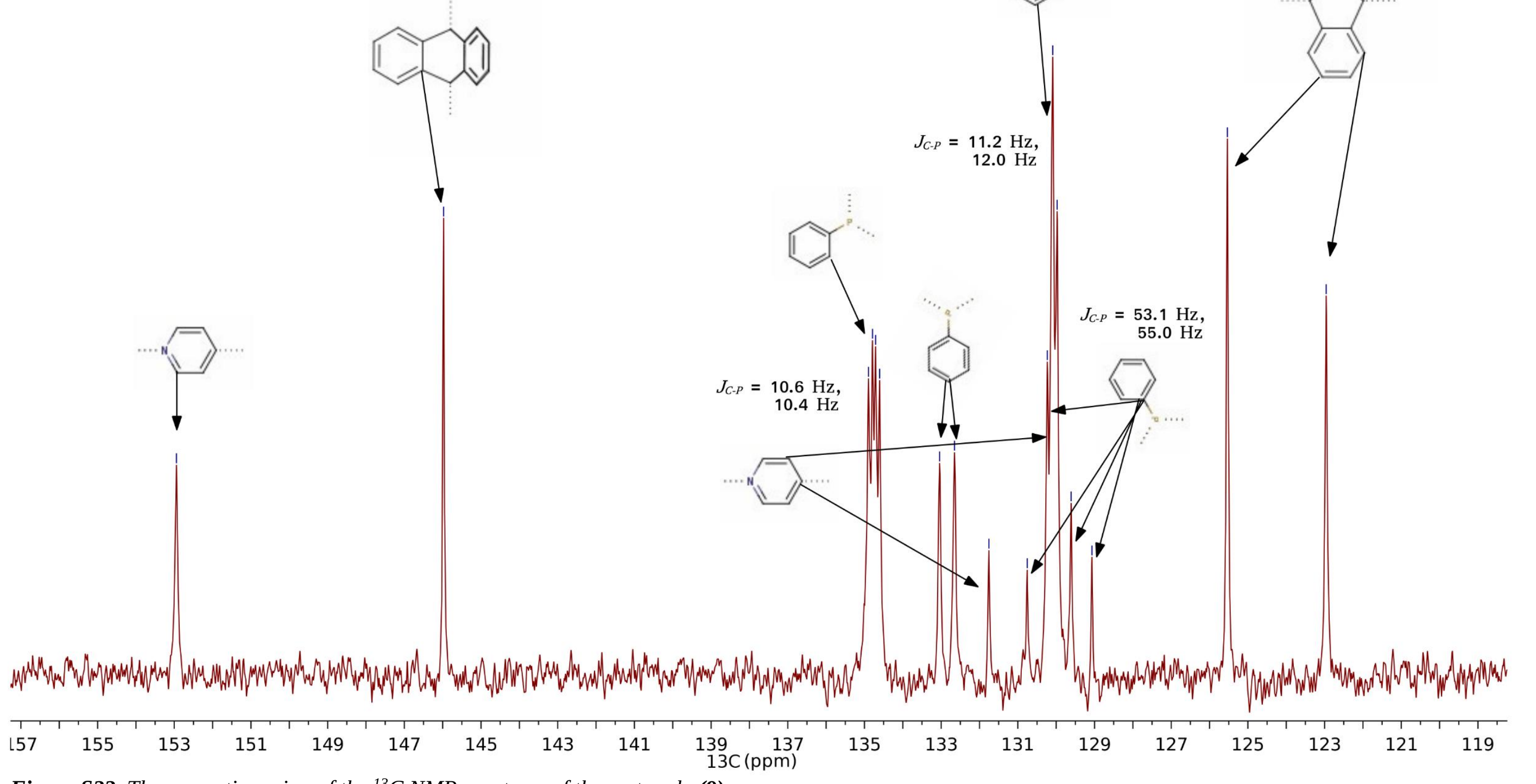

Figure S22. The aromatic region of the ${ }^{13} \mathrm{C} N M R$ spectrum of the rectangle (9). 


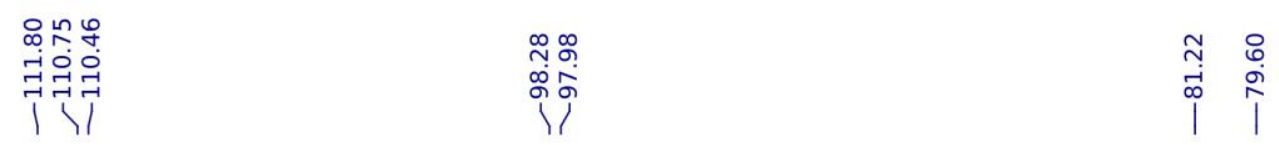

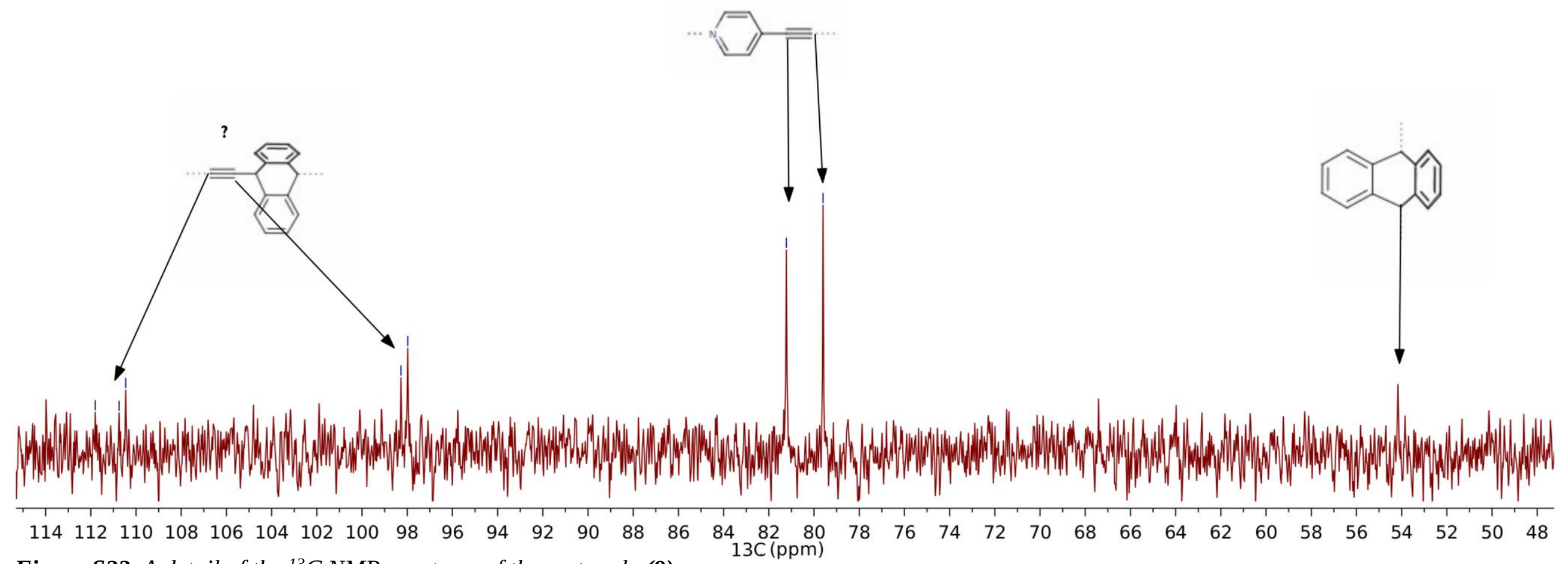

Figure S23. A detail of the ${ }^{13} \mathrm{C} N M R$ spectrum of the rectangle (9). 

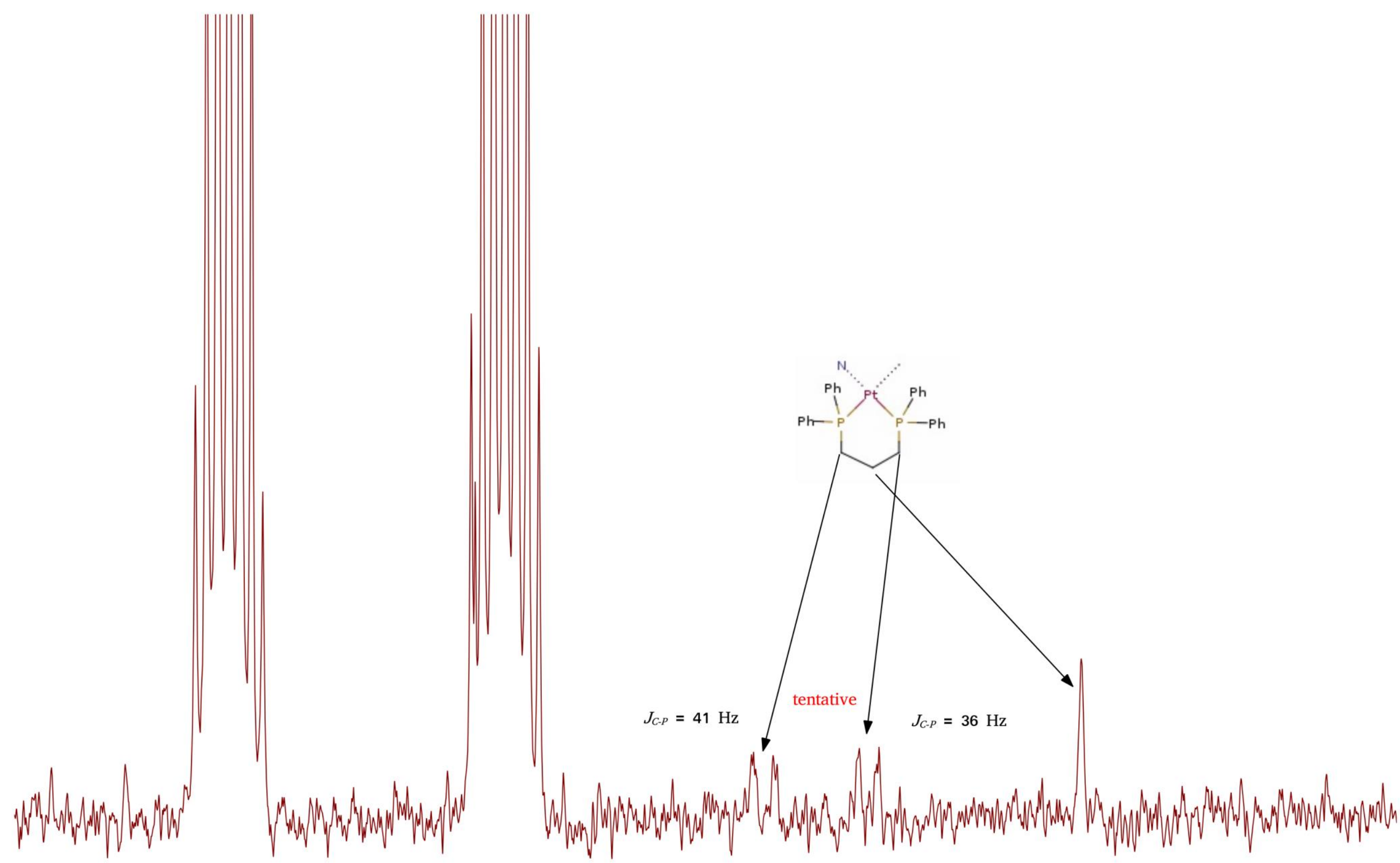


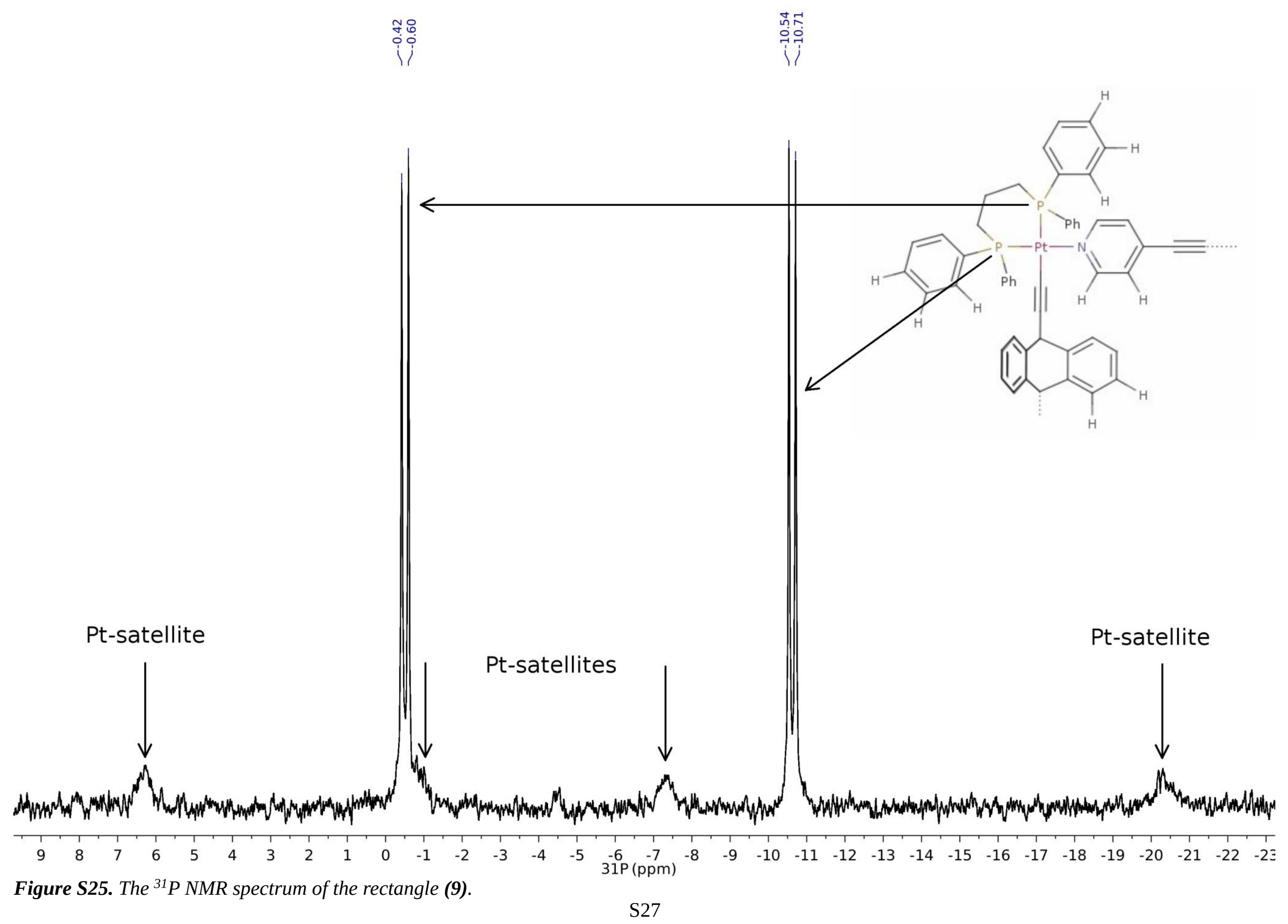




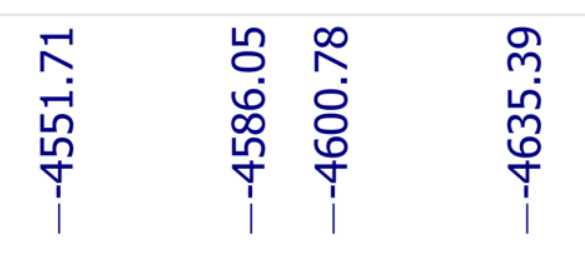

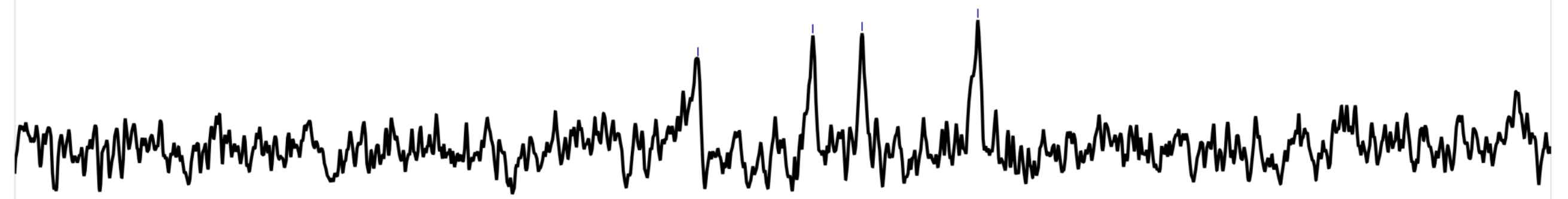

\begin{tabular}{llllllllll|l|l|}
-4360 & -4400 & -4440 & -4480 & -4520 & -4560 & -4600 & -4640 & -4680 & -4720 & -4760 & -480 \\
Figure S26. The ${ }^{195} \mathrm{Pt}$ NMR spectrum of the rectangle (9). & 195Pt (ppm)
\end{tabular}





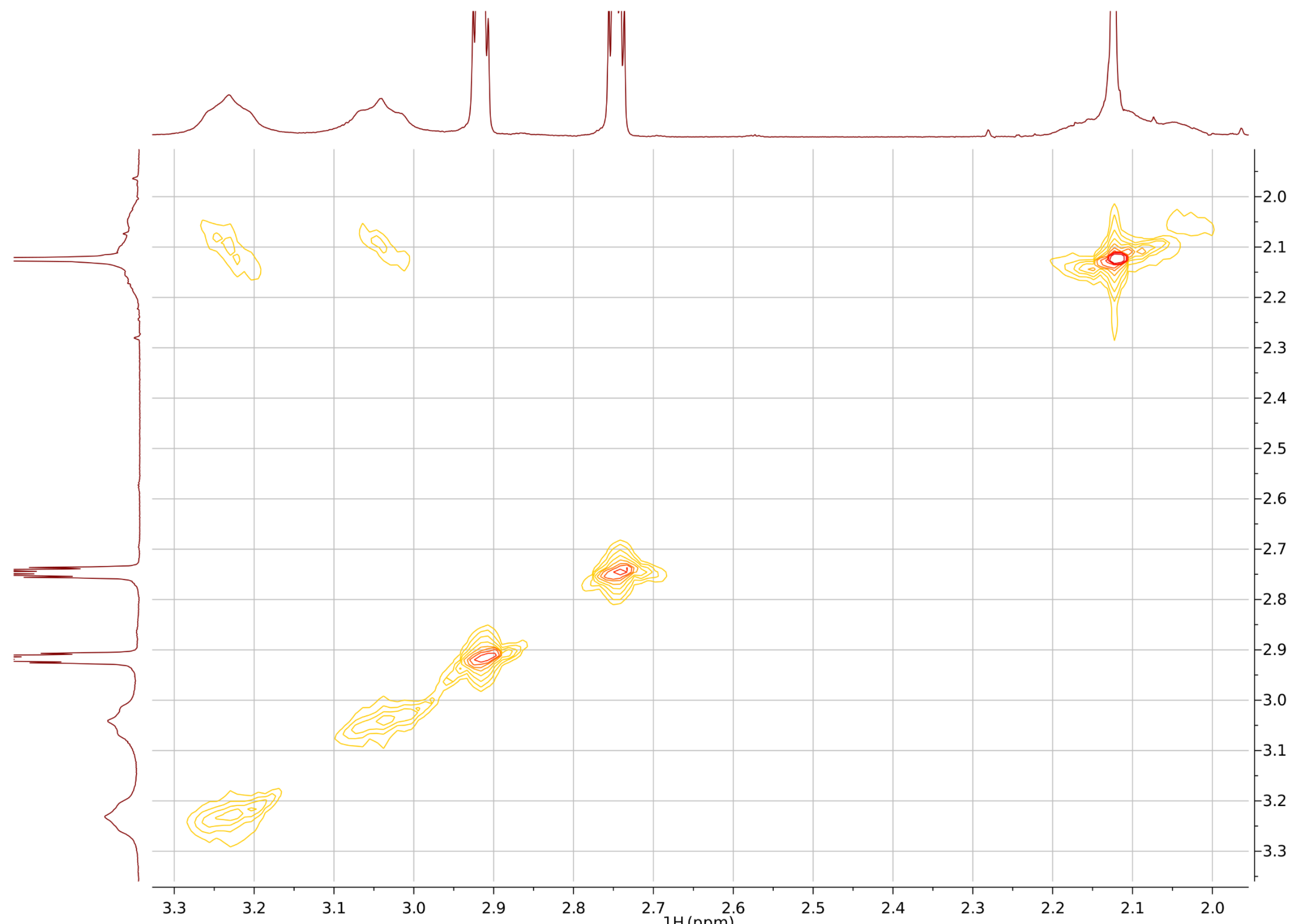




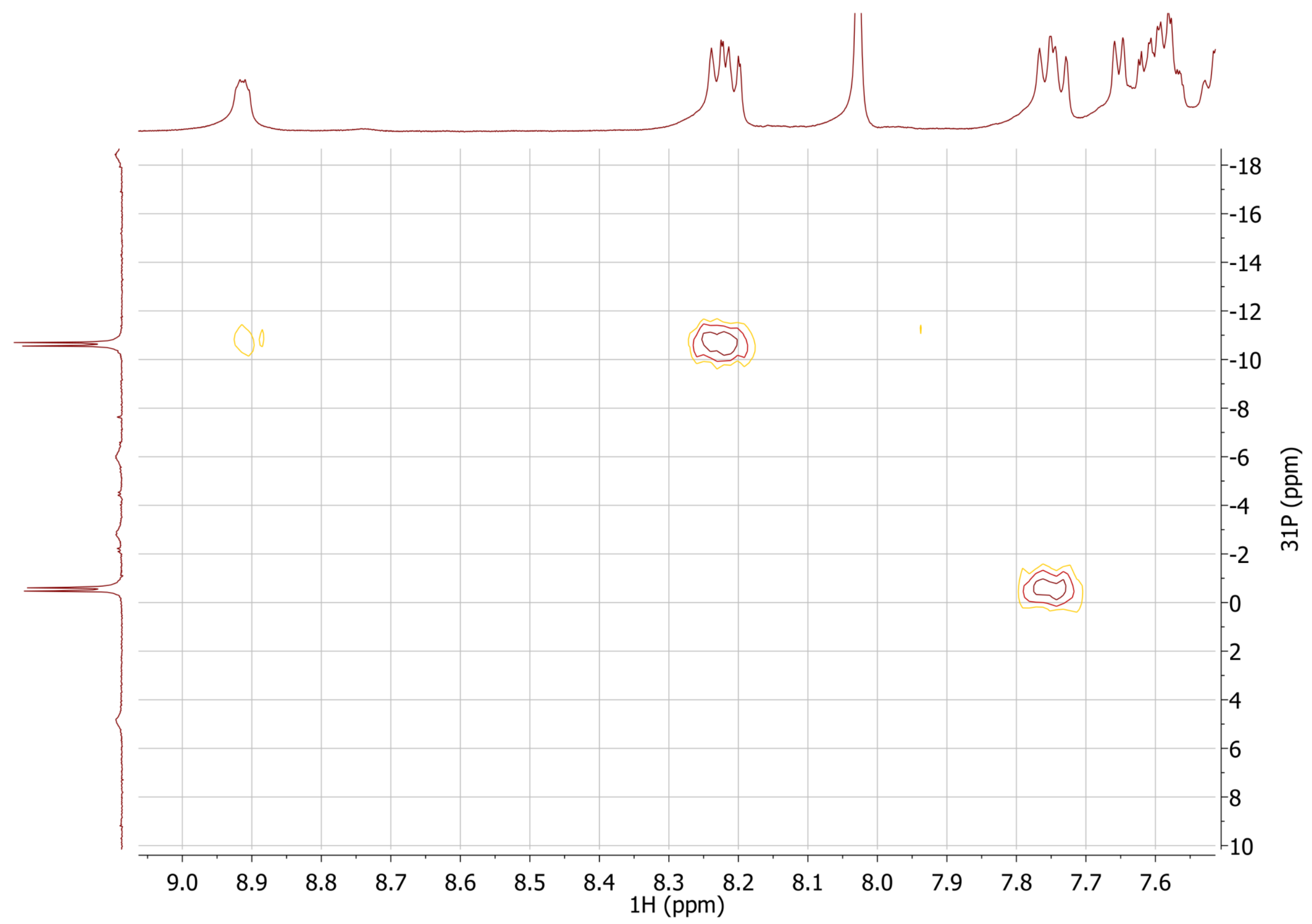

Figure S29. The ${ }^{1} H,{ }^{31} \mathrm{P}-H M B C N M R$ spectrum of the rectangle (9). 


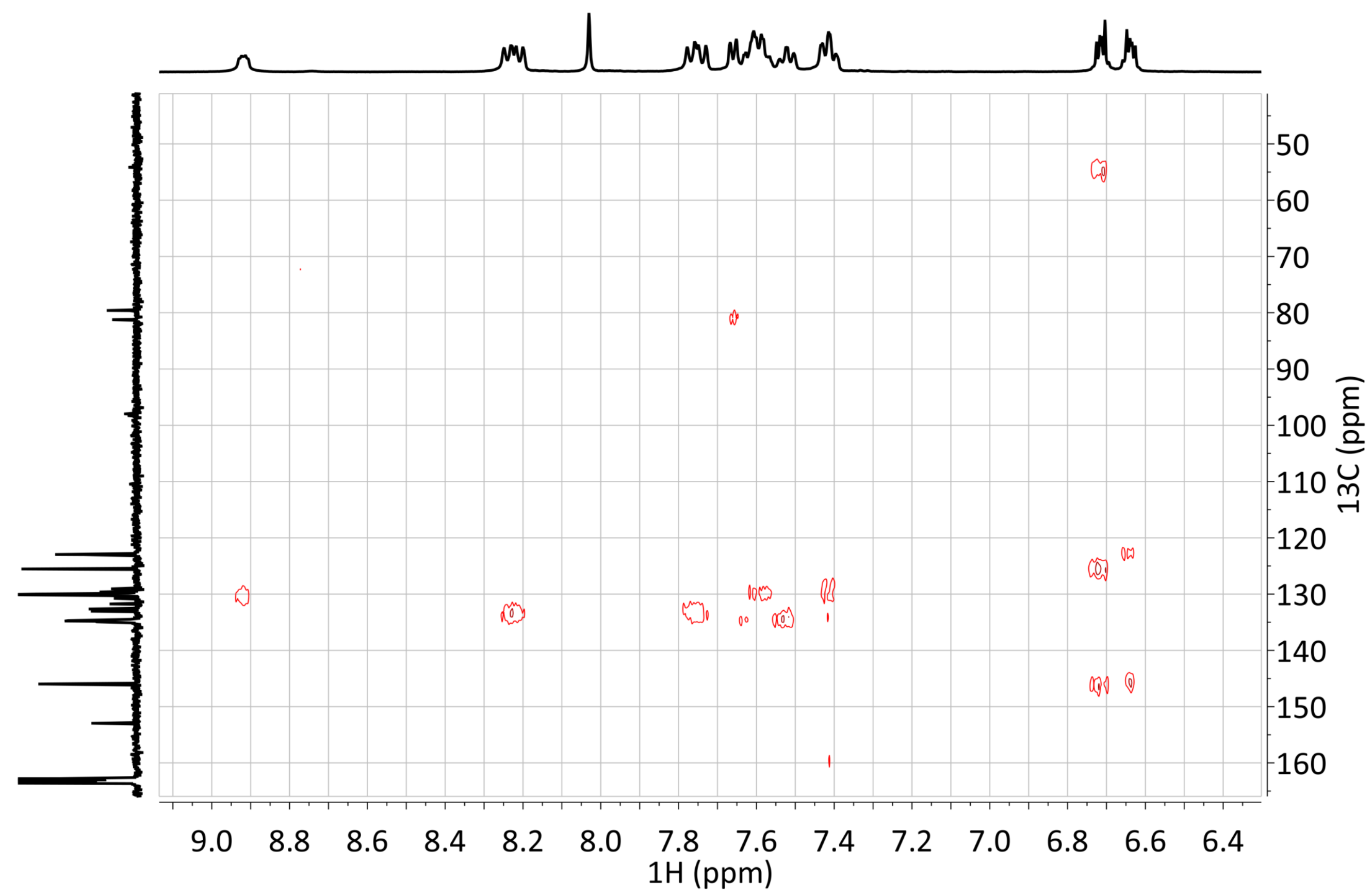

Figure S30. The aromatic region of the ${ }^{1} \mathrm{H},{ }^{13} \mathrm{C}-\mathrm{HMBC}$ NMR spectrum of the rectangle (9). 


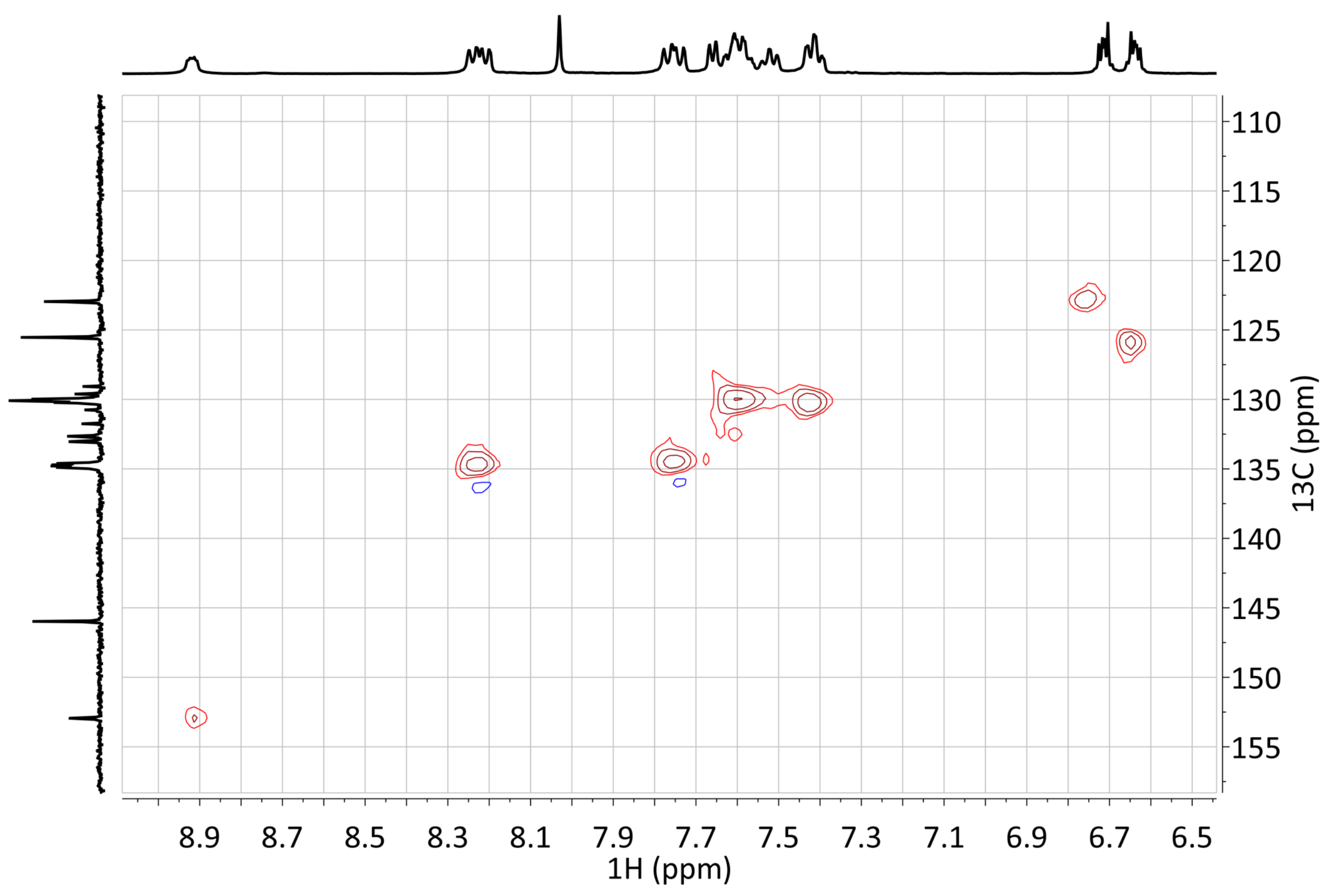

Figure S31. The aromatic region of the HSQC NMR spectrum of the rectangle (9). 


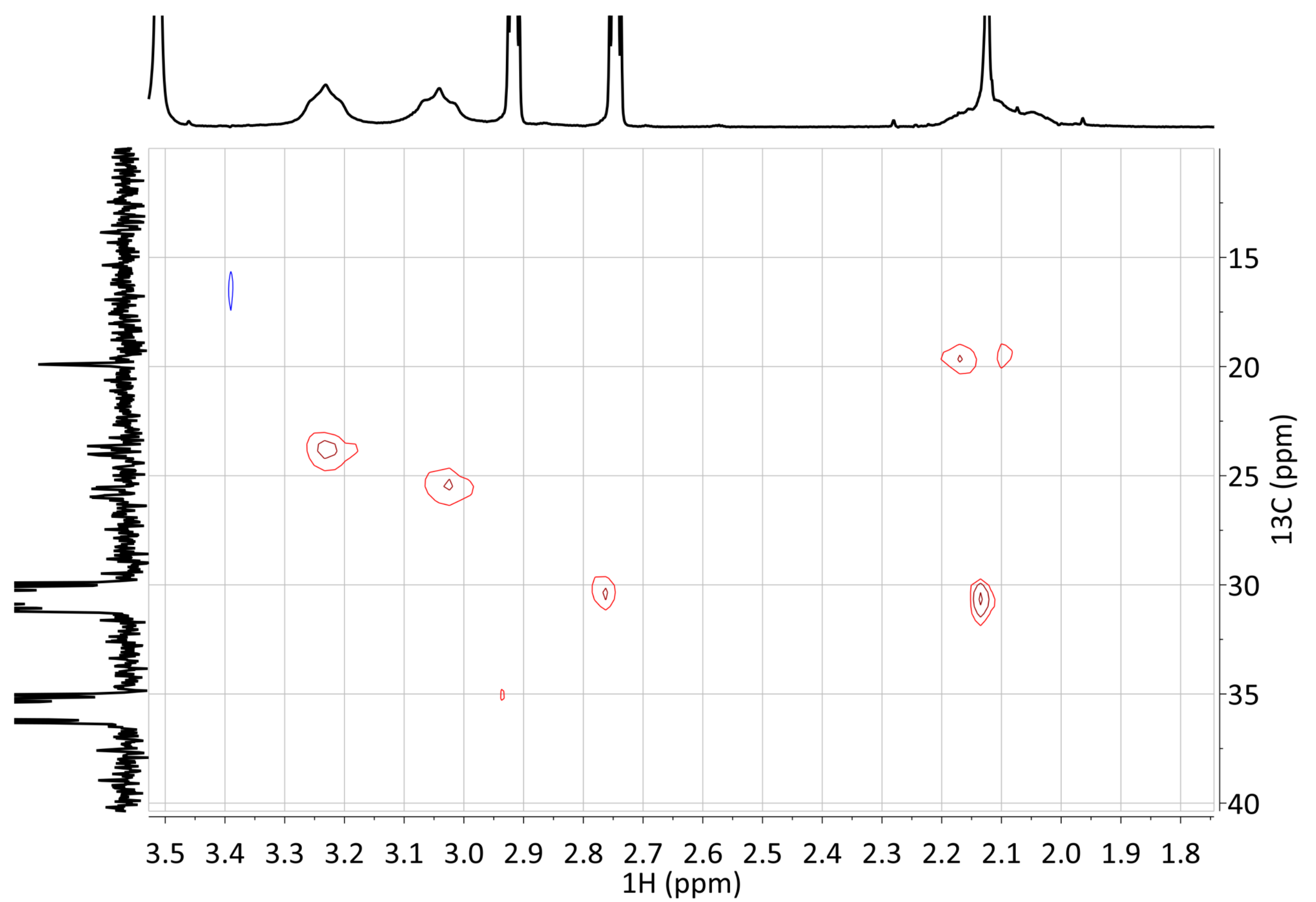

Figure S32. The aliphatic region of the HSQC NMR spectrum of the rectangle (9). 


$$
\text { ئل }
$$




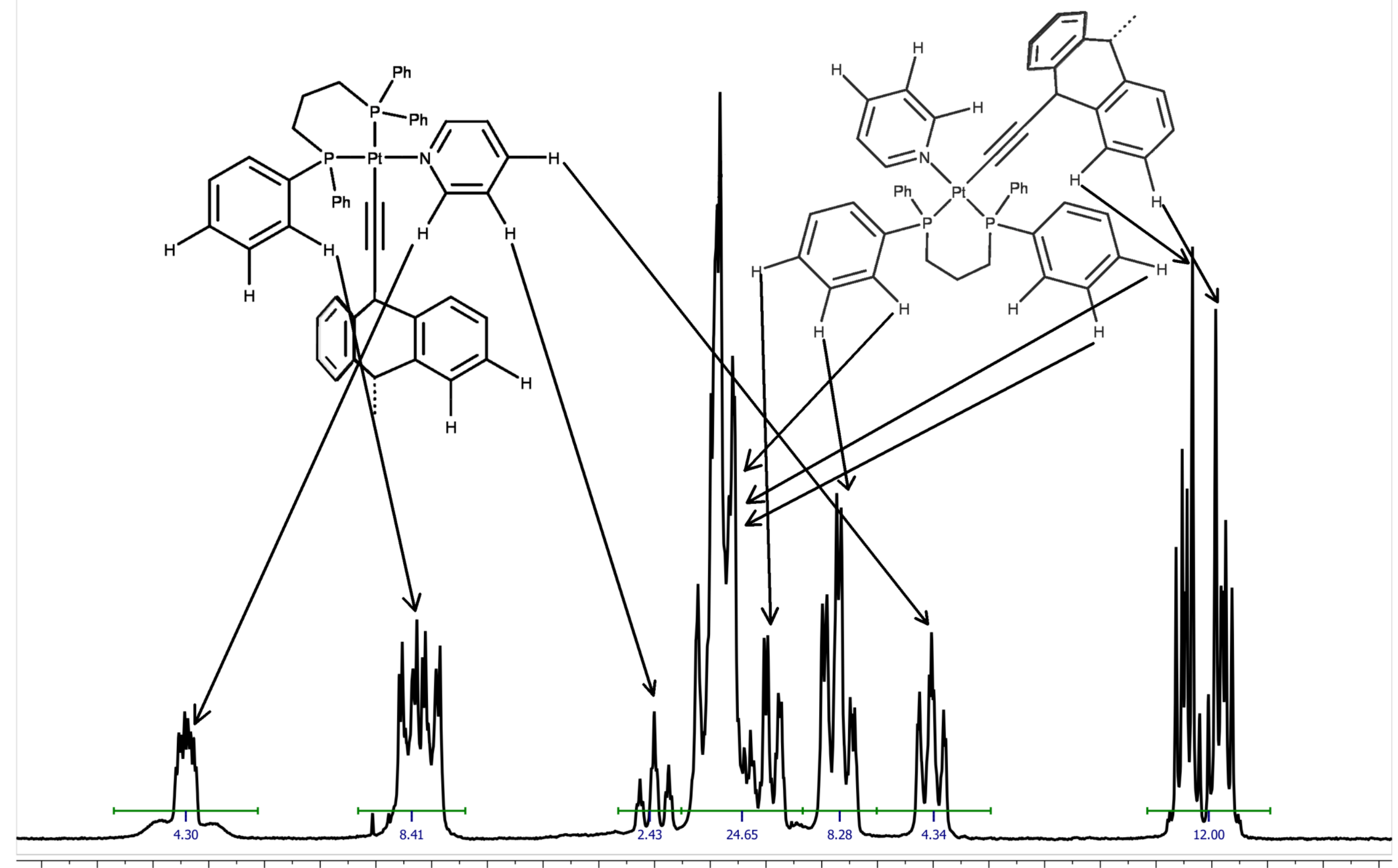

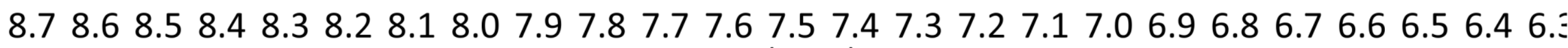
$1 \mathrm{H}(\mathrm{ppm})$

Figure S34. The aromatic region of the ${ }^{1} H$ NMR spectrum of complex (14). 


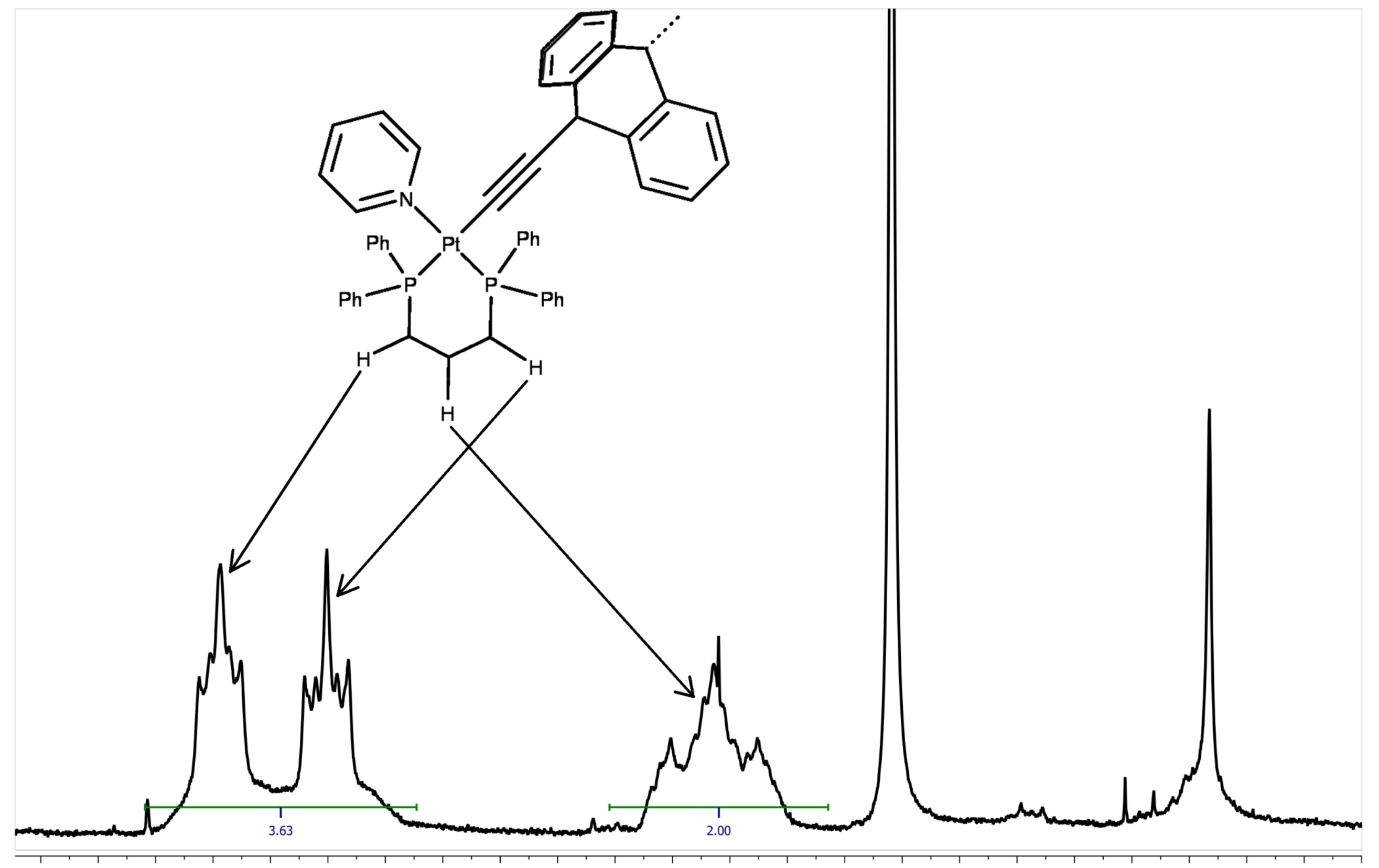

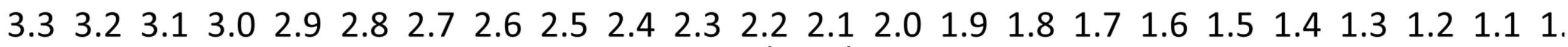
$1 \mathrm{H}(\mathrm{ppm})$

Figure S35. The aliphatic region of the ${ }^{1} H$ NMR spectrum of complex (14). 


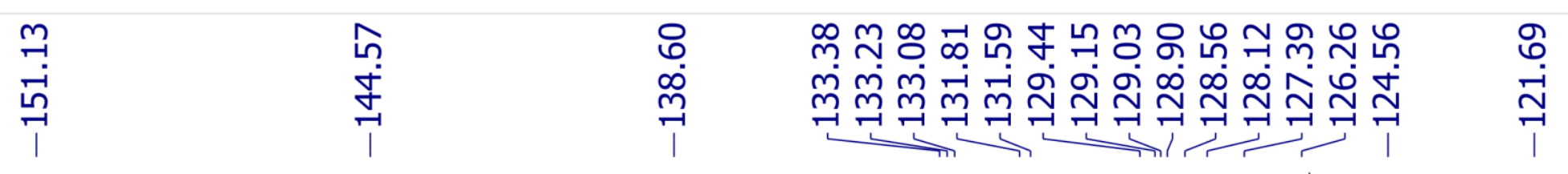

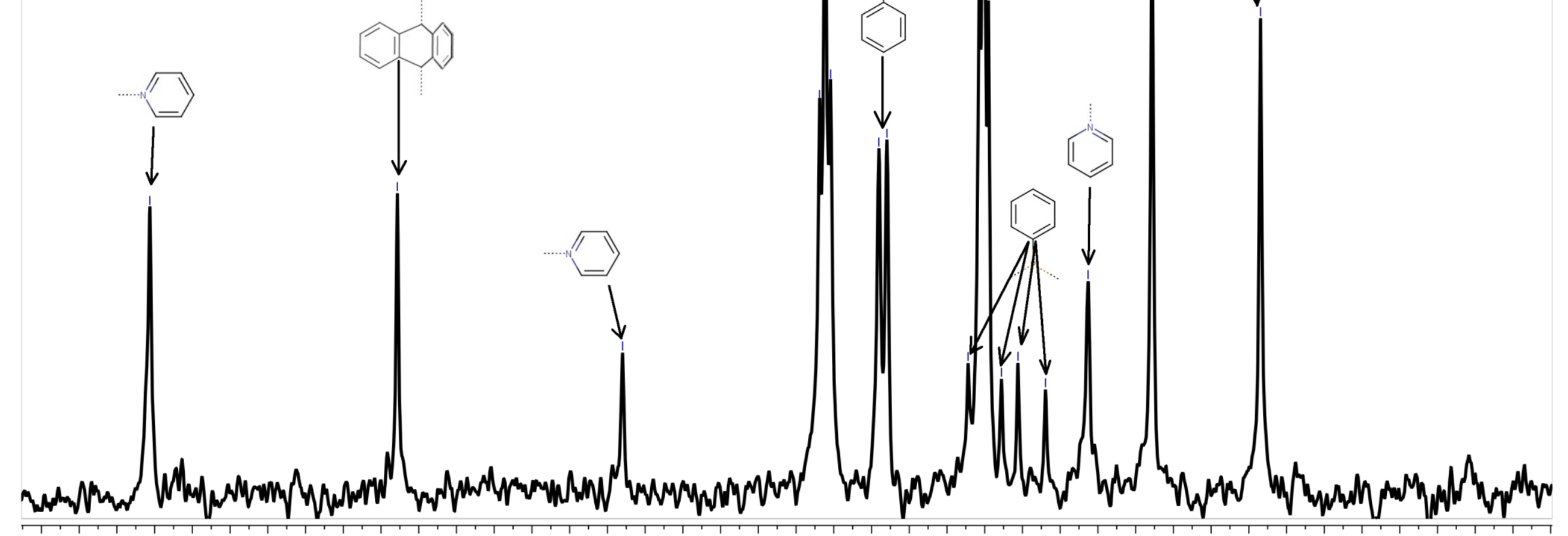

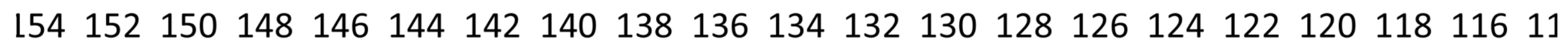
$13 \mathrm{C}$ (ppm)

Figure S36. The aromatic region of the ${ }^{13} C$ NMR spectrum of complex (14). 


\section{尽}

움
감

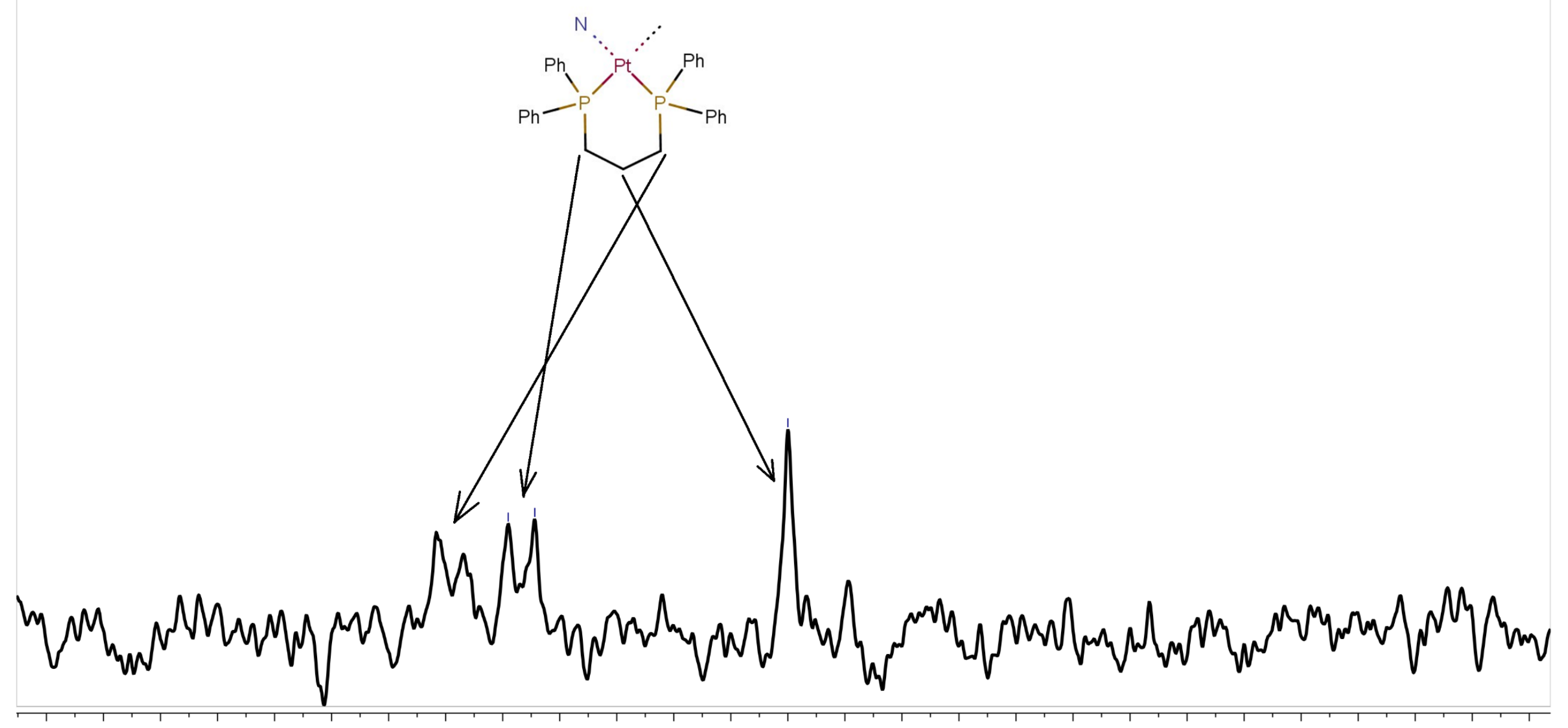

$\begin{array}{lllllllllllllllllllllllllll}32 & 31 & 30 & 29 & 28 & 27 & 26 & 25 & 24 & 23 & 22 & 21 & 20 & 19 & 18 & 17 & 16 & 15 & 14 & 13 & 12 & 11 & 10 & 9 & 8 & 7 & 6\end{array}$ $13 \mathrm{C}(\mathrm{ppm})$

Figure S37. The aliphatic region of the ${ }^{13} C$ NMR spectrum of complex (14). 


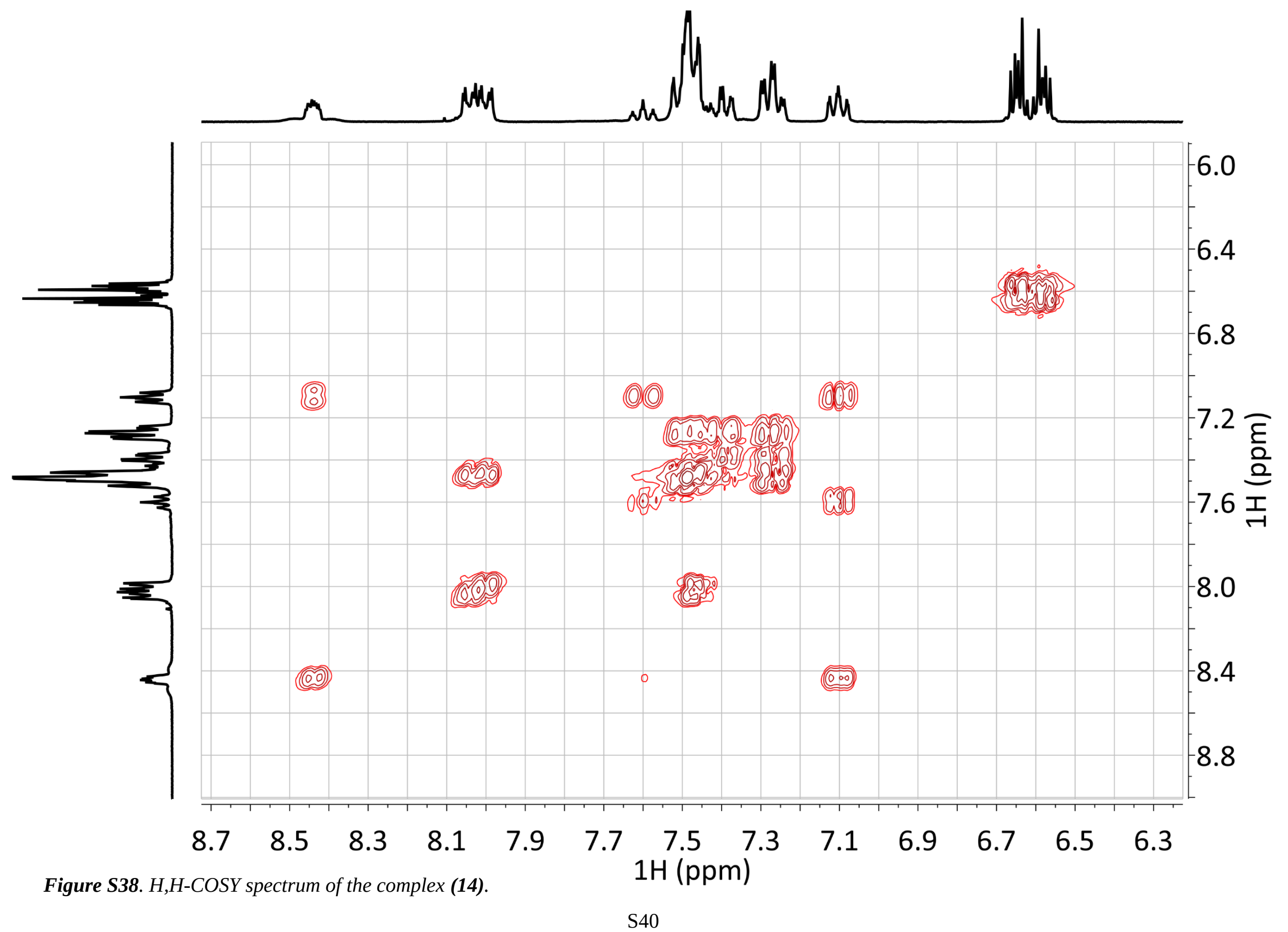




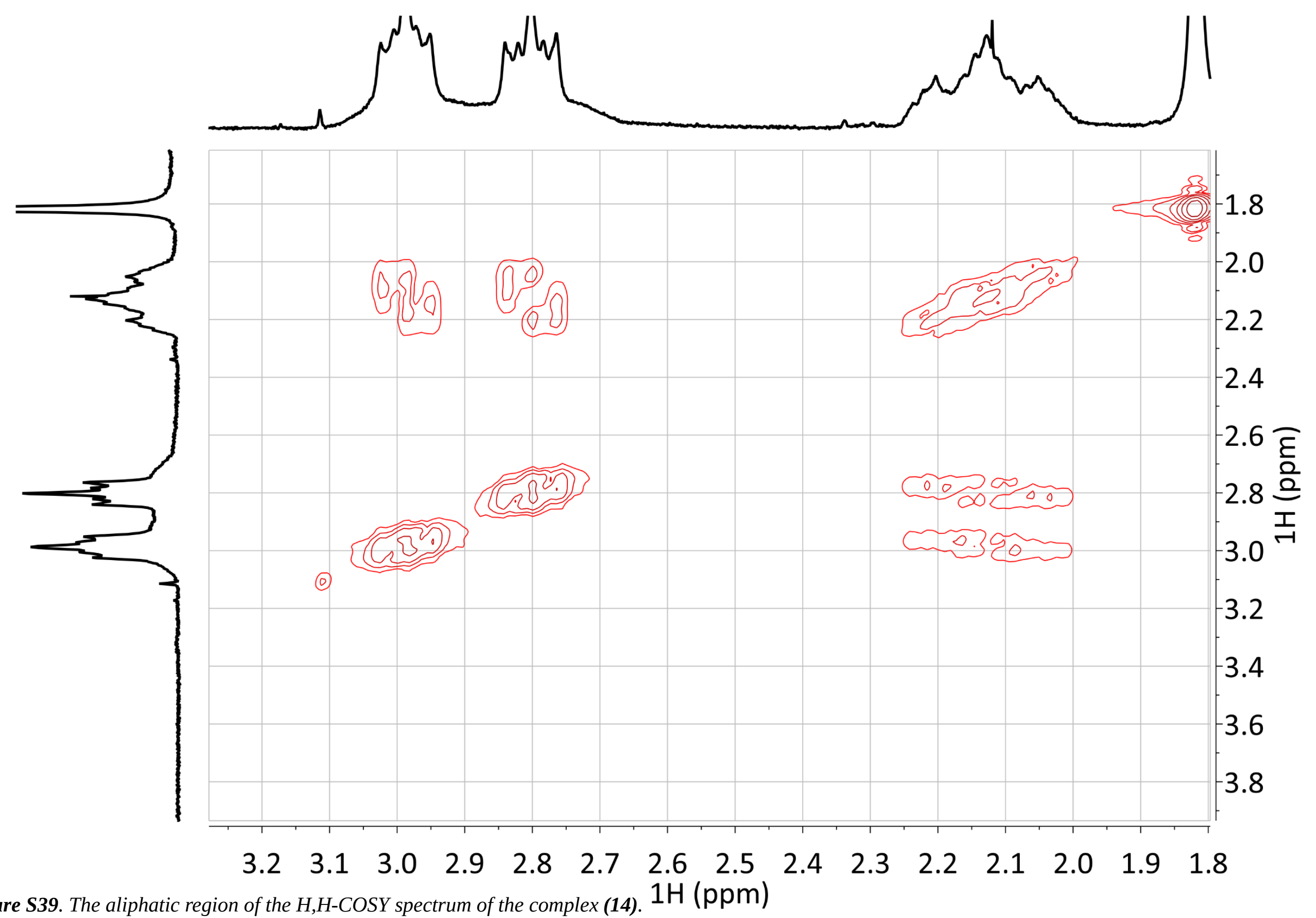




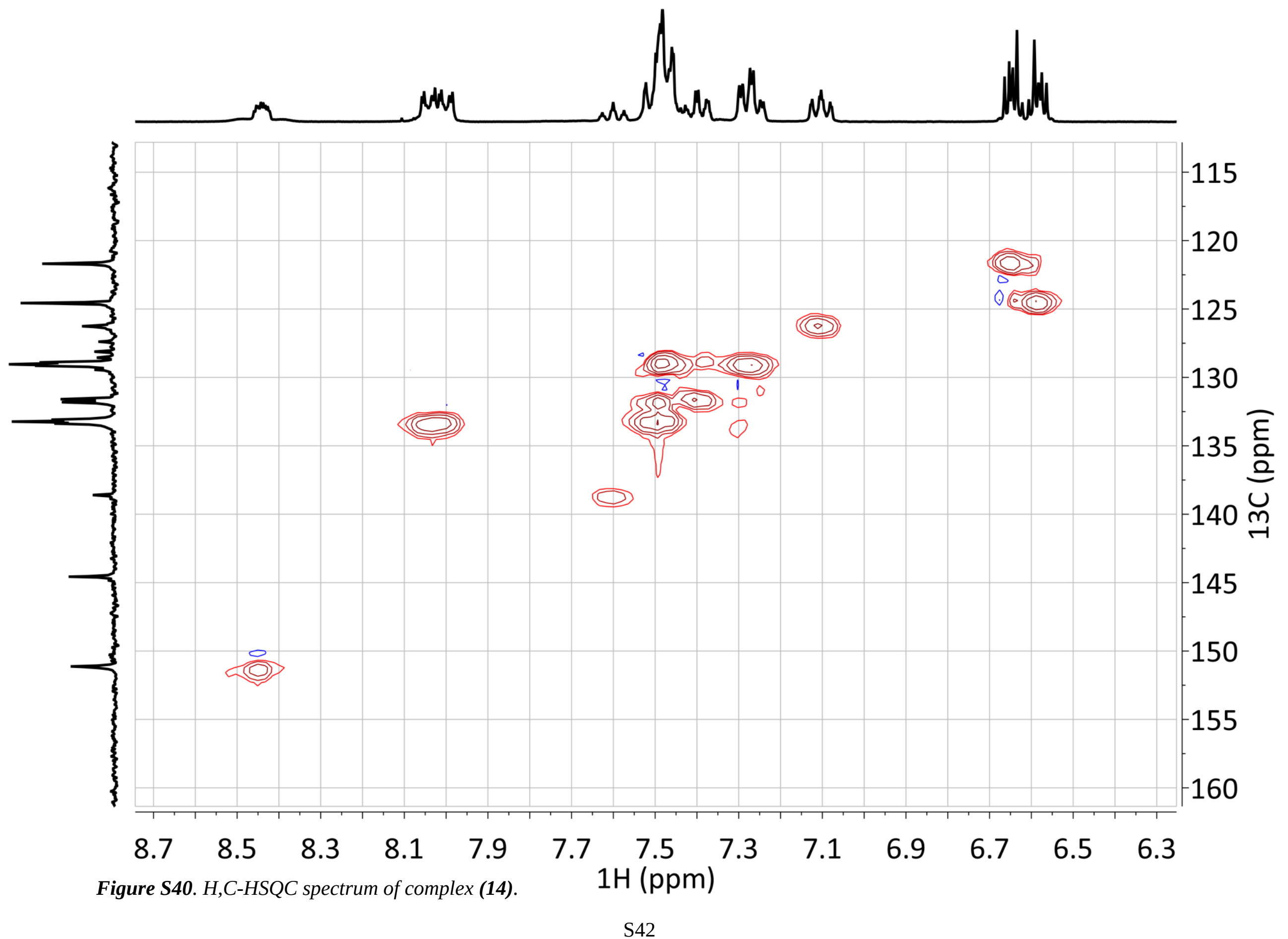




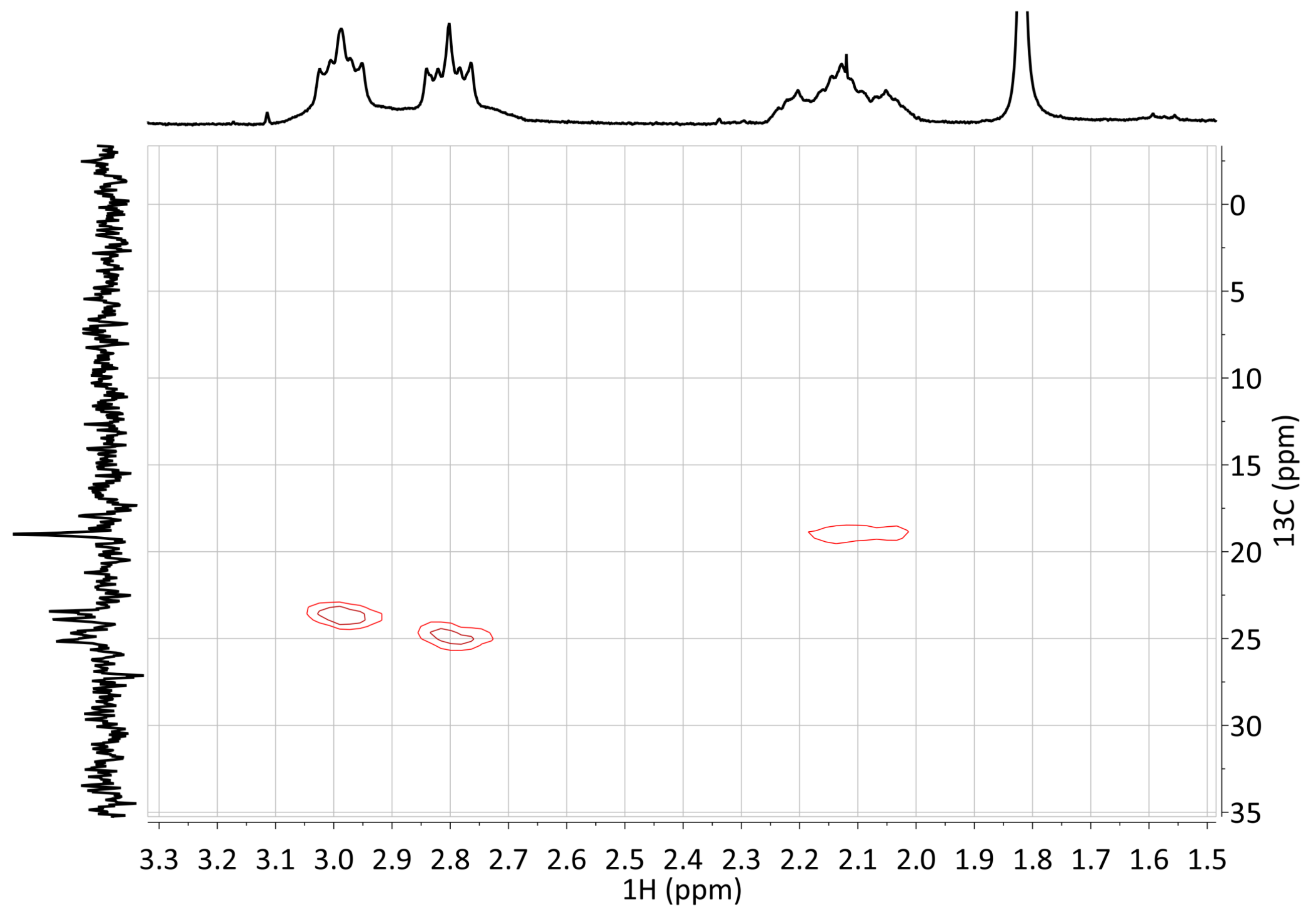

Figure S41. The aliphatic region of the H,C-HSQC spectrum of complex (14). 


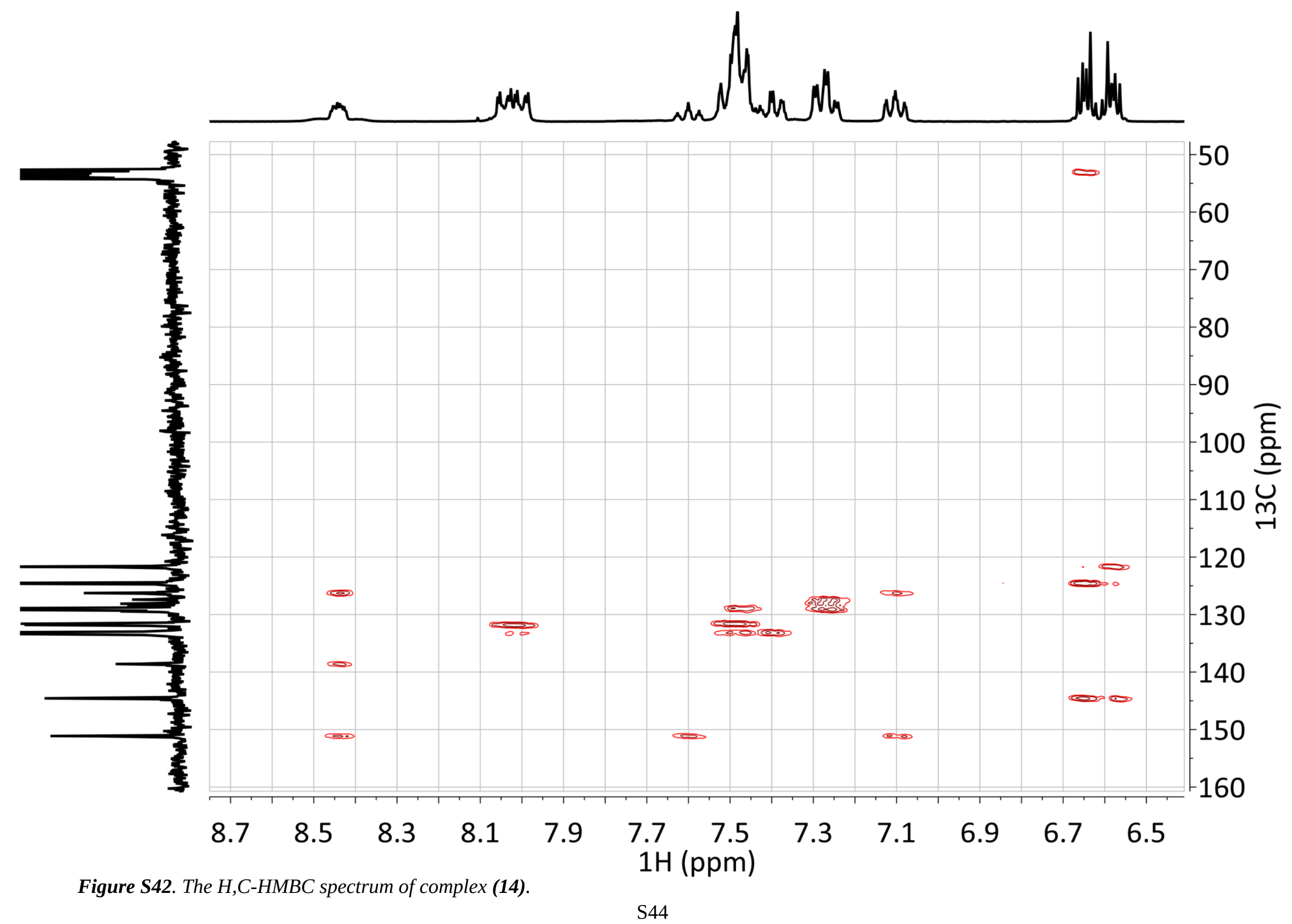




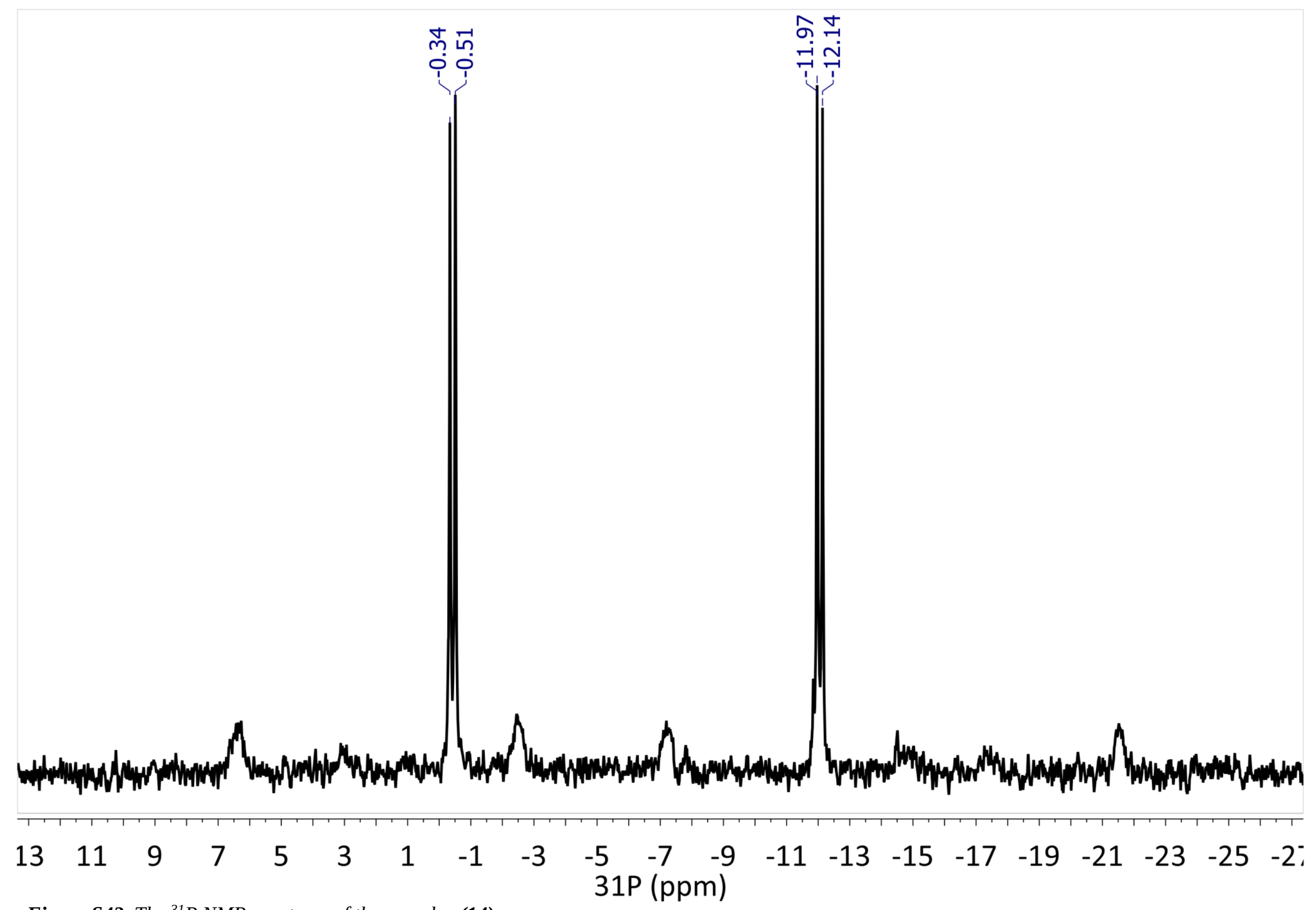

Figure S43. The ${ }^{31} P$ NMR spectrum of the complex (14). 


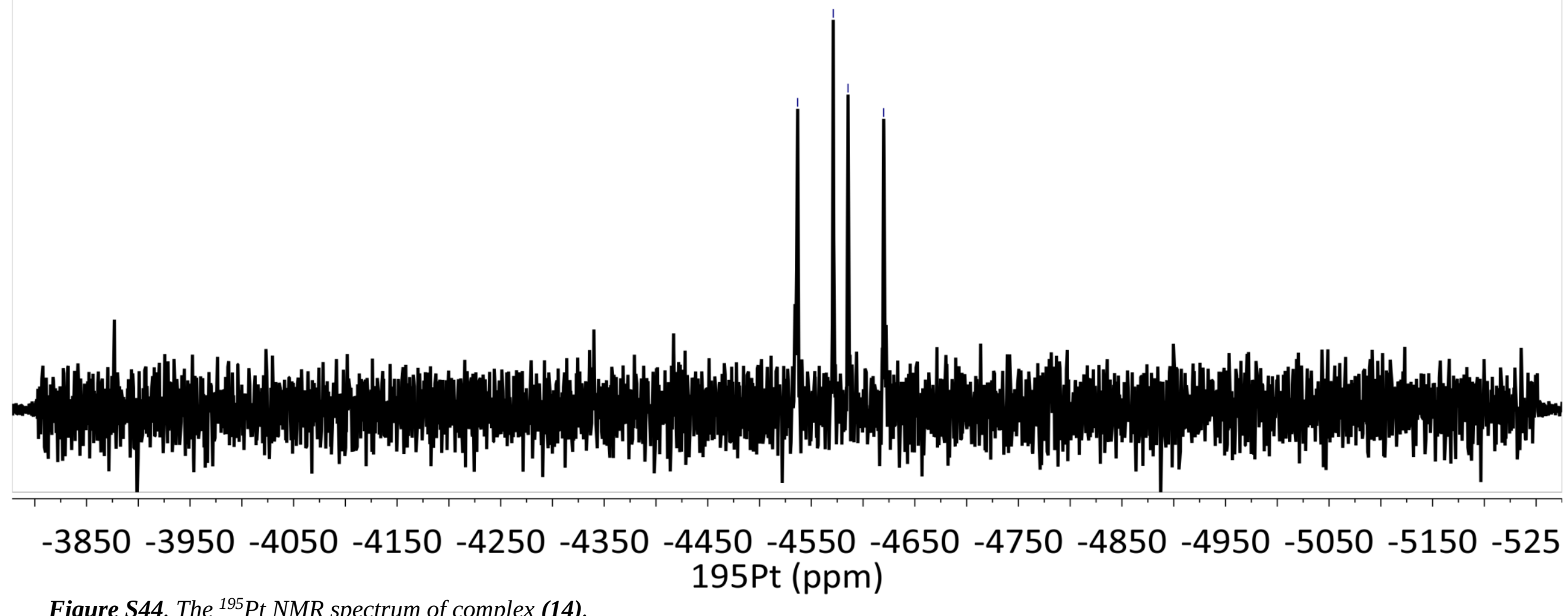

Figure S44. The ${ }^{195}$ Pt NMR spectrum of complex (14). 


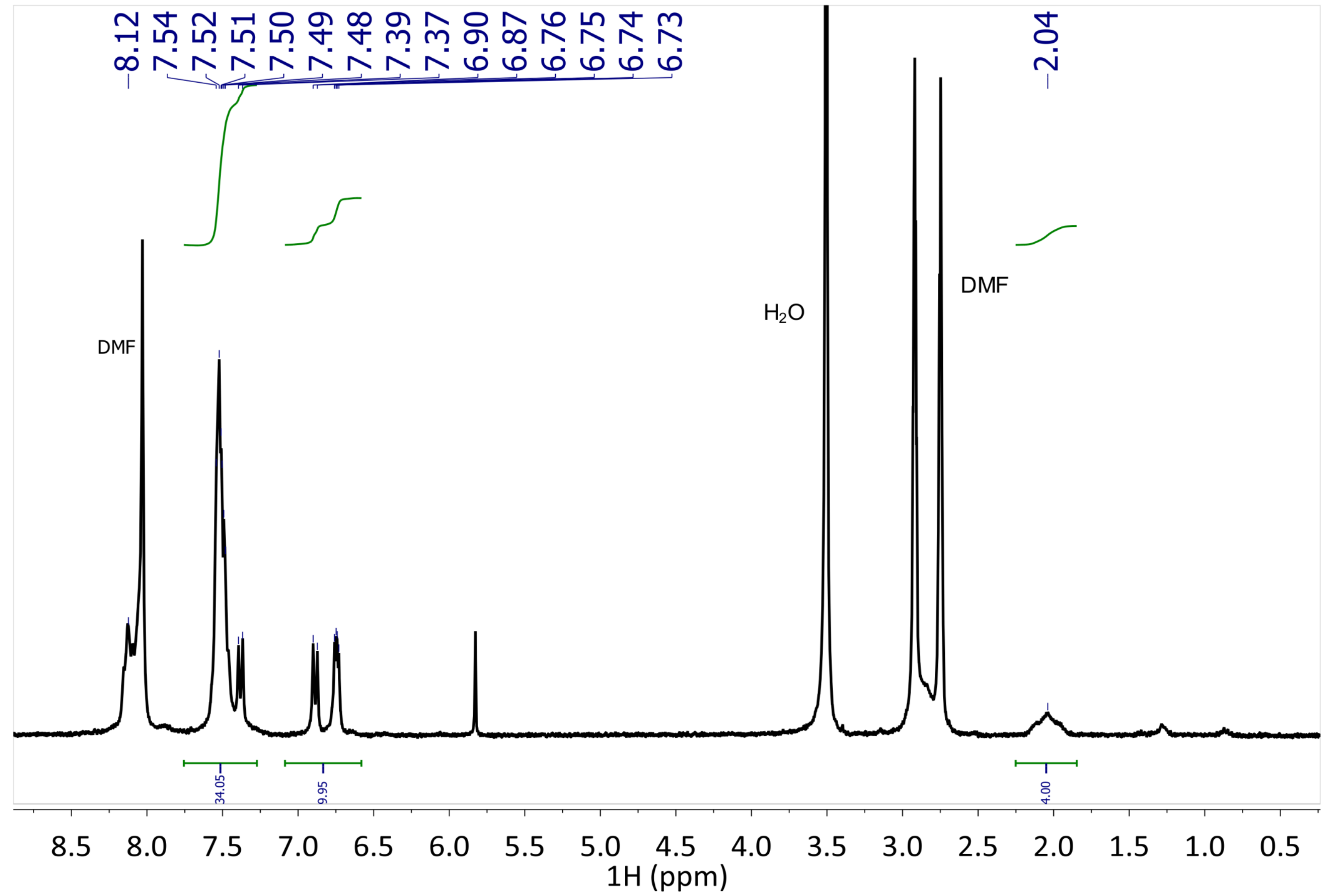

Figure S45. The ${ }^{1} H$ NMR spectrum of the rectangle (13). 


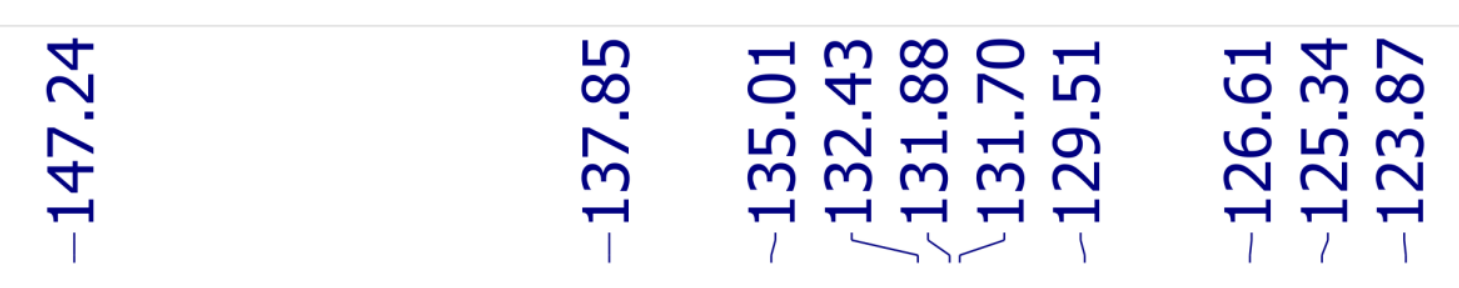

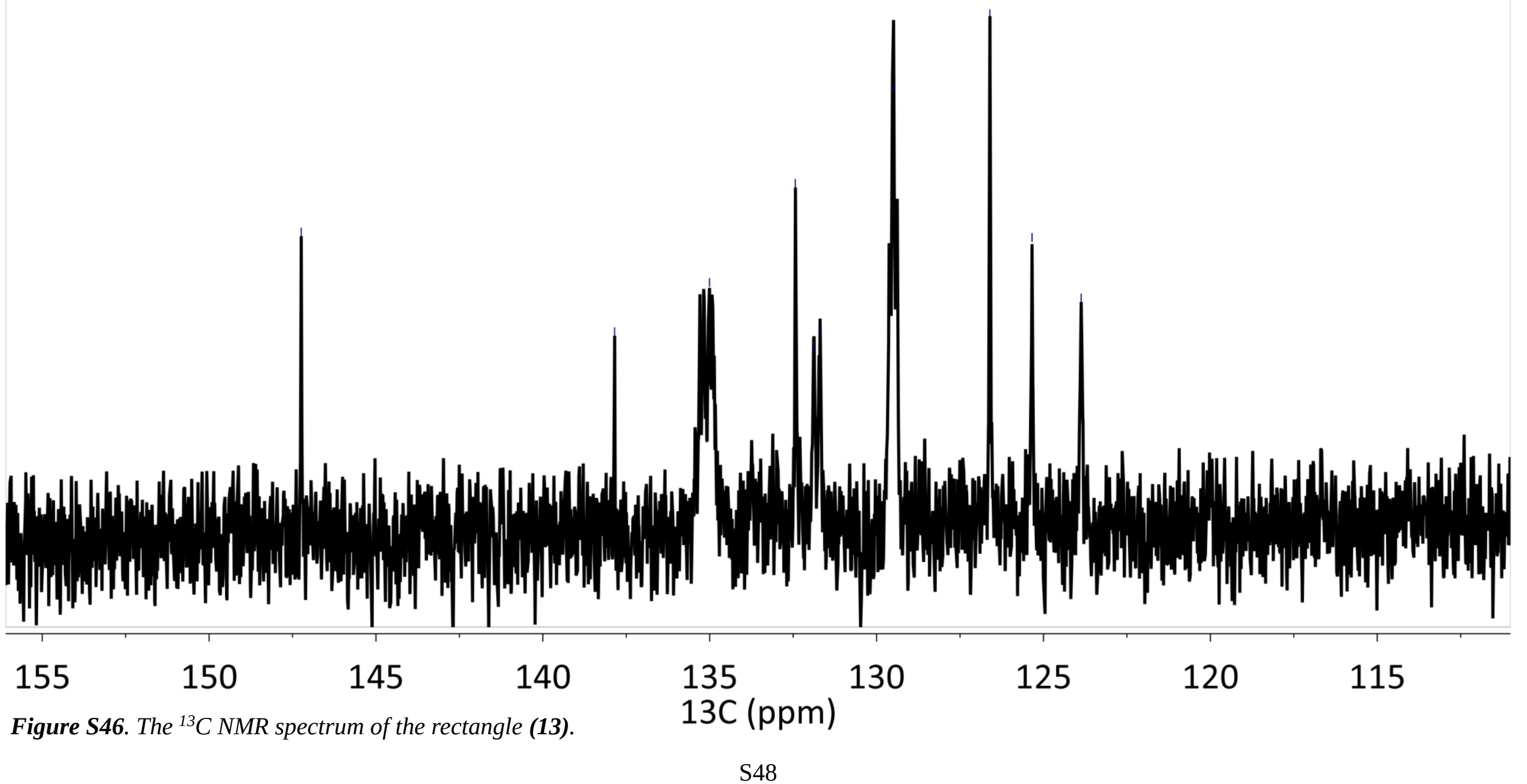




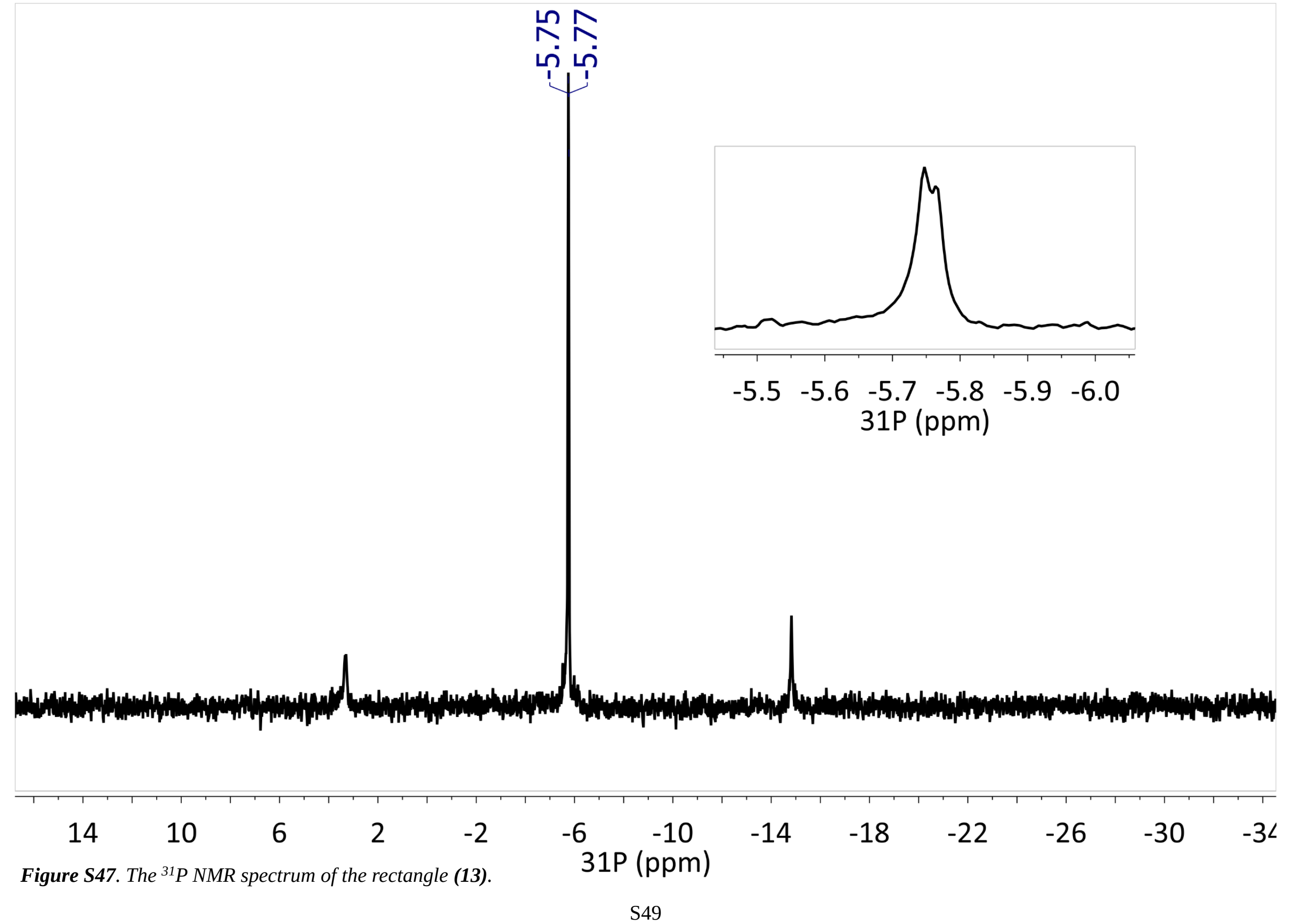




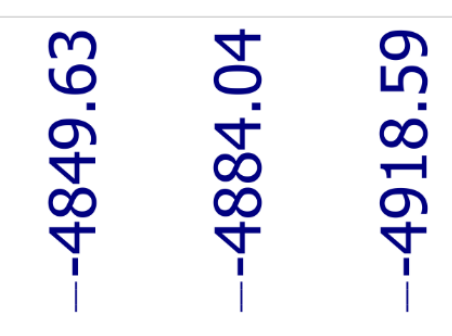

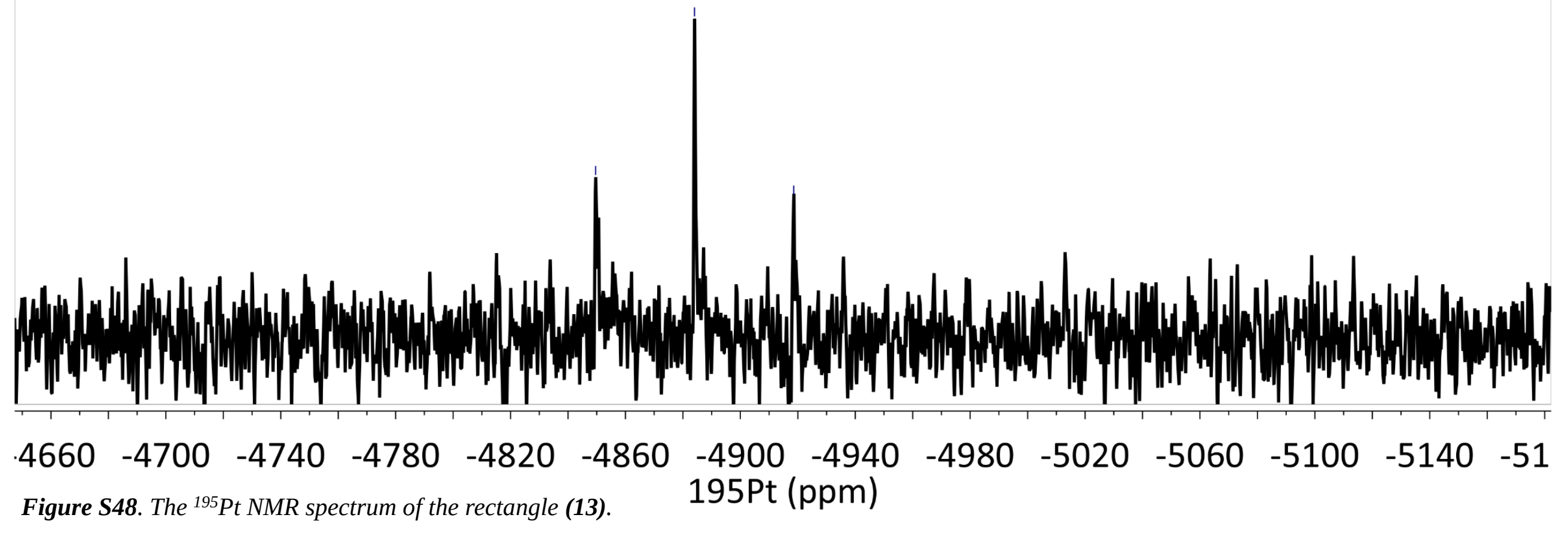




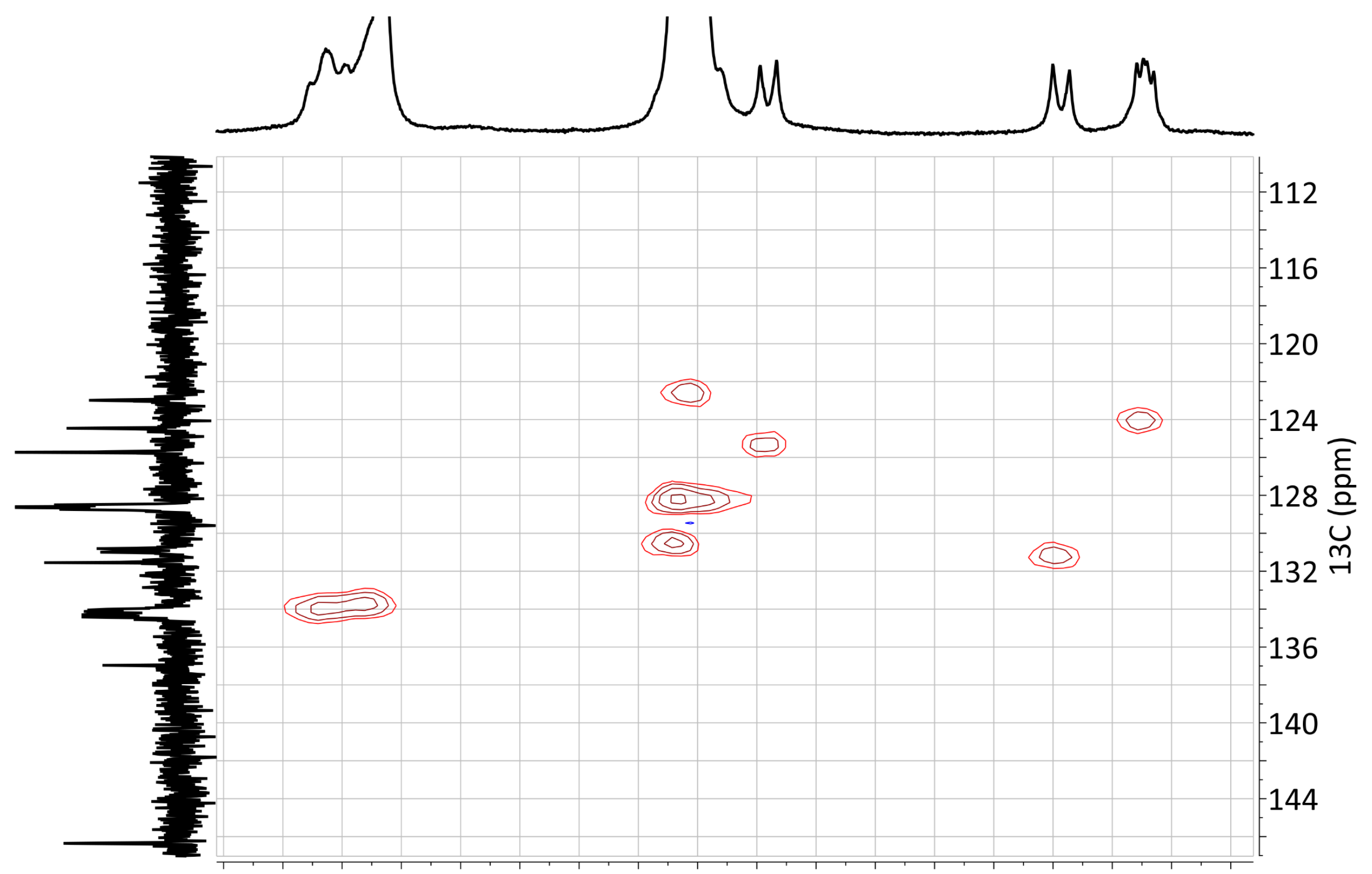

$\begin{array}{llllllllllllllllll}8.3 & 8.2 & 8.1 & 8.0 & 7.9 & 7.8 & 7.7 & 7.6 & 7.5 & 7.4 & 7.3 & 7.2 & 7.1 & 7.0 & 6.9 & 6.8 & 6.7 & 6.6\end{array}$ Figure S49. The H,C-HSQC spectrum of the rectangle (13). $1 \mathrm{H}(\mathrm{ppm})$ 


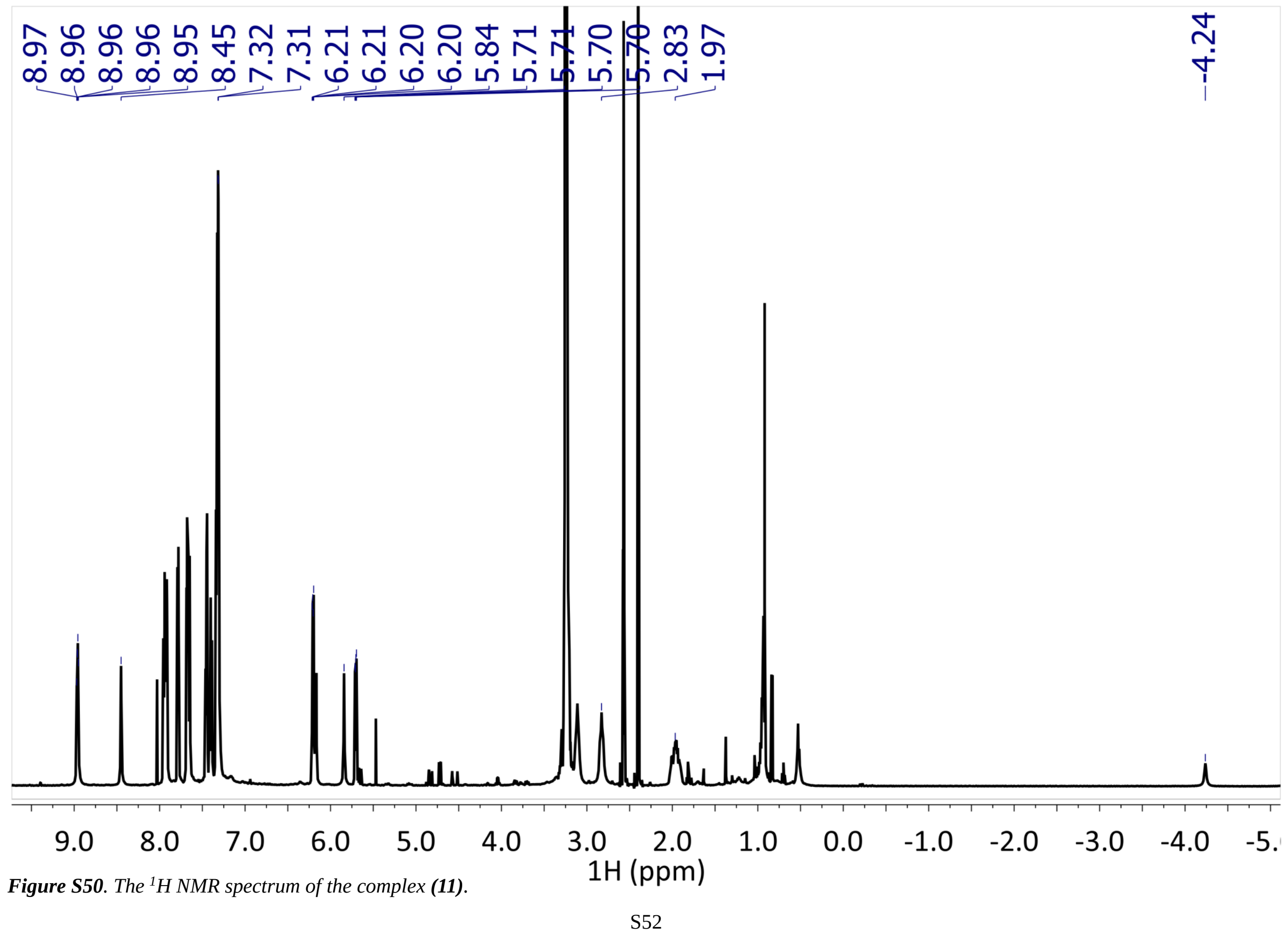


ลิ ด้ ด้ ด้ ฝூ

$\infty \infty \infty \infty$

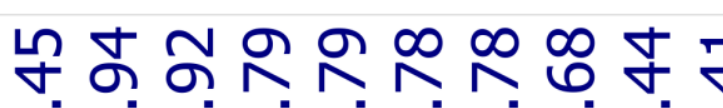

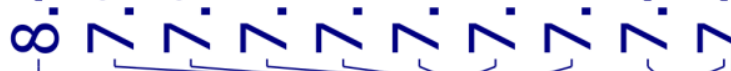

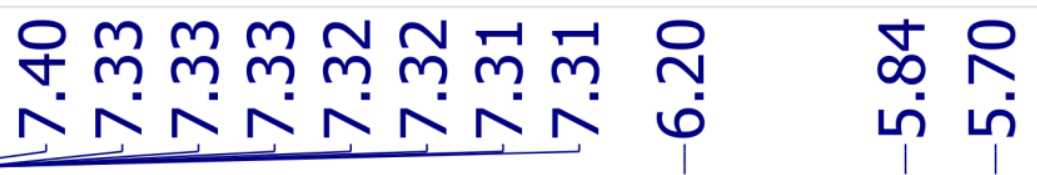

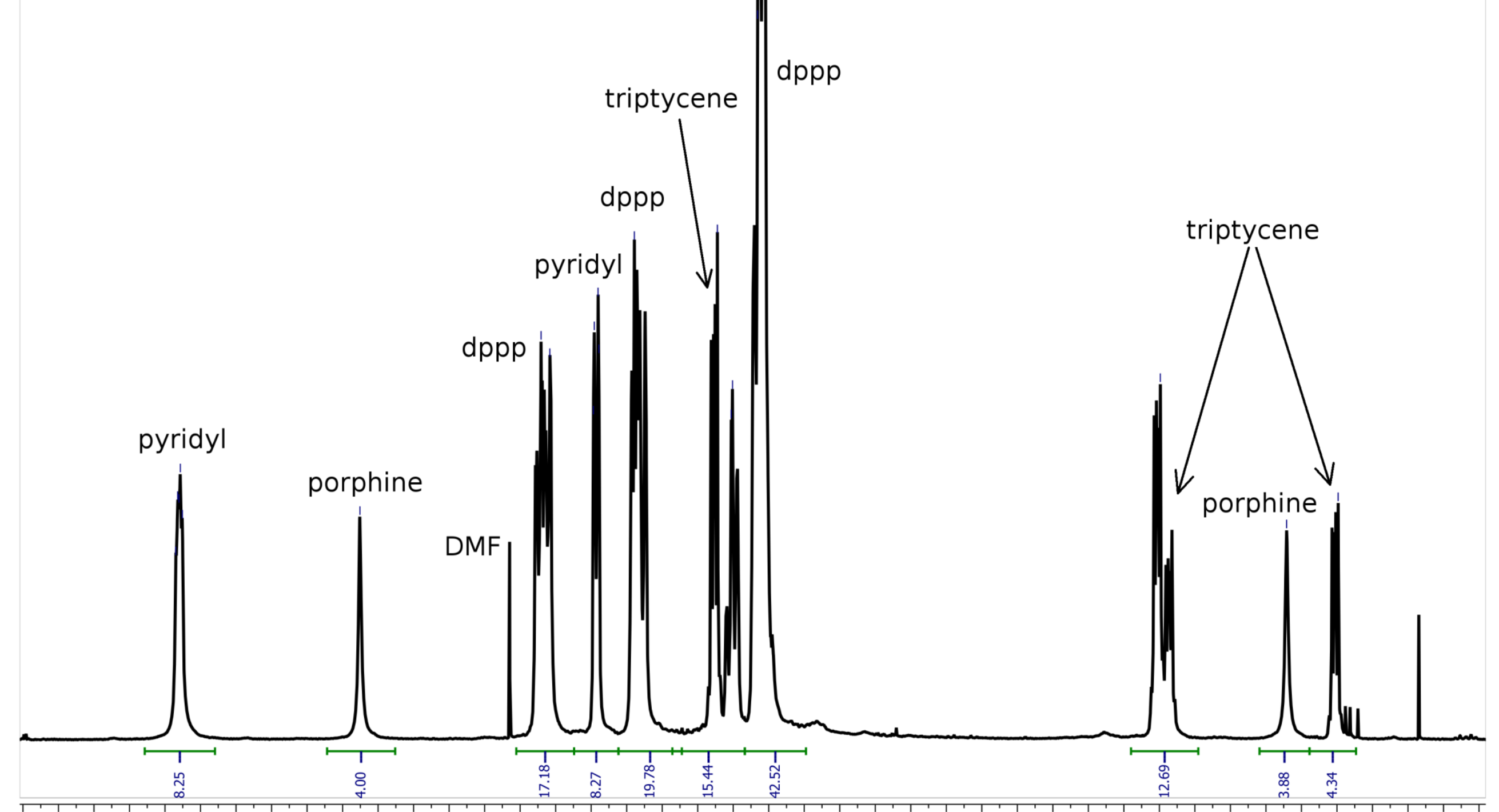

$\begin{array}{lllllllllllllllllllll}9.3 & 9.1 & 8.9 & 8.7 & 8.5 & 8.3 & 8.1 & 7.9 & 7.7 & 7.5 & 7.3 & 7.1 & 6.9 & 6.7 & 6.5 & 6.3 & 6.1 & 5.9 & 5.7 & 5.5 & 5 .\end{array}$ $1 \mathrm{H}(\mathrm{ppm})$

Figure S51. The aromatic region of the ${ }^{1} H$ NMR spectrum of complex (11). 


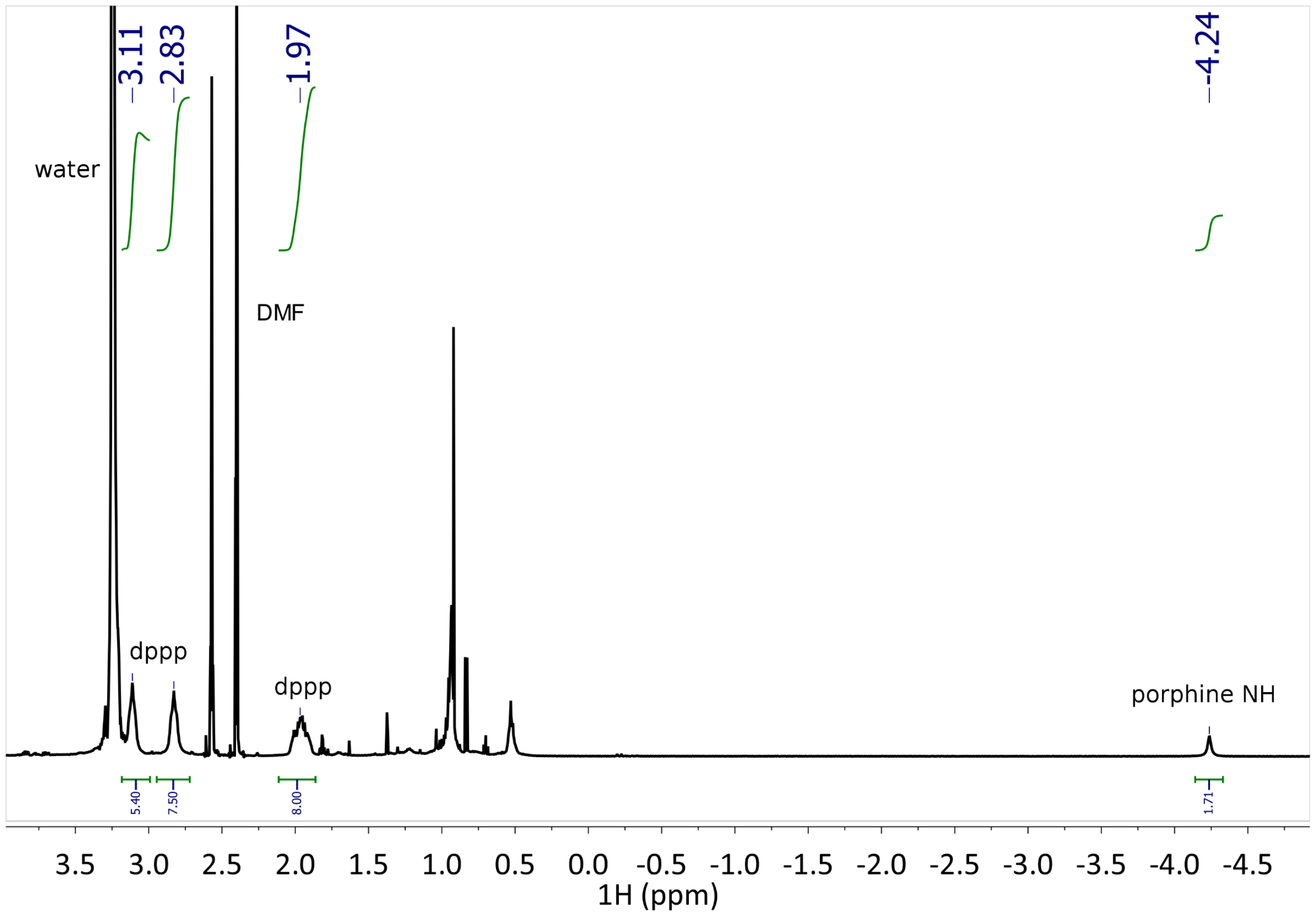

Figure S52. The aliphatic region of the ${ }^{1} H$ NMR spectrum of complex (11). 


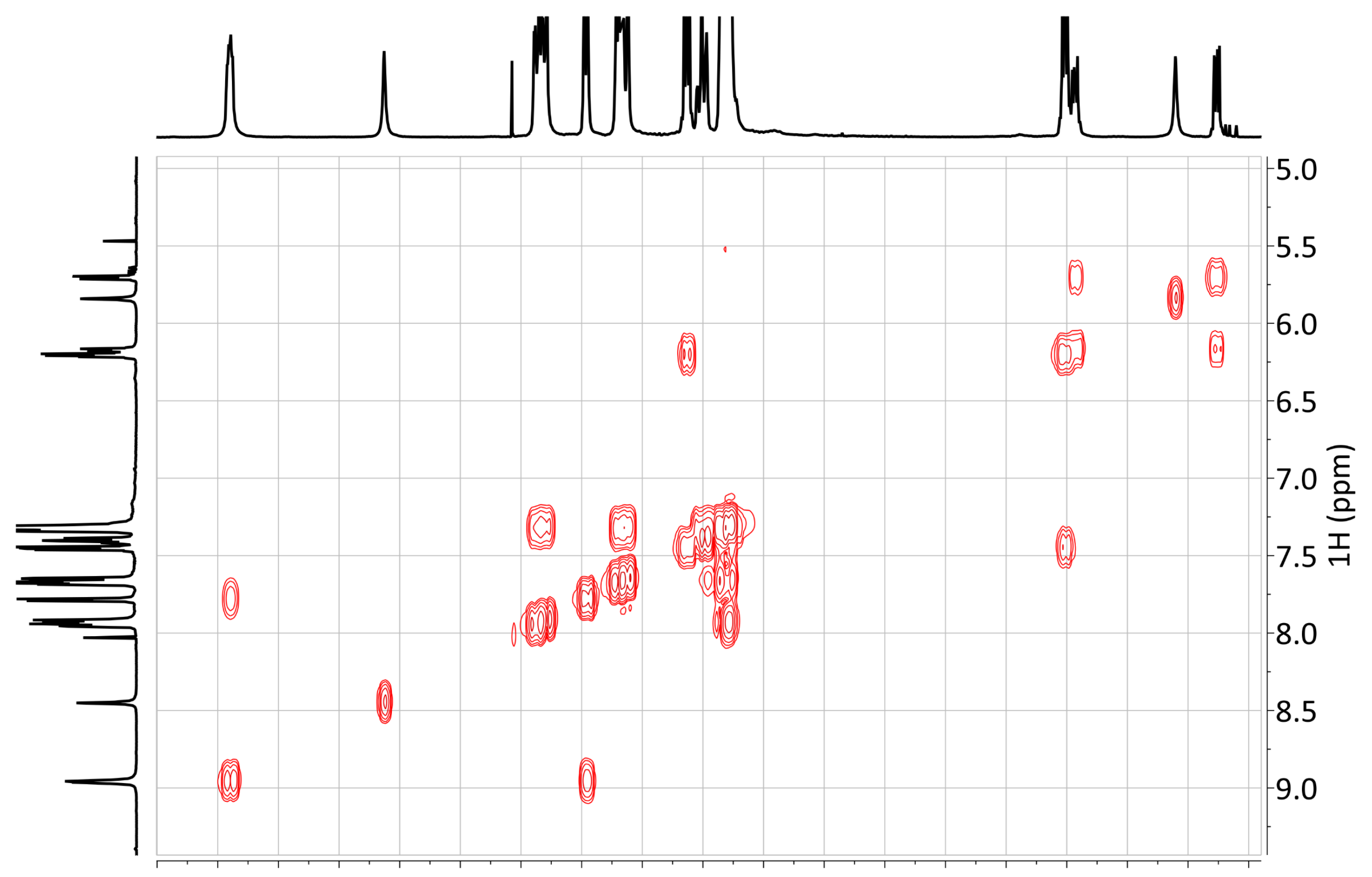

$\begin{array}{lllllllllllllllllll}9.2 & 9.0 & 8.8 & 8.6 & 8.4 & 8.2 & 8.0 & 7.8 & 7.6 & 7.4 & 7.2 & 7.0 & 6.8 & 6.6 & 6.4 & 6.2 & 6.0 & 5.8 & 5.6\end{array}$ Figure S53. The H,H-COSY spectrum of the complex (11). $\quad 1 \mathrm{H}(\mathrm{ppm})$ 


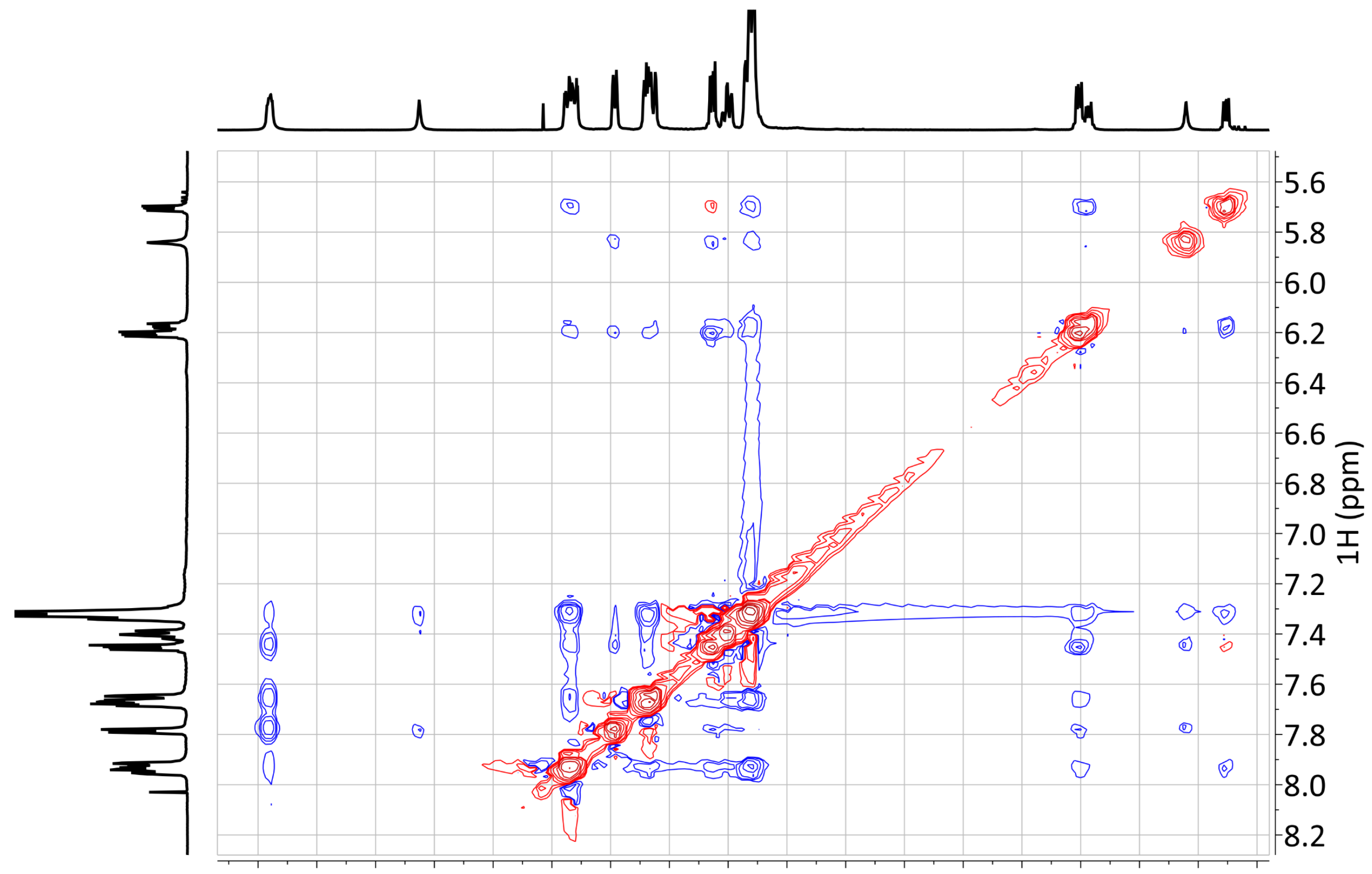

$\begin{array}{llllllllllllllllll}9.0 & 8.8 & 8.6 & 8.4 & 8.2 & 8.0 & 7.8 & 7.6 & 7.4 & 7.2 & 7.0 & 6.8 & 6.6 & 6.4 & 6.2 & 6.0 & 5.8 & 5.6\end{array}$ Figure S54. The ROESY spectrum of the complex (11). $1 \mathrm{H}(\mathrm{ppm})$ 


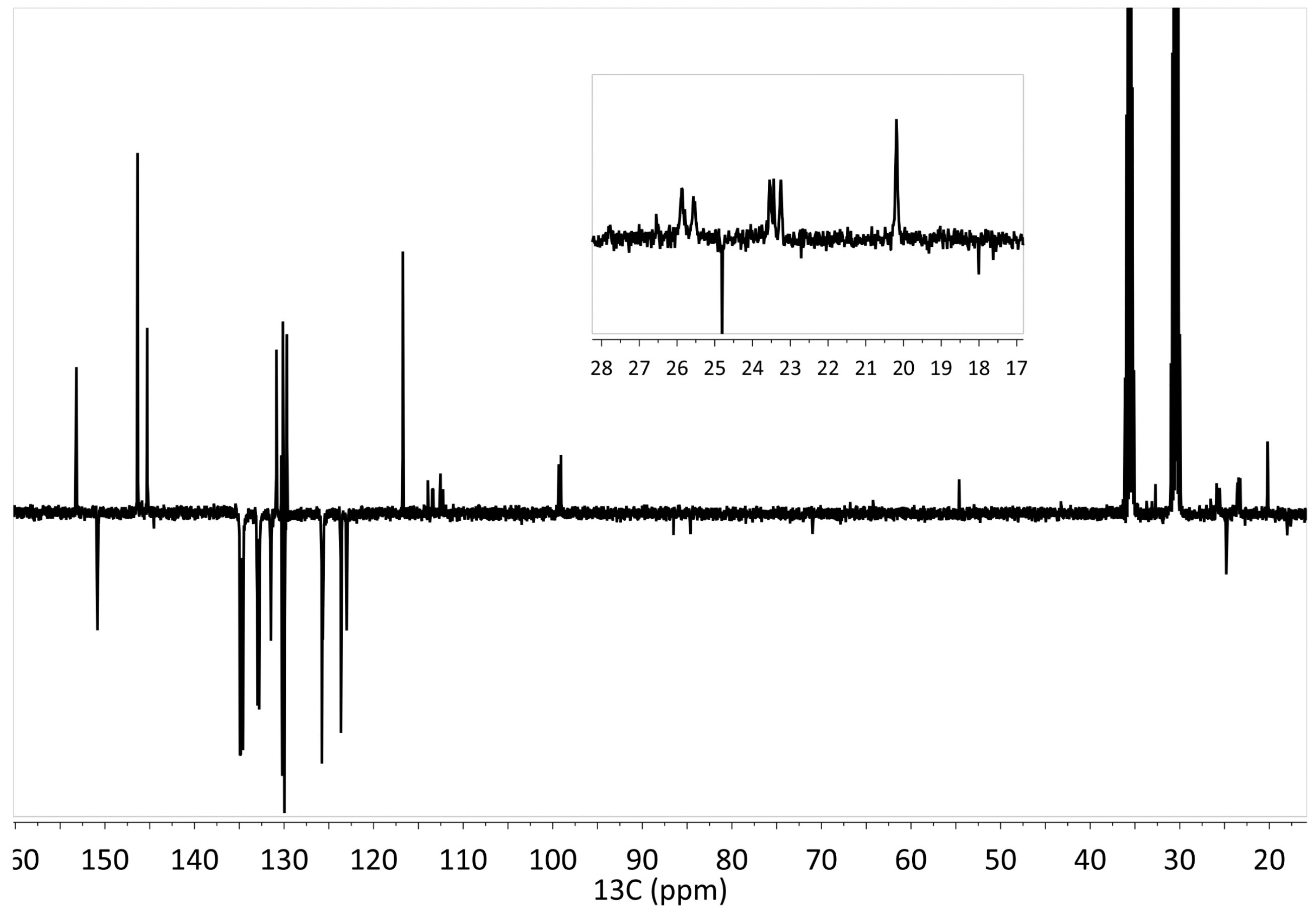

Figure S55. The ${ }^{13} C$ APT NMR spectrum of complex (11).

The inset shows the signals of aliphatic carbons of dppp. 


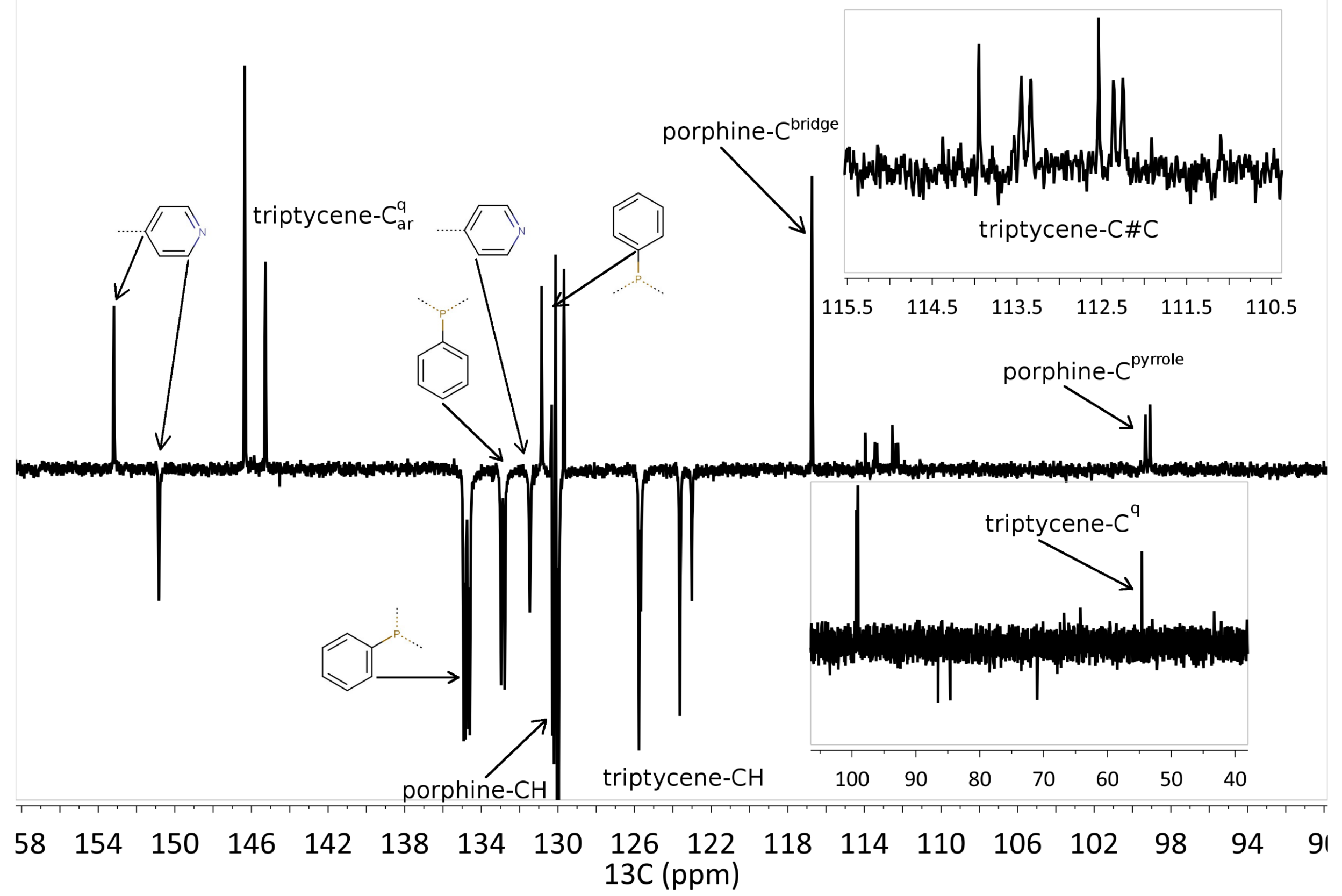

Figure S56. The aromatic region of the ${ }^{13} C$ APT NMR spectrum of complex (11). The insets show the alkyne carbons (top) and tertiary carbon atoms of the triptycene linker (bottom). 


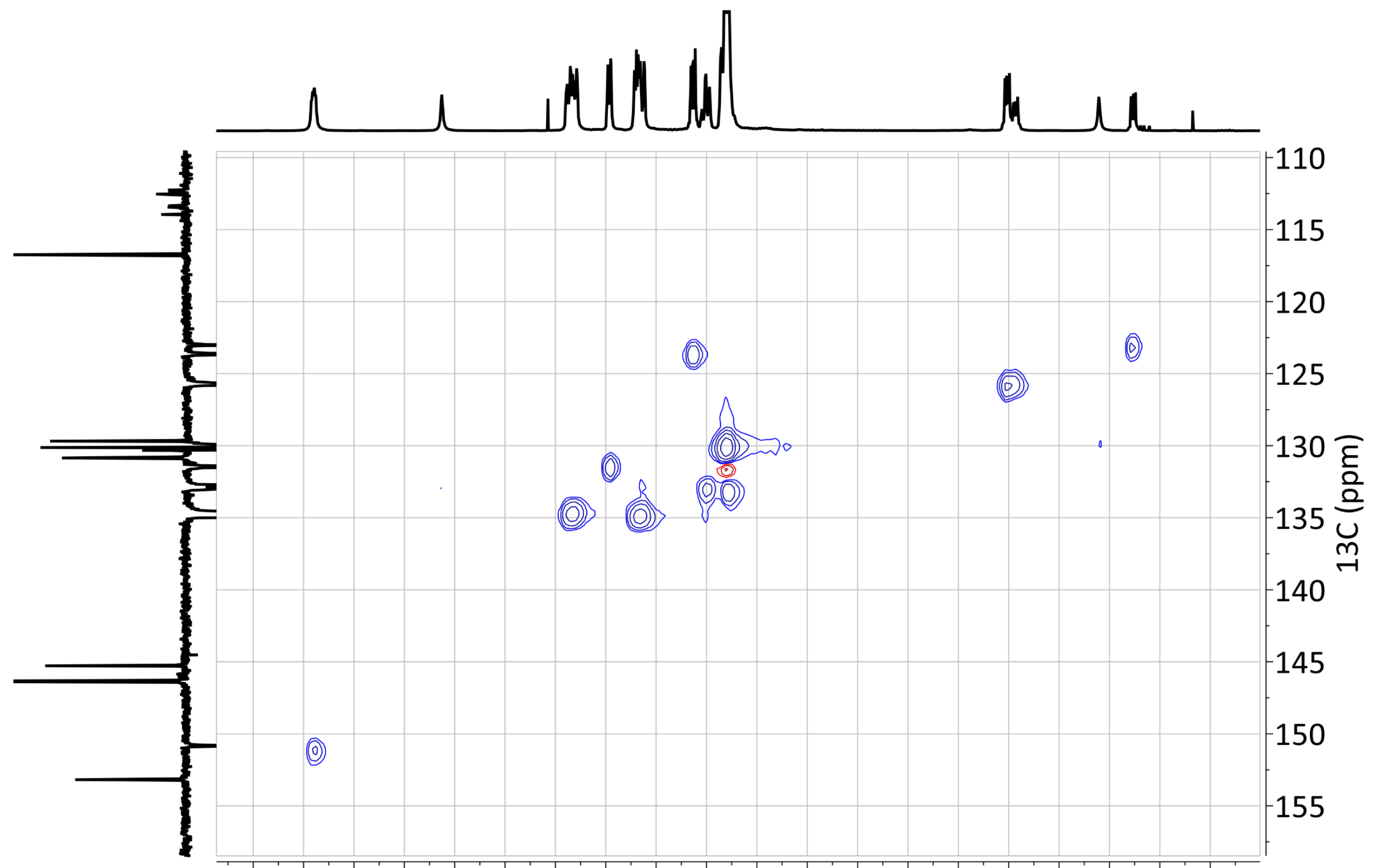

9.2 9.0 8.8 8.6 8.4 8.2 8.0 7.8 7.6 7.4 7.2 7.0 6.8 6.6 6.4 6.2 6.0 5.8 5.6 5.4 $1 \mathrm{H}(\mathrm{ppm})$

Figure S57. The aromatic region H,C-HSQC spectrum of the complex (11). 


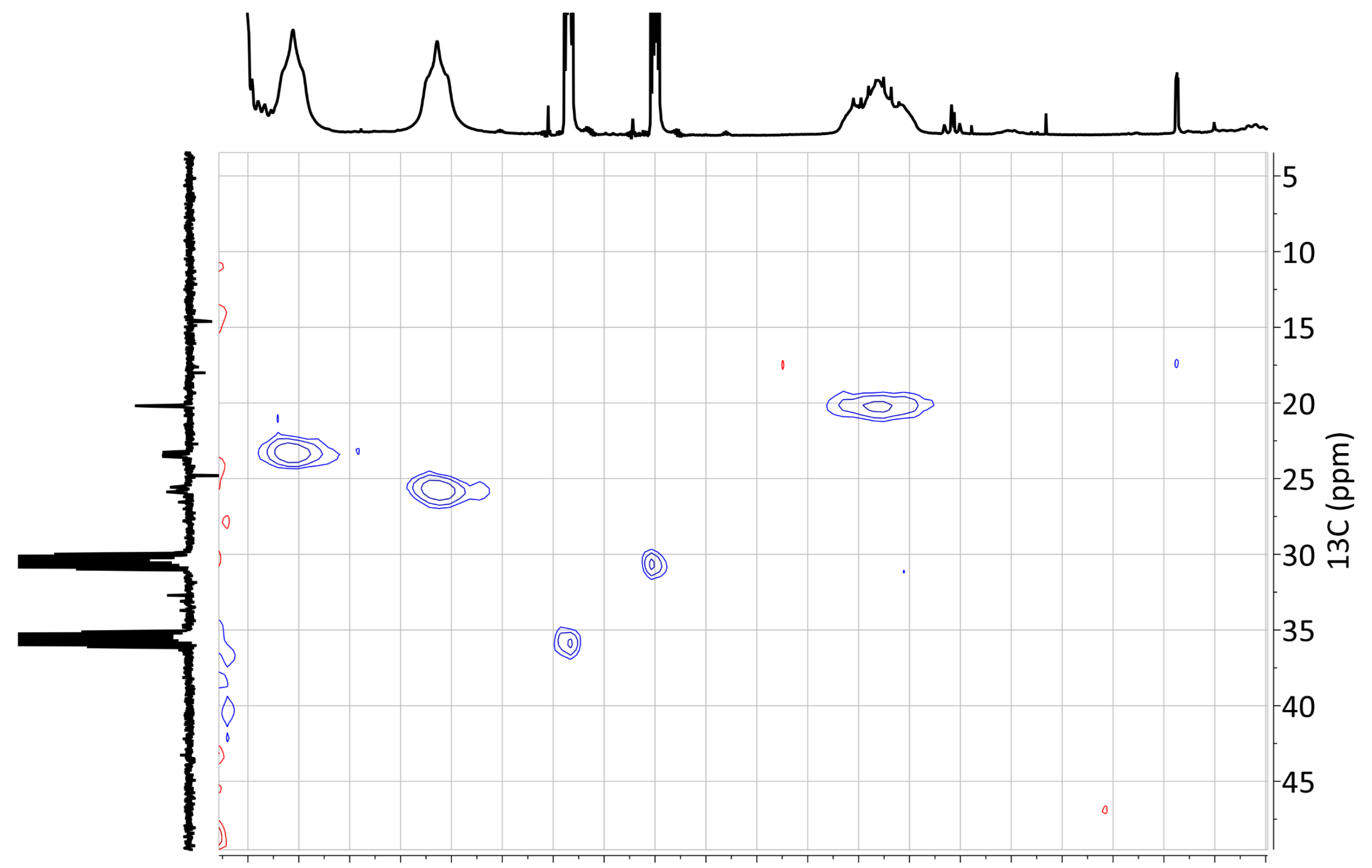

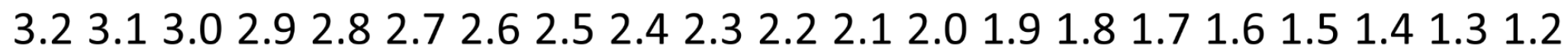
$1 \mathrm{H}(\mathrm{ppm})$

Figure S58. The aliphatic region of the H,C-HSQC spectrum of complex (11). 


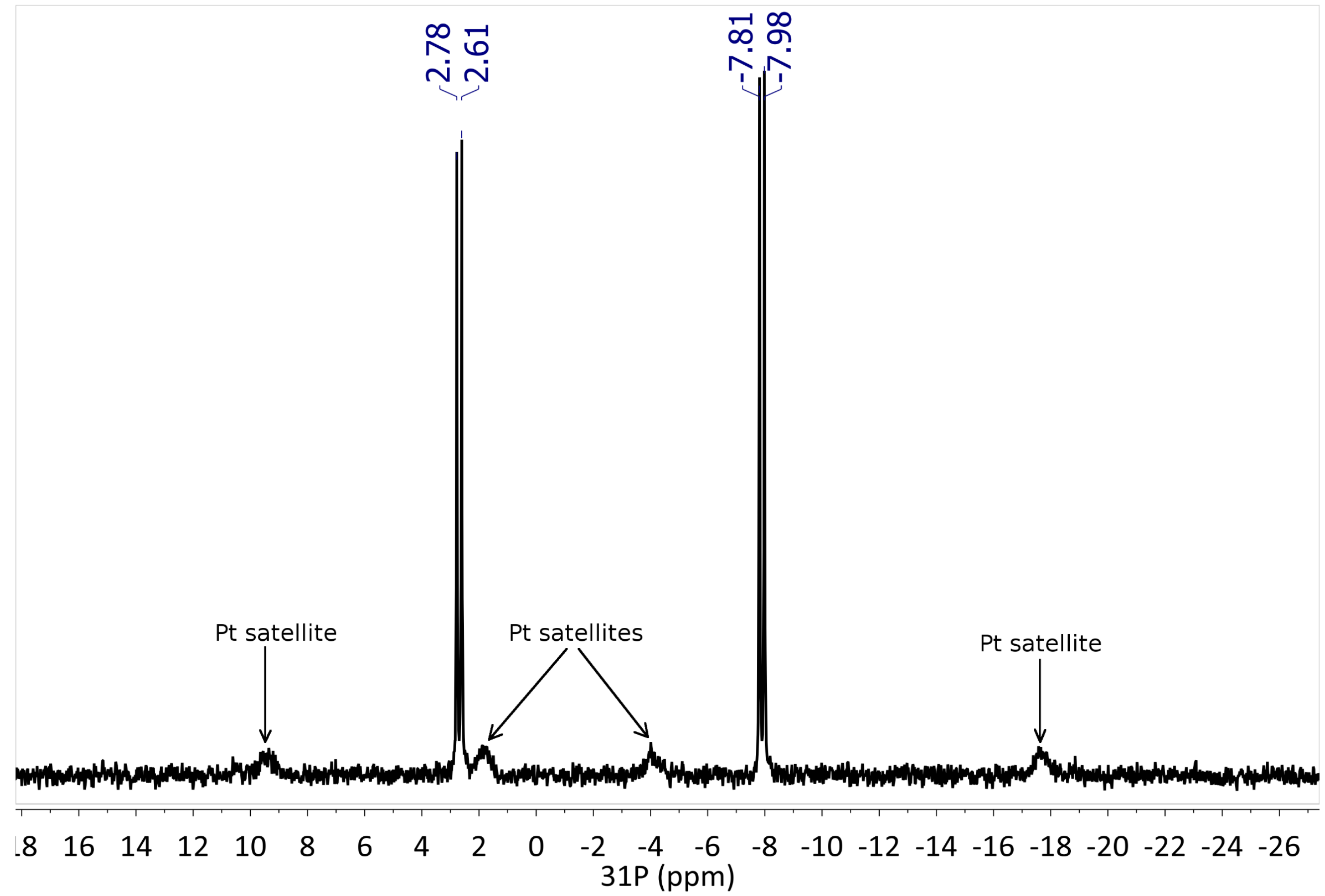

Figure S59. The ${ }^{31} P$ NMR spectrum of the complex (11). 


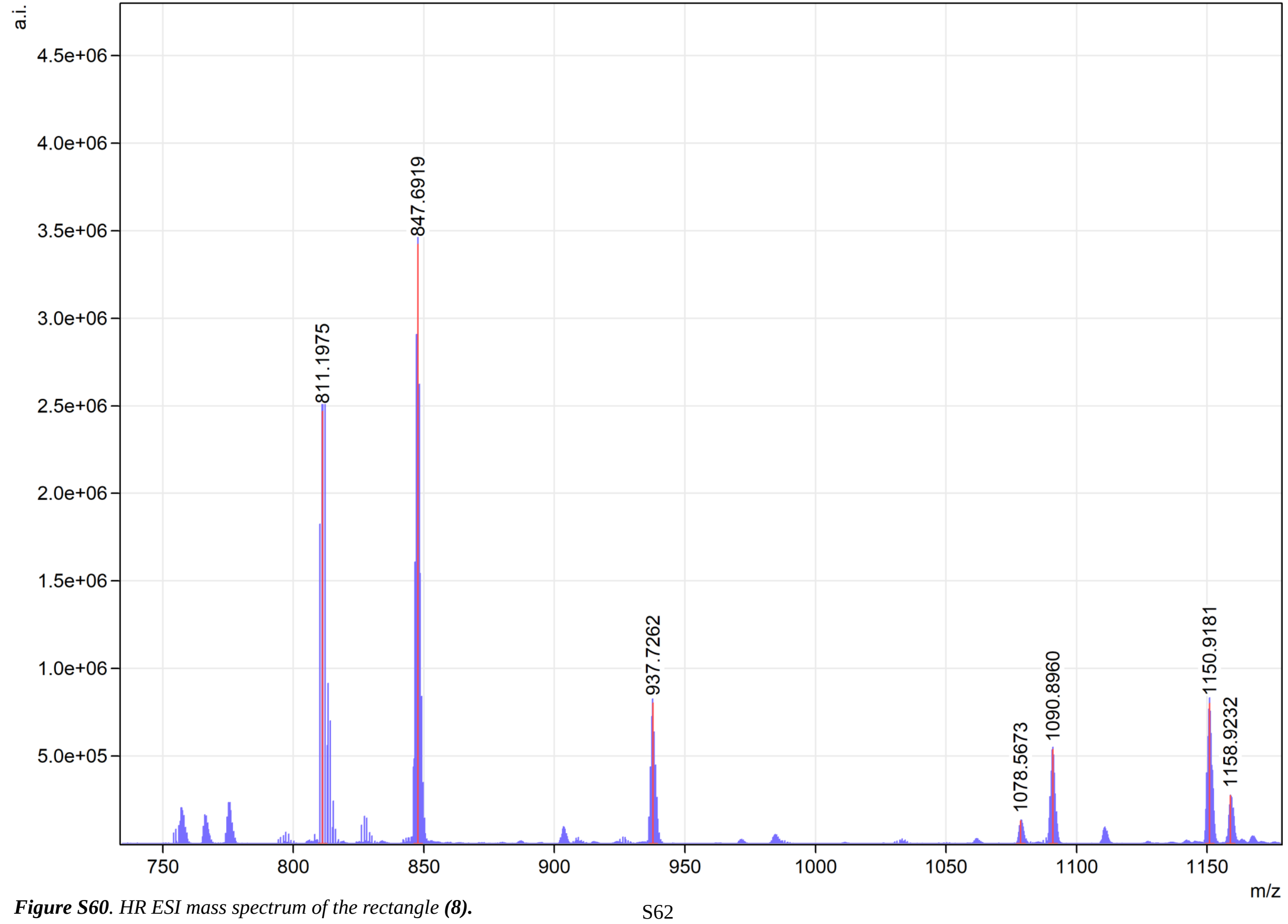




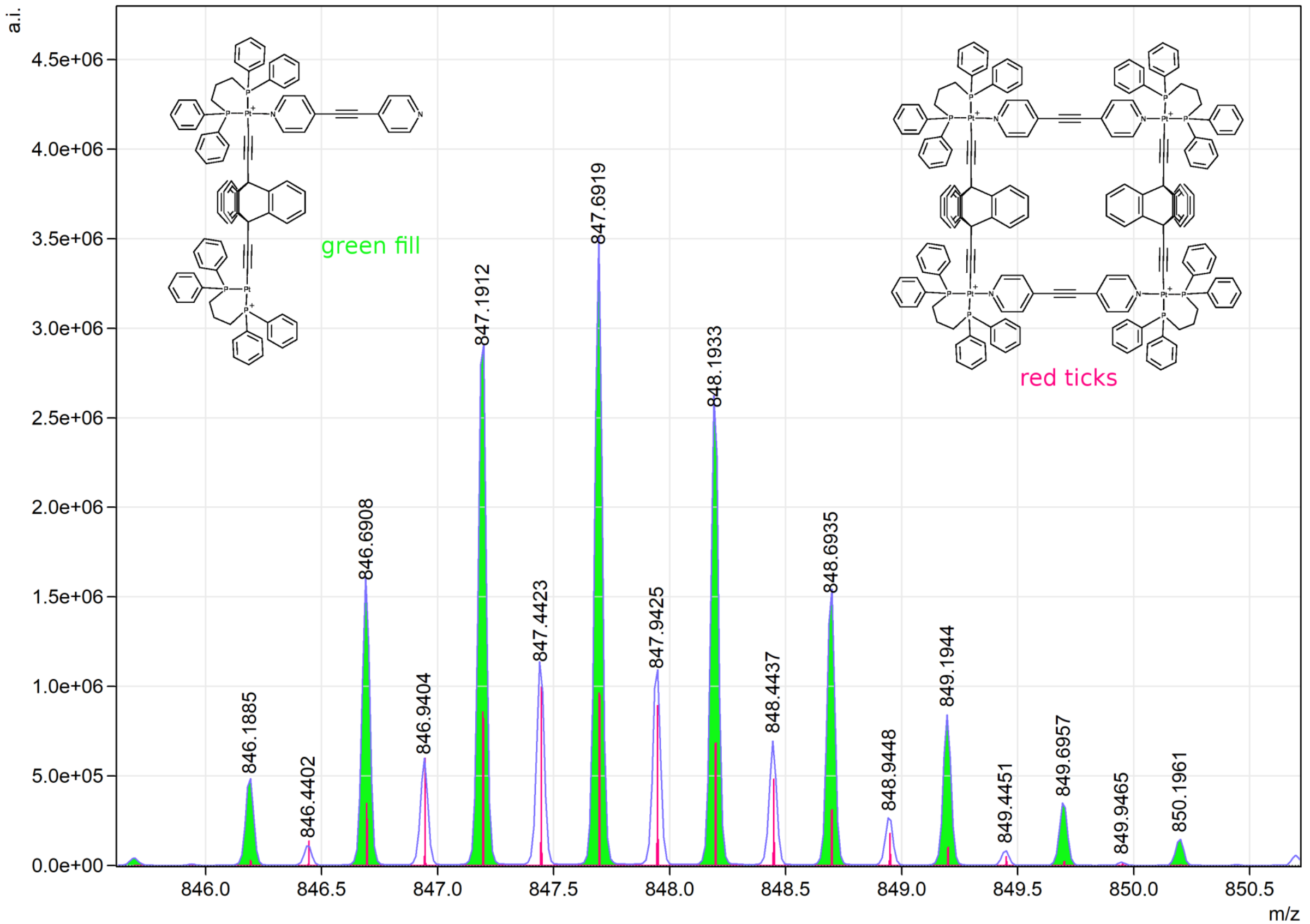

Figure S61. A detail of the HR ESI mass spectrum of the rectangle (8). The red ticks indicate positions of peaks assigned to the [M] ${ }^{4+}$ fragment (calculated), the green-filled peaks correspond to the $[M / 2]^{2+}$ fragment. 


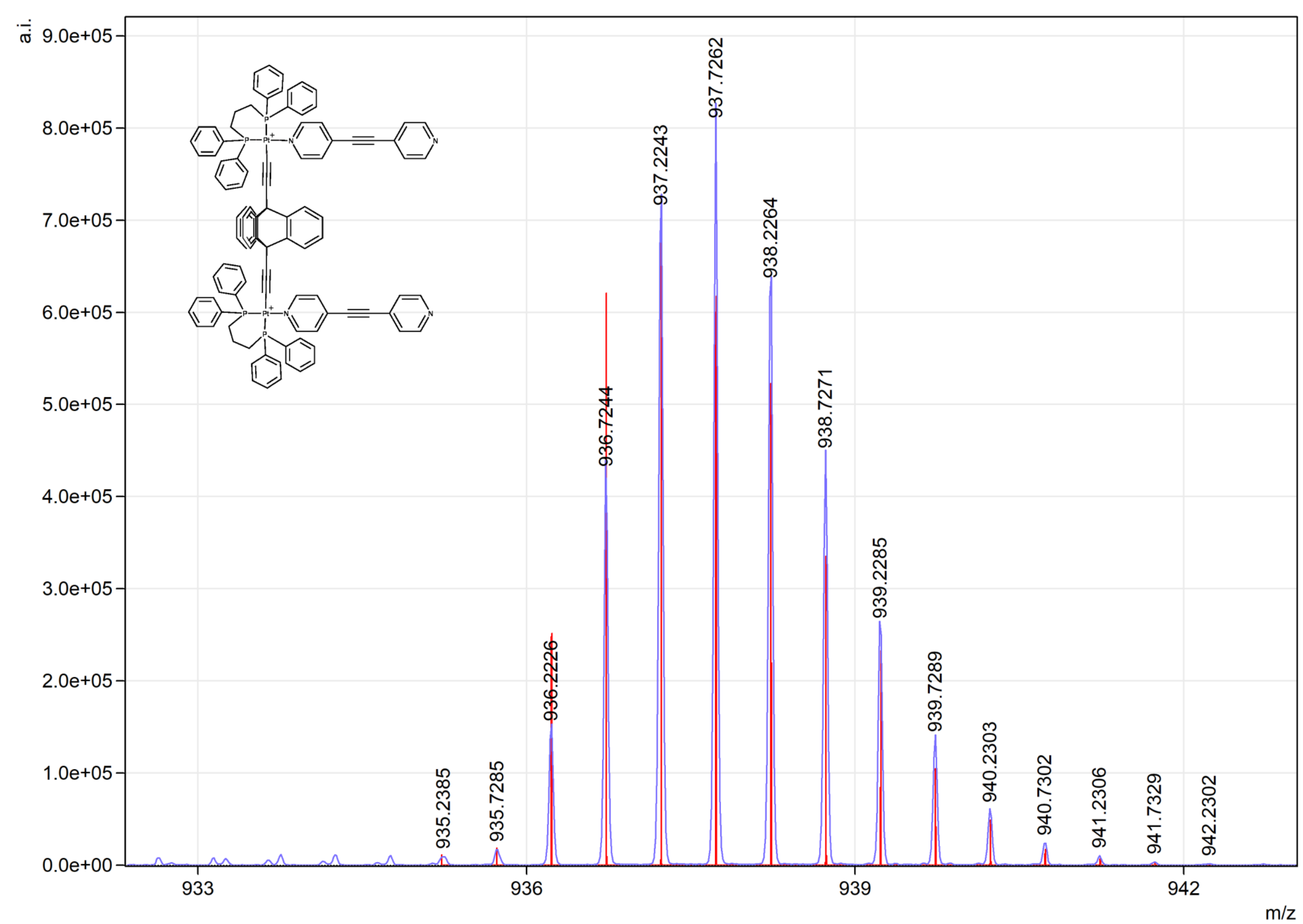

Figure S62. A detail of the HR ESI mass spectrum of the rectangle (8). The red ticks indicate the calculated positions of the peaks corresponding to the displayed fragment of the complex. 


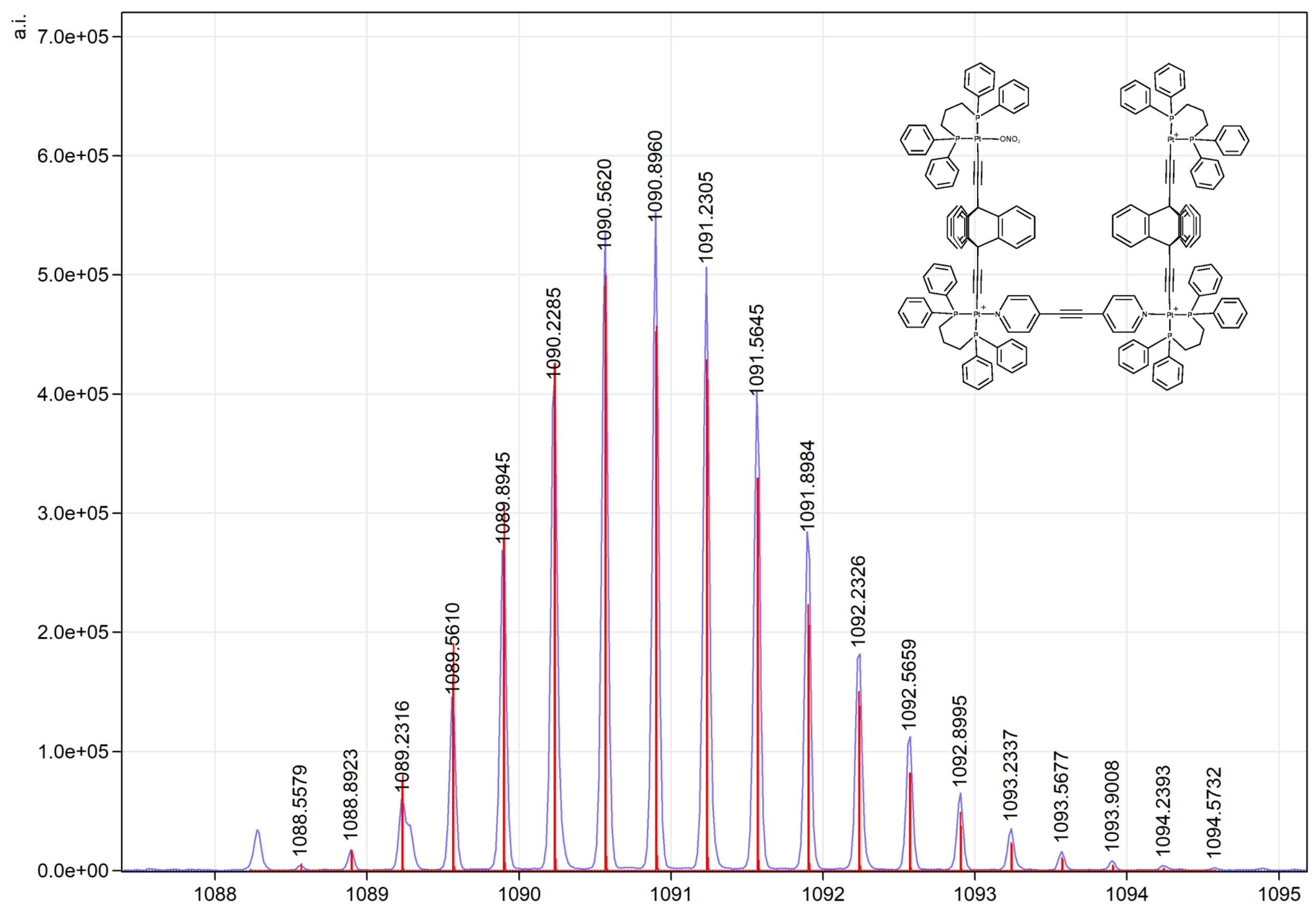

Figure S63. A detail of the HR ESI mass spectrum of the rectangle (8). The red ticks indicate the calculated positions of the peaks corresponding to $\mathrm{m} / \mathrm{z}$ the displayed fragment of the complex. 


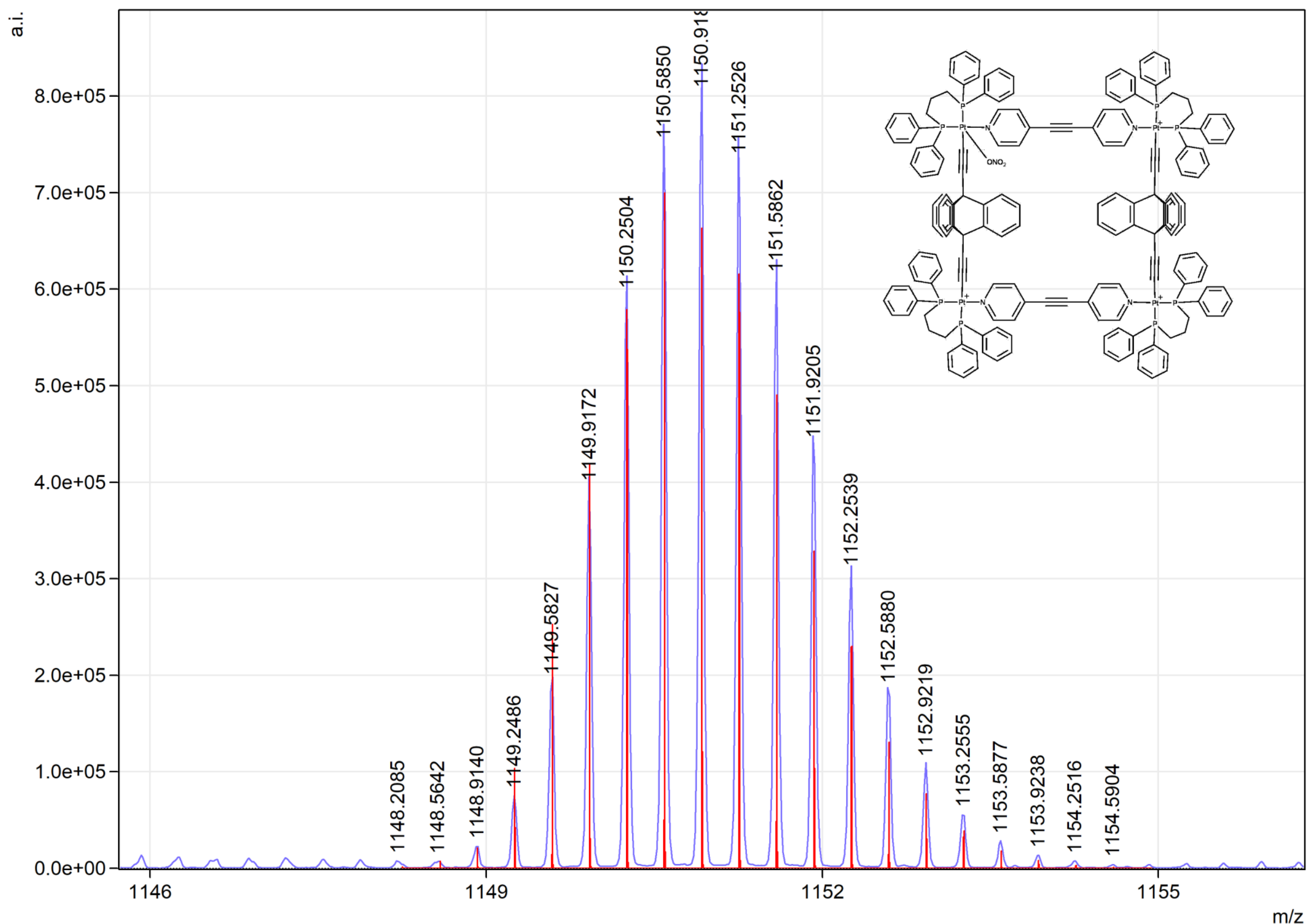

Figure S64. A detail of the HR ESI mass spectrum of the rectangle (8). The red ticks indicate the calculated positions of the peaks corresponding to the displayed fragment of the complex. 


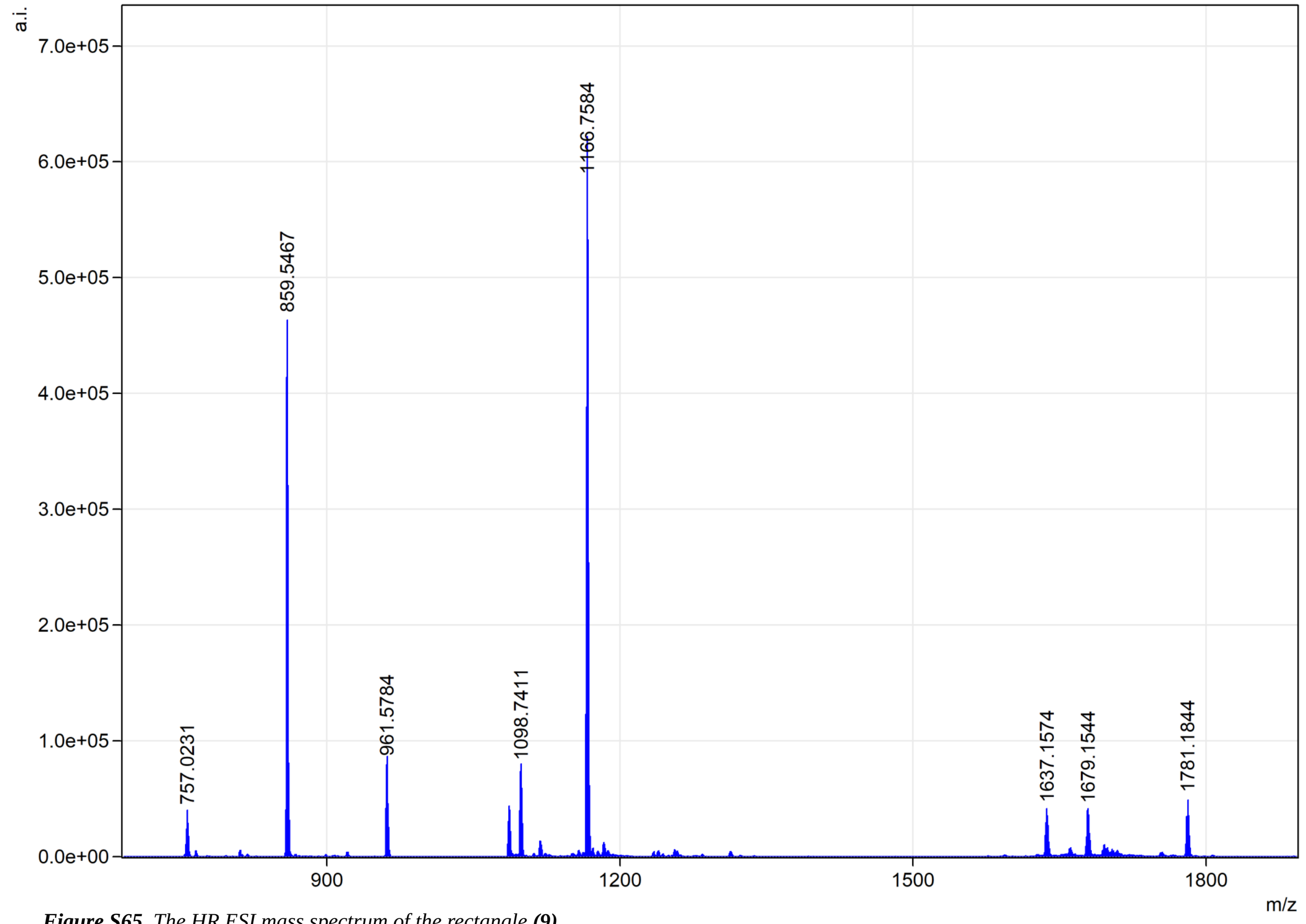

Figure S65. The HR ESI mass spectrum of the rectangle (9). 


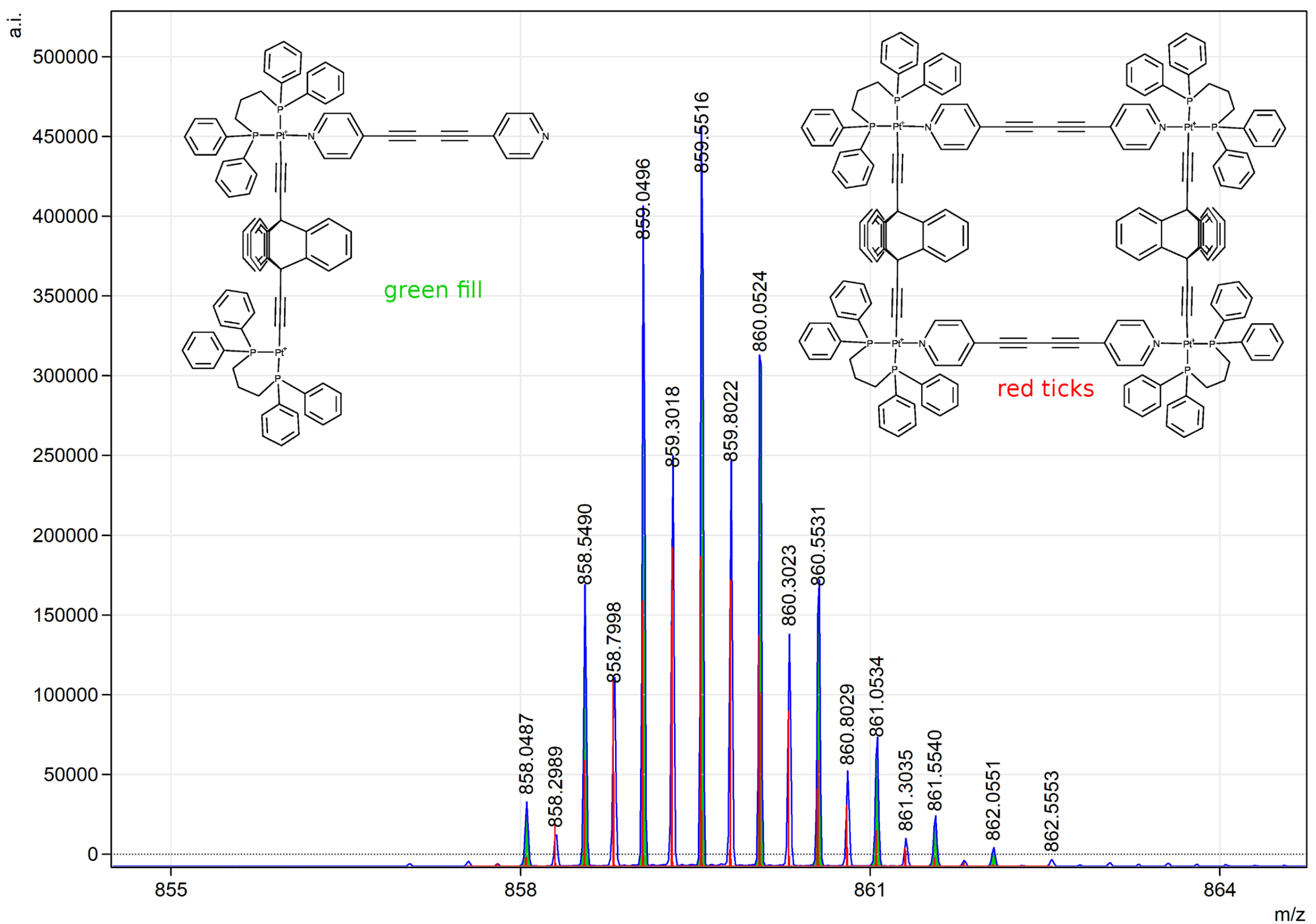

Figure S66. A detail of the HR ESI mass spectrum of the rectangle (9). The red ticks and green fills indicate the calculated positions of the peaks corresponding to the displayed fragments. 


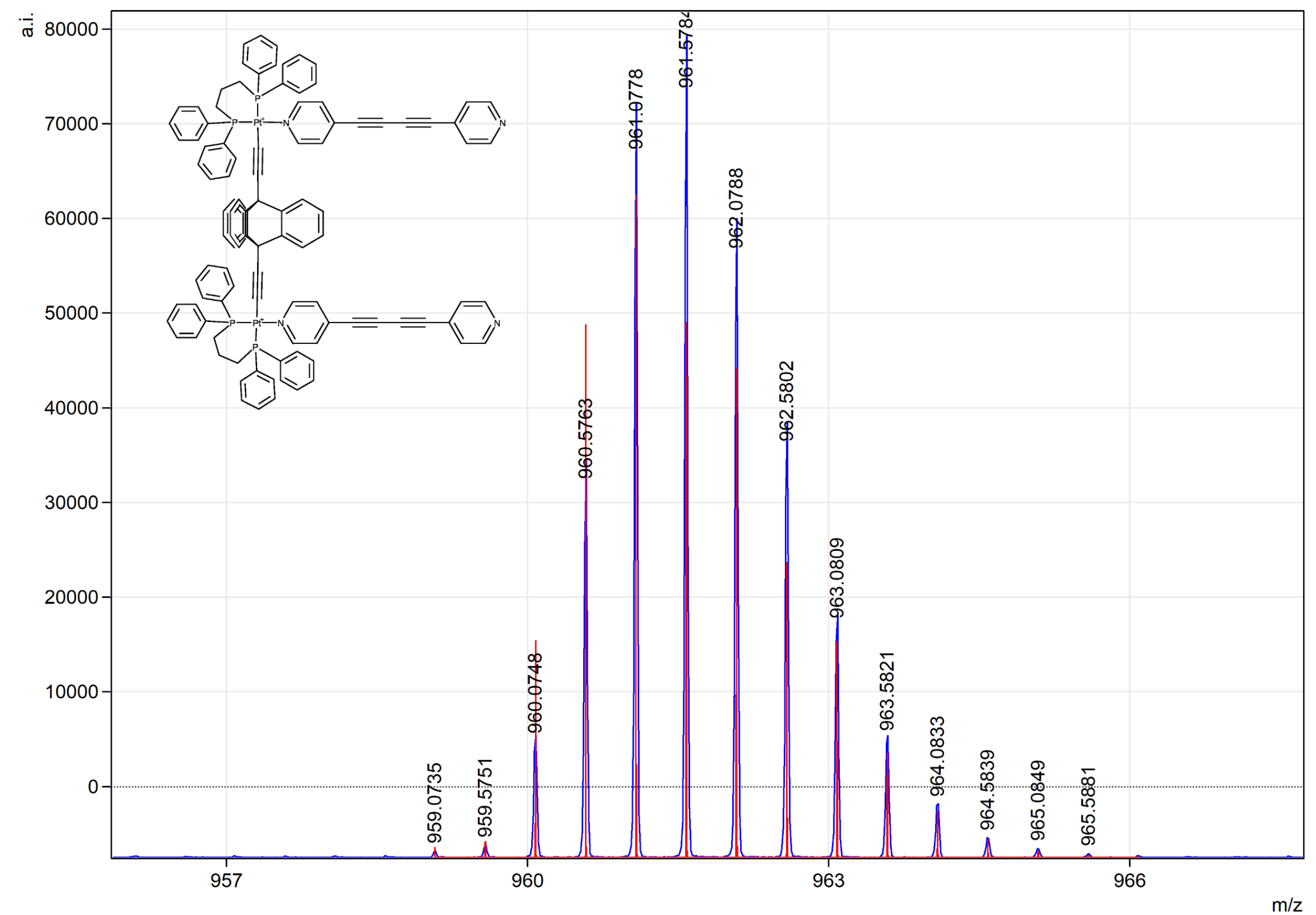

Figure S67. A detail of the HR ESI mass spectrum of the rectangle (9). The red ticks indicate the calculated positions of the peaks corresponding to the displayed fragment of the complex. 


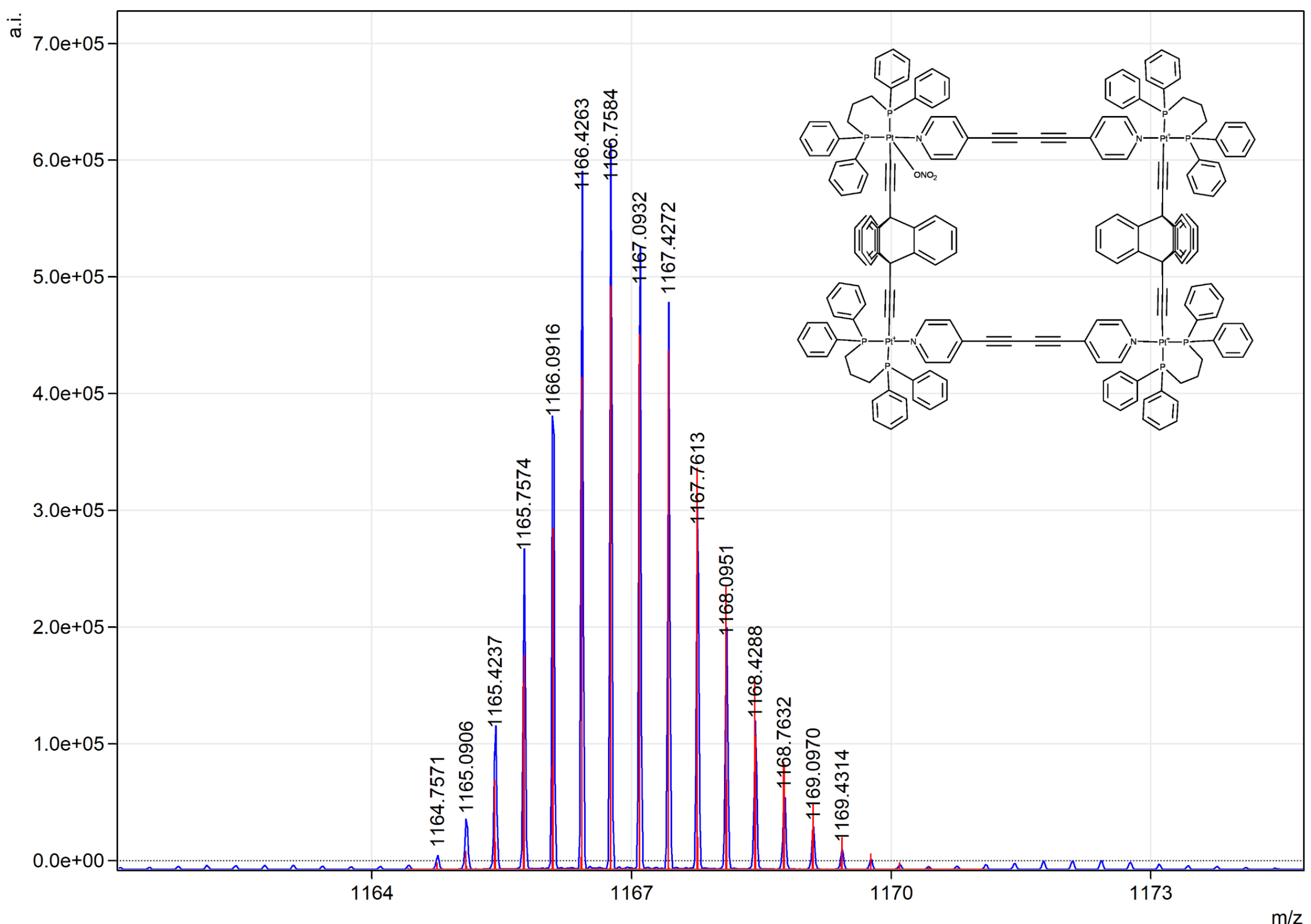

Figure S68. A detail of the HR ESI mass spectrum of the rectangle (9). The red ticks indicate the calculated positions of the peaks corresponding to the displayed fragment of the complex. 


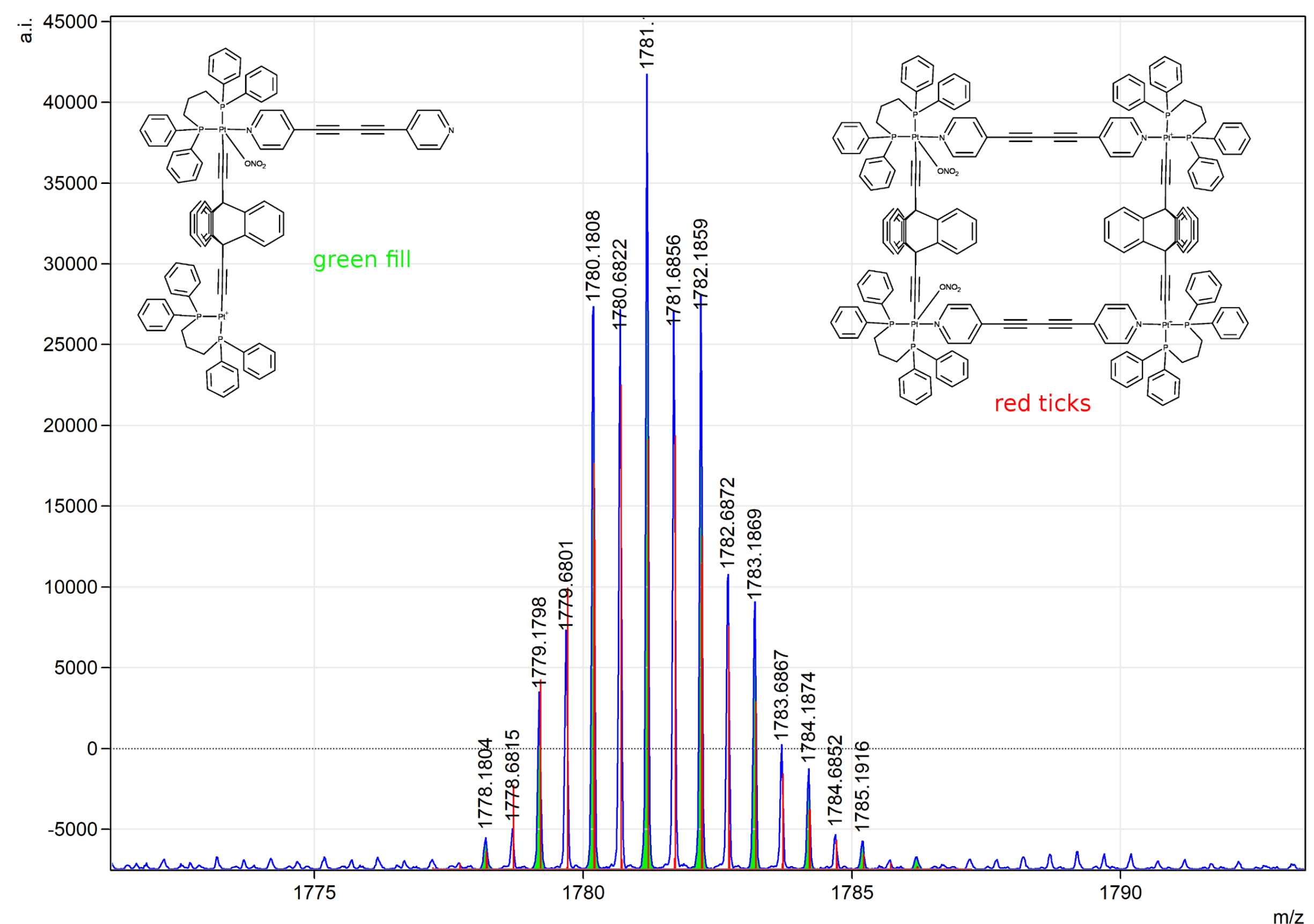

Figure S69. A detail of the HR ESI mass spectrum of the rectangle (9). The red ticks and green fills indicate the calculated positions of the peaks corresponding to the displayed fragments. 


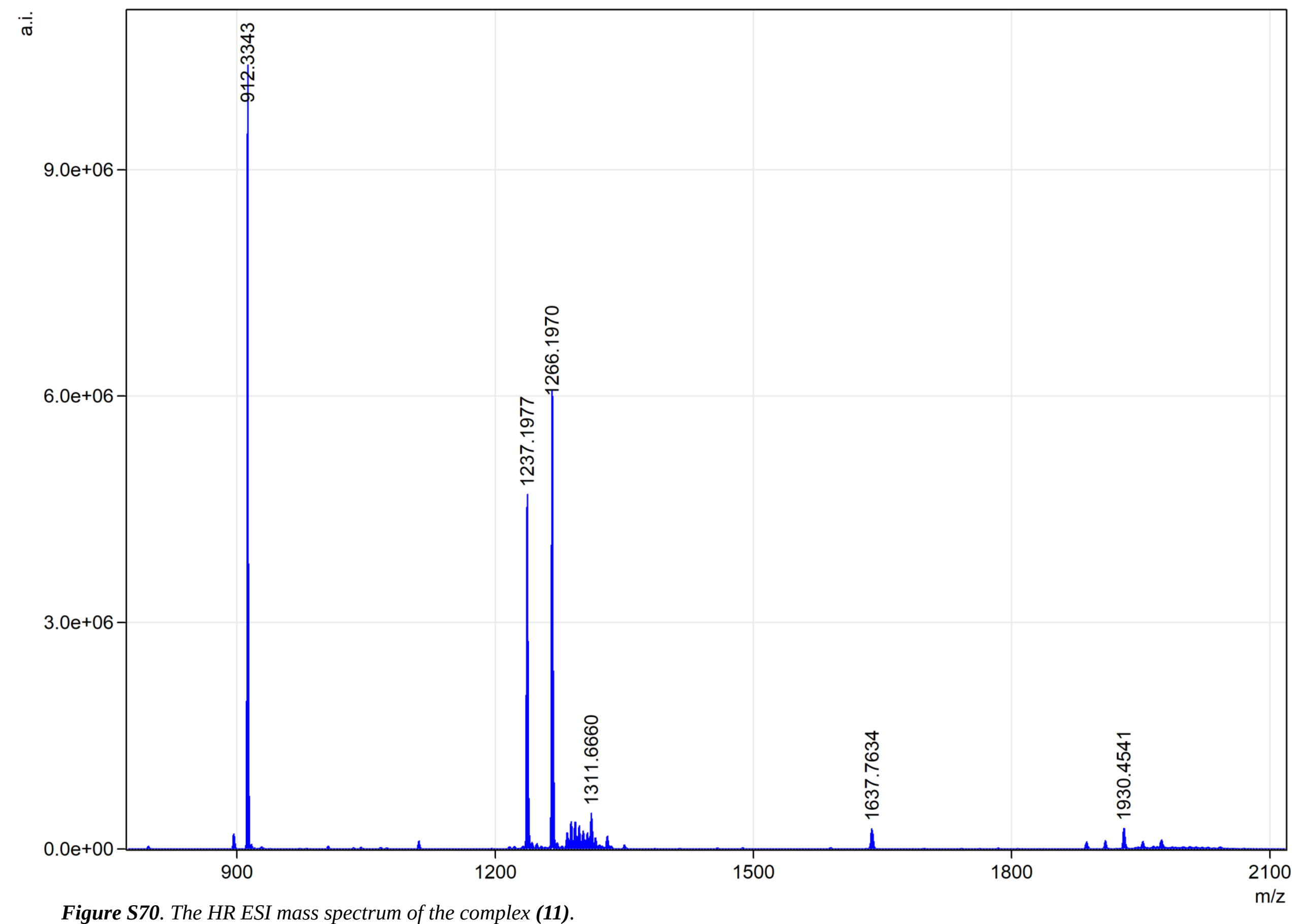

Figure S70. The HR ESI mass spectrum of the complex (11). 


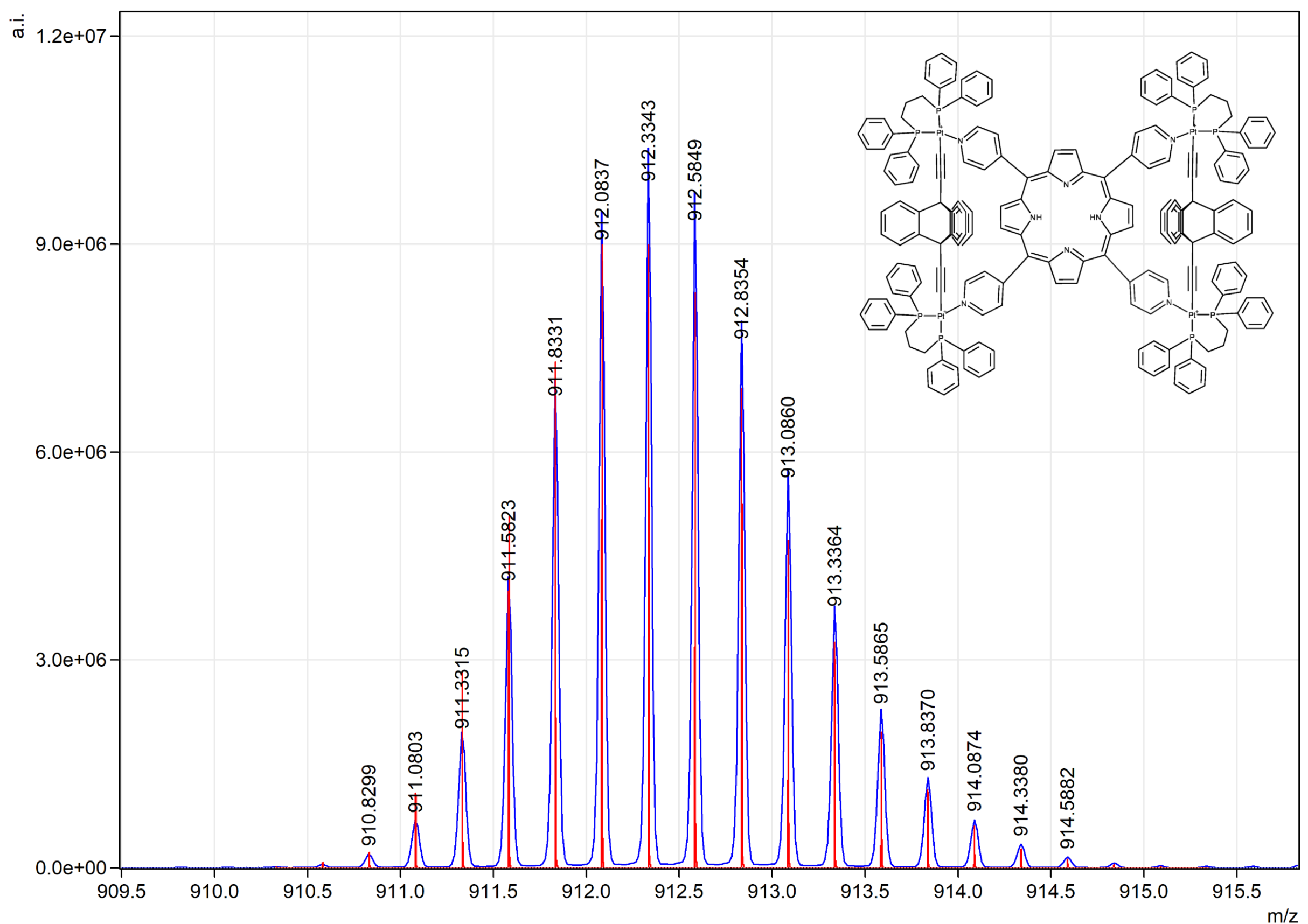

Figure S71. A detail of the HR ESI mass spectrum of the complex (11). The red ticks indicate the calculated positions of the peaks corresponding to the displayed fragment of the complex. 


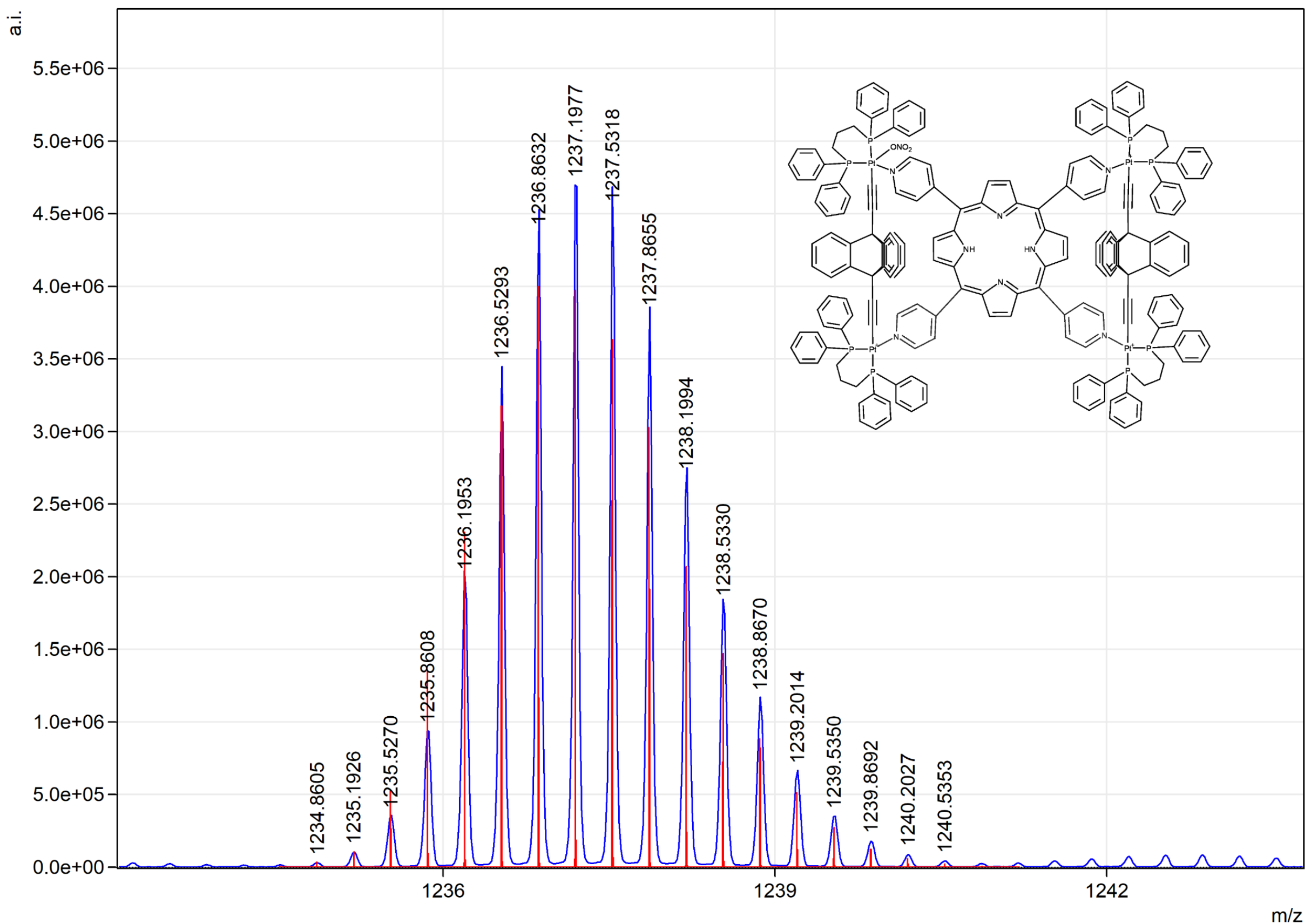

Figure S72. A detail of the HR ESI mass spectrum of the complex (11). The red ticks indicate the calculated positions of the peaks corresponding to the displayed fragment of the complex. 


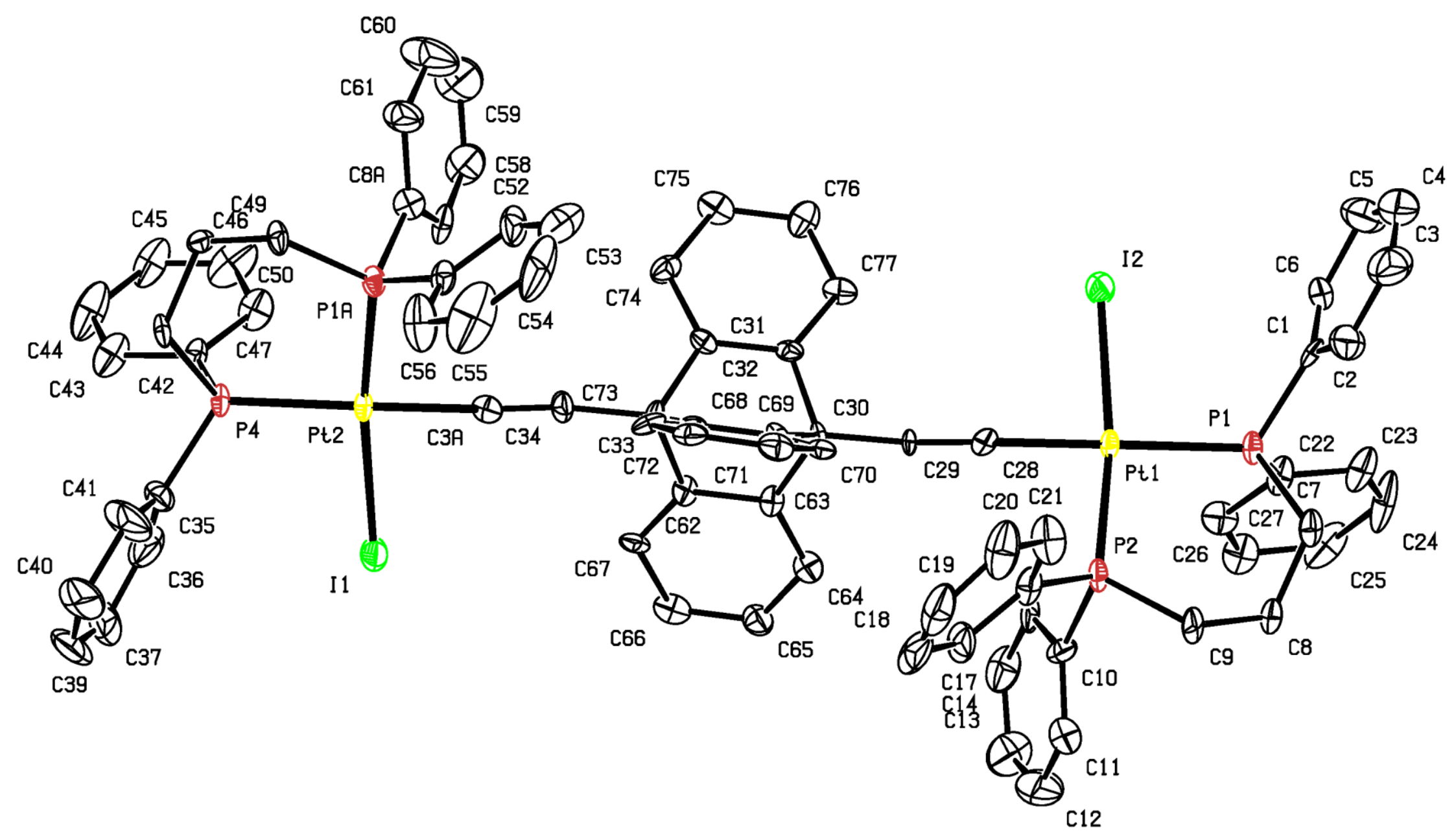

Figure S73. The ORTEP image of the complex (1a) with 30\% thermal probability ellipsoids. The torsional angle I-Pt-Pt-I is $133.81^{\circ}$. 


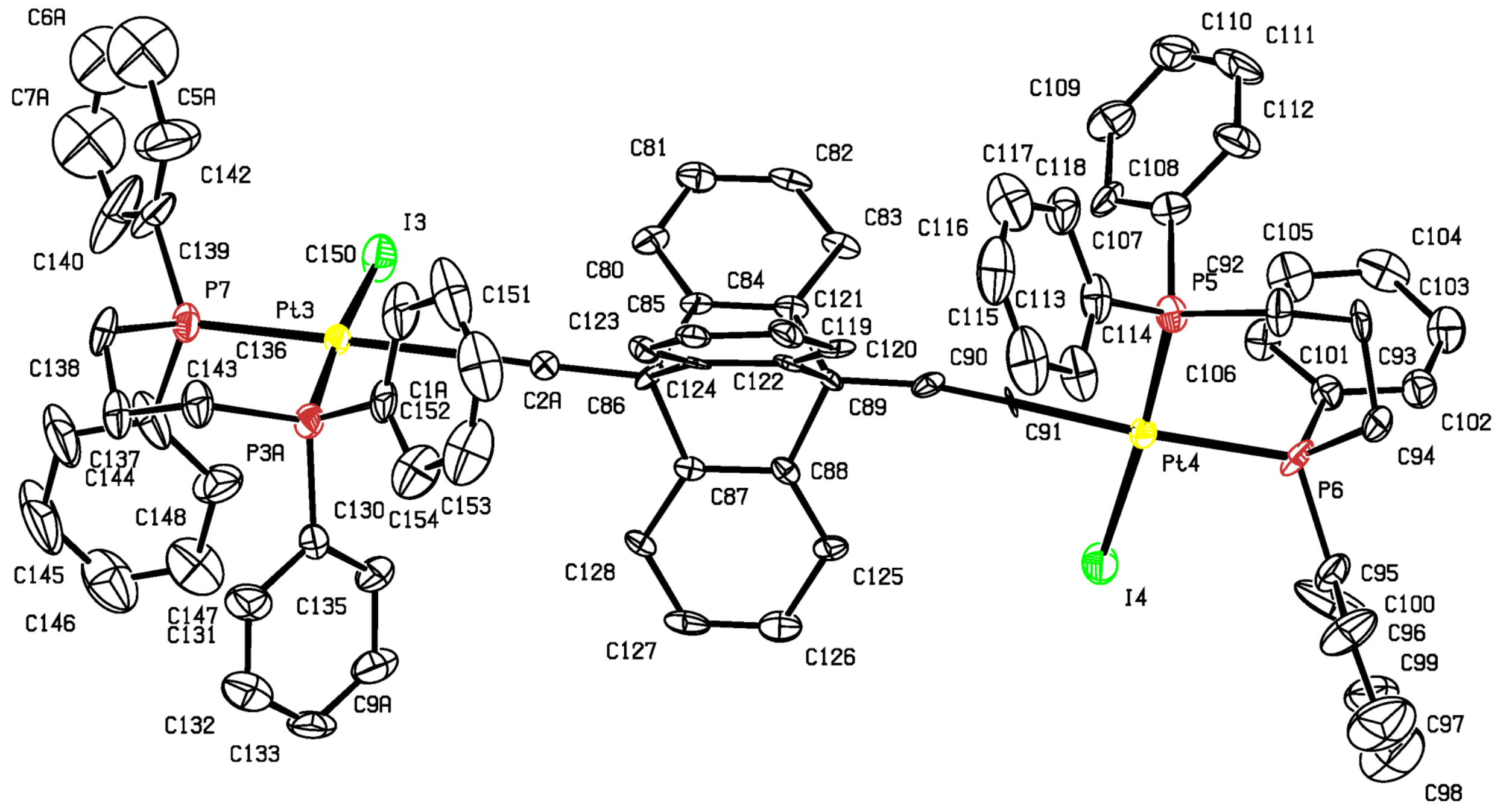

Figure S74. The ORTEP image of the complex (1a) with 30\% thermal probability ellipsoids. The torsional angle I-Pt-Pt-I is $78.23^{\circ}$. 


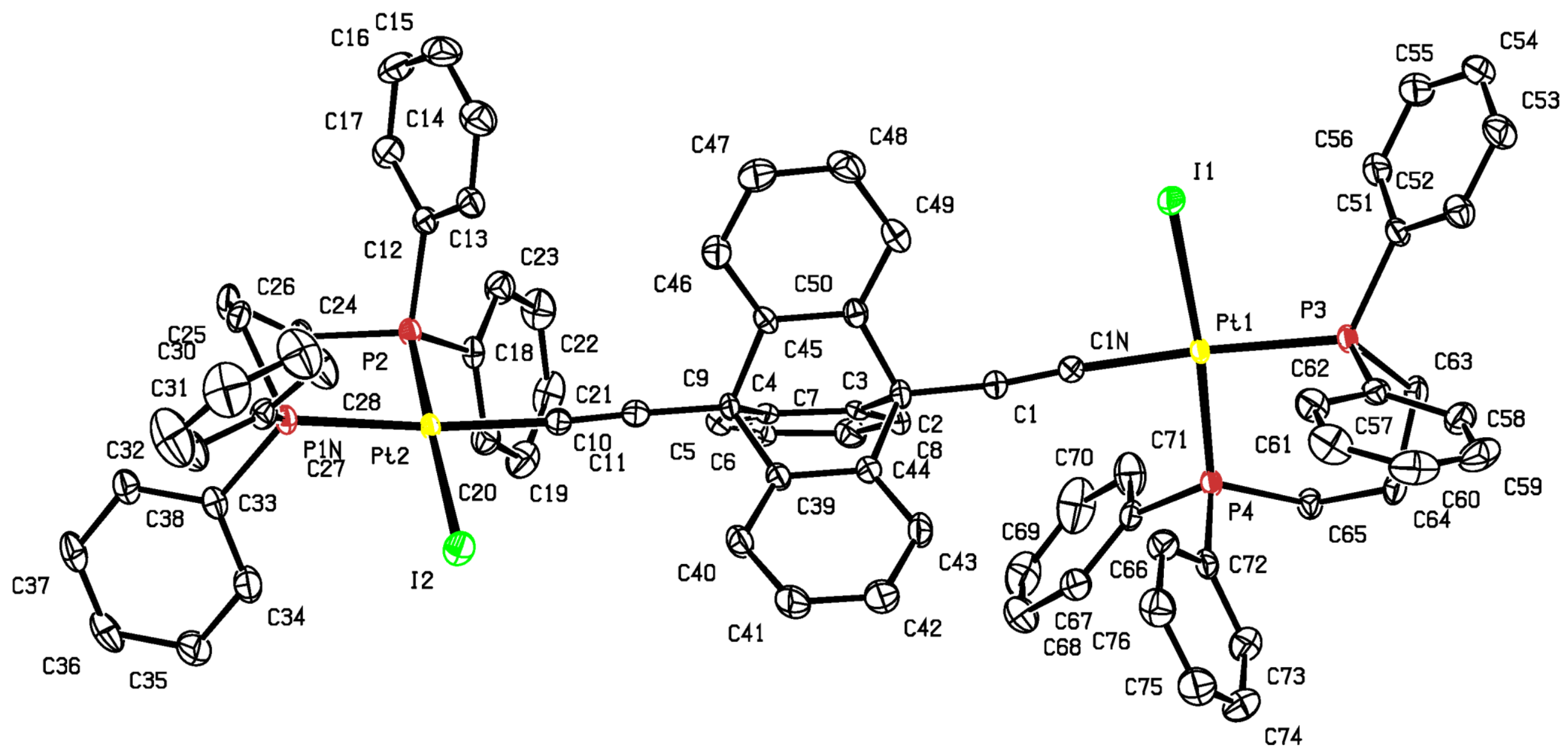

Figure $\mathbf{S 7 5}$. The ORTEP image of the complex (1b) with 30\% thermal probability ellipsoids. 
C28a

C29a

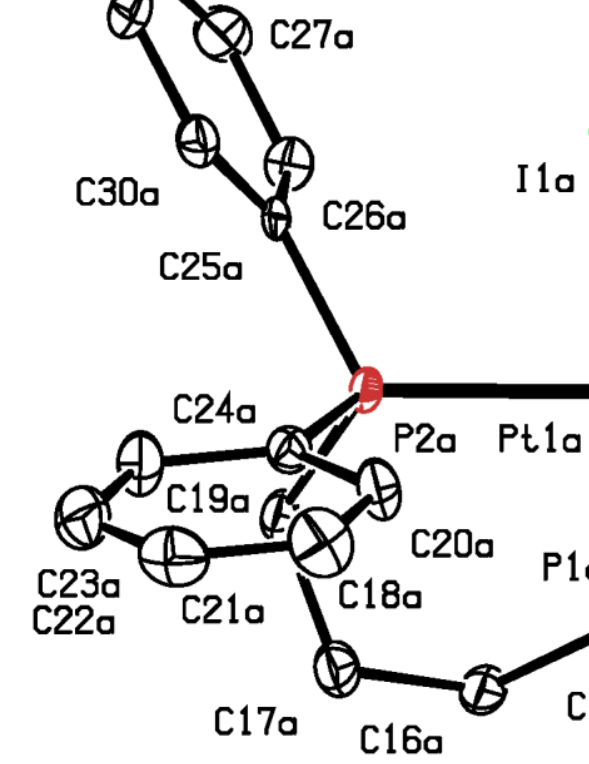

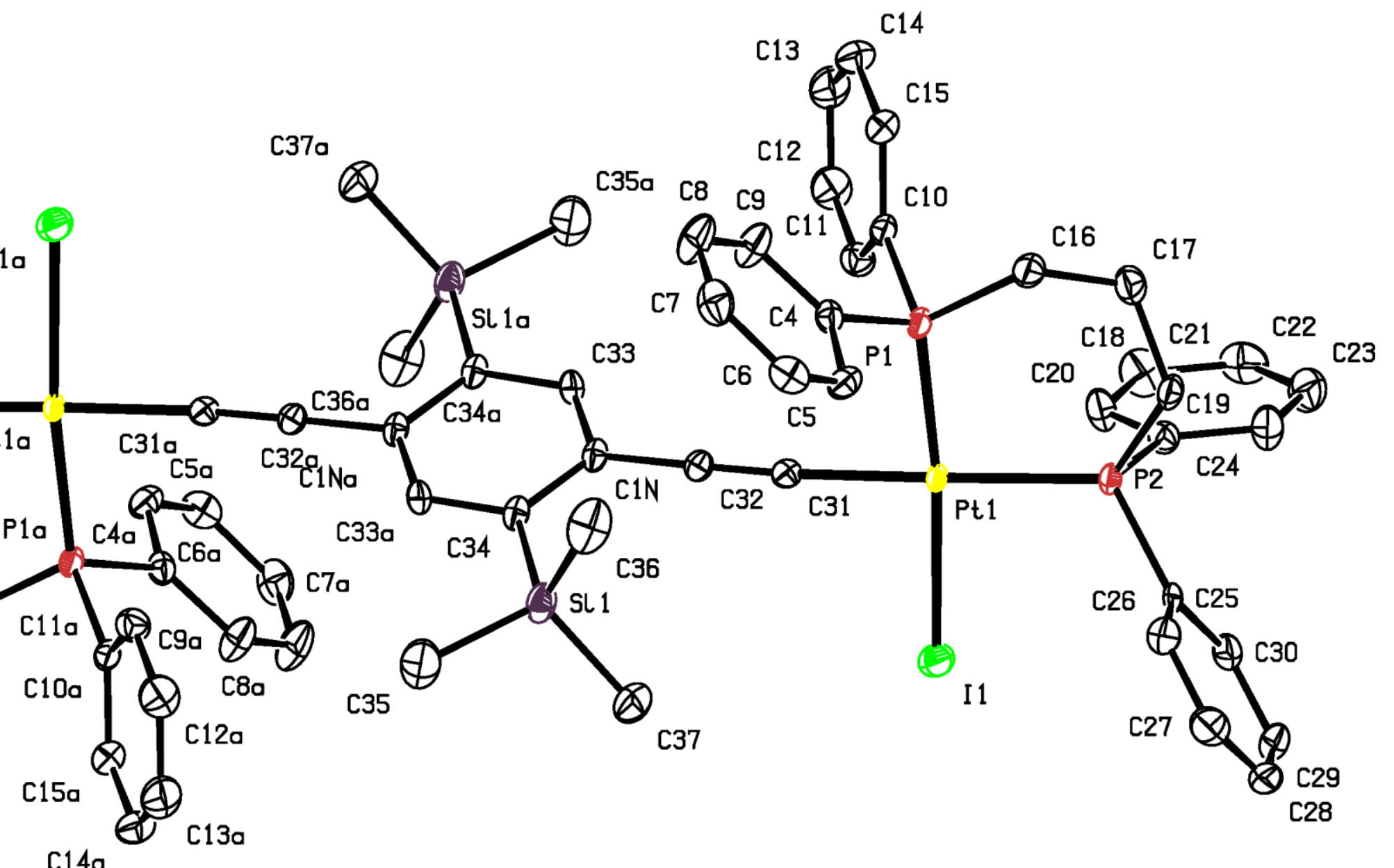

Figure S76. The ORTEP image of the complex (5) with 30\% thermal probability ellipsoids. 
Table S1. Crystallographic data of the characterized compounds.

(1a)

(1b)

3964.09

1769.14

$0.25 \times 0.13 \times 0.09$

$0.31 \times 0.28 \times 0.18$

Colourless

Colourless

Monoclinic

$\mathrm{P} 21 / n$

$16.5037(15)$

$44.273(4)$

$20.3548(19)$

90

$92.470(3)$

90

14859(2)

2

1.658

150

4.845

7168

$\omega-2 \vartheta$

$0.92-26.0$

87513

29184

19738

1591

1.014

$0.0931,0.1625$
(5)

(11)

(13)

$\mathrm{C}_{70} \mathrm{H}_{72} \mathrm{I}_{2} \mathrm{P}_{4} \mathrm{Pt}_{2} \mathrm{Si}_{2} .2 \mathrm{dmf}$ 2021.62

$\mathrm{C}_{198} \mathrm{H}_{154} \mathrm{~N}_{8} \mathrm{P}_{8} \mathrm{Pt}_{4}$

$\mathrm{C}_{188} \mathrm{H}_{144} \mathrm{P}_{8} \mathrm{Pt}_{4}$

4355.80

3431.15

$0.22 \times 0.13 \times 0.13$

$0.09 \times 0.05 \times 0.01$

$0.31 \times 0.11 \times 0.11$

Colourless

Red orange

Light yellow

Triclinic

Monoclinic

Triclinic

P1

$\mathrm{P} 21 / n$

P1

11.7965(3)

24.3550(9)

14.3897(7)

13.5794(3)

17.0767(7)

16.3086(7)

14.3928(3)

24.4866(9)

25.1678(11)

70.570(1)

90

$95.283(2)$

79.938(1)

108.650(2)

104.037(2)

69.511(1)

90

111.791(2)

2032.29(8)

9649.3(6)

$5210.6(4)$

1

2

1

1.652

1.499

1.093

150

100

120

4.356

3.751

2.778

1002

4359

1704

$\omega-2 \vartheta$

$\omega-2 \vartheta$

$1.5-27.5$

2.239-27.206

1.46-26.1

24418

79389

44737

9300

16518

20377

8129

12269

11078

487

1246

901

1.017

1.047

0.960

$0.0377,0.0575$

$0.0998,0.2353$

$0.129,0.153$ 


\section{Syntheses of the Model Compounds}

4,4'-Bis\{[trans-bis(triethylphosphine)(pyridine)platinum(II)]ethynyl\}biphenyl (8).

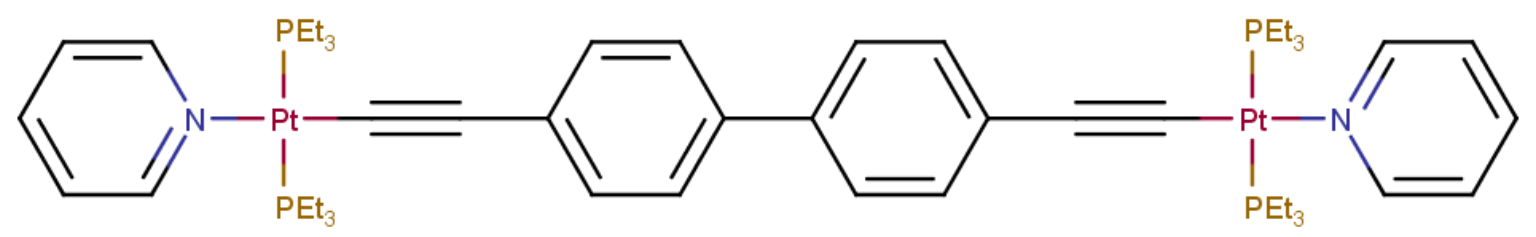

Biphenyl-4,4'-diethynylbis[bis(triethylphosphine)iodoplatinum] (100 mg, $76 \mu$ mol) was dissolved in dry methylene chloride $(4 \mathrm{ml})$ in a $10 \mathrm{ml}$ aluminum foil-wrapped flask. Silver(I) nitrate $(25.8 \mathrm{mg}, 152 \mu \mathrm{mol})$ was added to the solution and the mixture was stirred in the dark at room temperature overnight. The silver(I) iodide precipitate was filtered off with a Whatman $0.2 \mu \mathrm{m}$ filter and freshly distilled pyridine $(12 \mu \mathrm{l}, 152 \mu \mathrm{mol})$ was added to the filtrate. The solution was stirred for $30 \mathrm{~min}$ and the product was precipitated with pentane. White needles (69.5 mg, 68 \%). Mp $215.5-216^{\circ} \mathrm{C}(\mathrm{dec}) .{ }^{1} \mathrm{H} \mathrm{NMR}\left(400 \mathrm{MHz}, \mathrm{CD}_{2} \mathrm{Cl}_{2}\right): \delta=8.66$ (d, J = 5.1 Hz, 4H), $8.10(\mathrm{t}, 2 \mathrm{H}, J=7.7 \mathrm{~Hz}), 7.82-7.67(\mathrm{~m}, 4 \mathrm{H}), 7.52(\mathrm{~d}, 4 \mathrm{H}, J=8.2 \mathrm{~Hz}), 7.34$ (d, $4 \mathrm{H}, J=8.1 \mathrm{~Hz}), 1.81(\mathrm{ddd}, 24 \mathrm{H}, J=11.0,7.2,3.8 \mathrm{~Hz}), 1.18(\mathrm{dq}, 36 \mathrm{H}, J=16.1,9.1,7.8 \mathrm{~Hz}) .{ }^{13} \mathrm{C}\left\{{ }^{1} \mathrm{H}\right\}$ $\operatorname{NMR}\left(100 \mathrm{MHz}, \mathrm{CD}_{2} \mathrm{Cl}_{2}\right): \delta=152.9,140.8,138.9,132.0,128.9\left({ }^{3} \mathrm{JPt}_{\mathrm{Pt} C}=27 \mathrm{~Hz}\right), 127.0,126.7$, 107.0, $76.1\left(\mathrm{~d},{ }^{2} J_{\mathrm{P}-\mathrm{C}}=16 \mathrm{~Hz}\right), 14.8\left(\mathrm{dd},{ }^{3} \mathrm{JP}_{\mathrm{P}-\mathrm{C}}={ }^{1} J_{\mathrm{P}-\mathrm{C}}=17 \mathrm{~Hz}\right), 8.24\left({ }^{3} J_{\mathrm{Pt}-\mathrm{C}}=19 \mathrm{~Hz}\right) .{ }^{1} \mathrm{P}\left\{{ }^{1} \mathrm{H}\right\} \mathrm{NMR}$ $\left(162 \mathrm{MHz}, \mathrm{CD}_{2} \mathrm{Cl}_{2}\right): \delta=15.71\left({ }^{1} \mathrm{JPt}_{\mathrm{P}}=2325.0 \mathrm{~Hz}\right) .{ }^{195} \mathrm{Pt} \mathrm{NMR}\left(107 \mathrm{MHz}, \mathrm{CD}_{2} \mathrm{Cl}_{2}\right): \delta=-4361.0$ $\left(\mathrm{t}, 1_{\mathrm{P}-\mathrm{Pt}}=2326 \mathrm{~Hz}\right) \cdot \mathrm{MS}(\mathrm{ESI}+): \mathrm{m} / \mathrm{z} 711.2\left(\left\{\mathrm{M}-\left[\left(\mathrm{PEt}_{3}\right)_{2} \mathrm{Pt}(\mathrm{py})\right]\right\}^{+}, 91\right), 610.2\left(\mathrm{M}^{2+}, 92\right), 570.7[(\mathrm{M}$ - py) $\left.{ }^{2+}, 69\right], 430.0$ [( $\left.\mathrm{PEt}_{3}\right)_{2} \mathrm{Pt}^{+}, 100 \%$ ]. Anal. (\%) Calcd for $\mathrm{C}_{50} \mathrm{H}_{78} \mathrm{~N}_{4} \mathrm{O}_{6} \mathrm{P}_{4} \mathrm{Pt}_{2}: \mathrm{C}, 44.64 ; \mathrm{H}, 5.84 ; \mathrm{N}$, 4.16; Pt, 29.0. Found: C, 44.35; H, 5.79; N, 4.09; Pt, 28.65. 
(9).

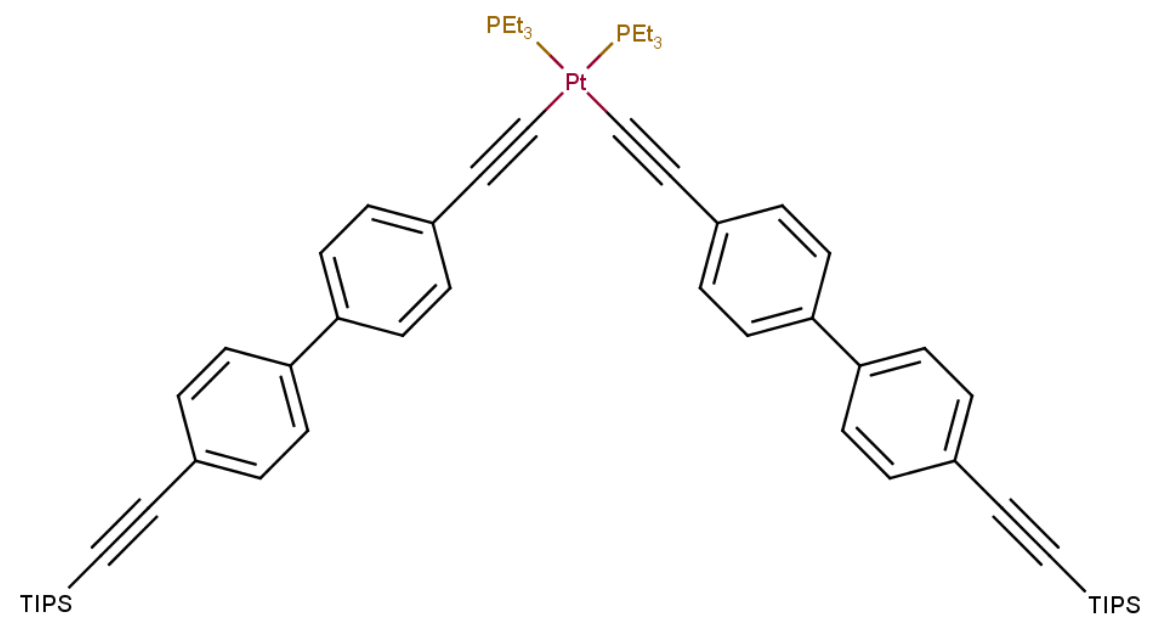

Cis-[Pt( $\left.\mathrm{PEt}_{3}\right)_{2} \mathrm{Cl}_{2}$ ] $(120 \mathrm{mg}, 0.24 \mathrm{mmol})$, 4-ethynyl-4'-[(triisopropylsilyl)ethynyl]-1,1'-biphenyl (170 $\mathrm{mg}, 0.48 \mathrm{mmol})$ and dry diethylamine $(70 \mathrm{ml})$ was added to a flame-dried three-necked flask. The mixture was degassed and stirred under Ar-atmosphere for 10 minutes. $\mathrm{CuCl}$ (10 $\mathrm{mg}$ ) was added and the flask was wrapped in aluminum foil. The reaction mixture was stirred in the dark under inert atmosphere at room temperature overnight. The mixture was filtered, the filtrate evaporated under vacuum and re-dissolved in methylene chloride ( $30 \mathrm{ml})$. The solution was washed by water, dried over $\mathrm{MgSO}_{4}$ and evaporated. The resulting yellow oil was chromatographed on $\mathrm{SiO}_{2}$ using methylene chloride/hexane (2:1) as the eluent. The eluted fractions containing the product were collected and evaporated to give a $158 \mathrm{mg}$ of a yellow oil containing the cis-isomer of the TIPS-protected product and $42 \mathrm{mg}$ of a mixture containing $88 \%$ of the cis- and $12 \%$ of the trans-isomer. Cis-isomer: ${ }^{1} \mathrm{H} N \mathrm{NMR}\left(400 \mathrm{MHz}, \mathrm{CDCl}_{3}\right)$ : $\delta=7.63-7.31(\mathrm{~m}, 16 \mathrm{H}), 2.18-1.97(\mathrm{~m}, 12 \mathrm{H}), 1.39-1.13(\mathrm{~m}, 18 \mathrm{H}), 1.13(\mathrm{~s}, 42 \mathrm{H}) .{ }^{31} \mathrm{P}\left\{{ }^{1} \mathrm{H}\right\} \mathrm{NMR}$ $\left(162 \mathrm{MHz}, \mathrm{CDCl}_{3}\right): \delta=4.81(\mathrm{~d}, J=2259.1 \mathrm{~Hz})$. Trans-isomer: ${ }^{31} \mathrm{P}\left\{{ }^{1} \mathrm{H}\right\} \mathrm{NMR}\left(162 \mathrm{MHz}, \mathrm{CDCl}_{3}\right): \delta$ $=11.07(\mathrm{~d}, \mathrm{~J}=2372.3 \mathrm{~Hz})$. 

(10b)).

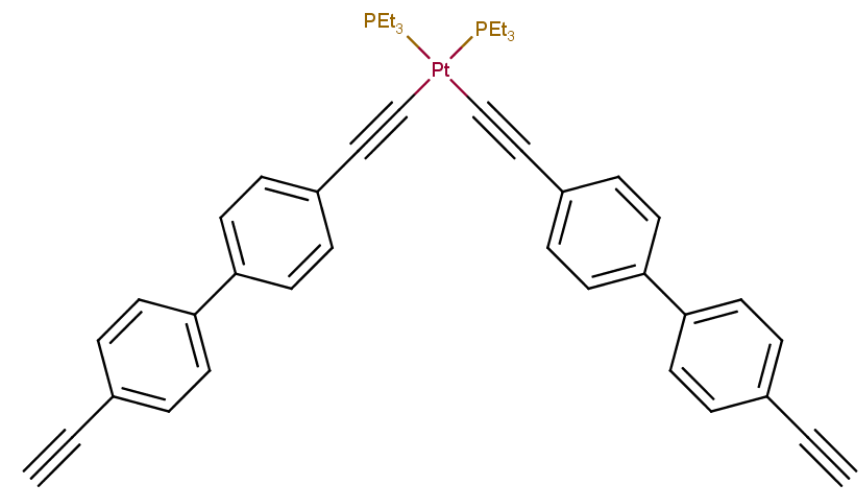

The yellow oily cis-isomer of (9) prepared as described above (158 mg) was dissolved in THF $(30 \mathrm{ml})$ and tetrabutylammonium fluoride hydrate $(100 \mathrm{mg})$ was added to this solution and stirred at room temperature overnight. The solvent was evaporated and the residue chromatographed on $\mathrm{SiO}_{2}$ column using methylene chloride/ethyl acetate/hexane (2:2:10) mixture as the eluent to get $90 \mathrm{mg}$ of pure cis- $\left(R_{f}=0.4\right)$ and $10 \mathrm{mg}$ of pure trans-isomer $\left(R_{f}=\right.$ 0.7) with the overall yield from cis-[Pt( $\left.\left(\mathrm{PEt}_{3}\right)_{2} \mathrm{Cl}_{2}\right] 88 \%$. Cis-isomer ((IVa)): ${ }^{1} \mathrm{H} \mathrm{NMR}(400 \mathrm{MHz}$, $\left.\mathrm{CDCl}_{3}\right): \delta=7.53(\mathrm{~s}, 8 \mathrm{H}), 7.51-7.41(\mathrm{~m}, 8 \mathrm{H}), 3.11(\mathrm{~s}, 2 \mathrm{H}), 2.23-1.84(\mathrm{~m}, 12 \mathrm{H}), 1.17(\mathrm{dt}, J=$ 15.5, 7.5 Hz, 18H). ${ }^{13} \mathrm{C}\left\{{ }^{1} \mathrm{H}\right\} \mathrm{NMR}\left(100 \mathrm{MHz}, \mathrm{CDCl}_{3}\right): \delta=141.57,136.78,132.54,131.92,128.25$, $126.66,126.35,120.53,106.63,83.81,77.66,17.25,8.57 .{ }^{31} \mathrm{P}\left\{{ }^{1} \mathrm{H}\right\} N M R(162 \mathrm{MHz}$, Chloroformd): $\delta=4.78(\mathrm{~d}, J=2255.9 \mathrm{~Hz}) ; \mathrm{MS}(\mathrm{ESI}+): \mathrm{m} / \mathrm{z} 834.4\left([\mathrm{M}+\mathrm{H}]^{+}, 100\right), 856.4\left([\mathrm{M}+\mathrm{Na}]^{+}, 55\right)$. Transisomer ((IVb)): ${ }^{1} \mathrm{H} \mathrm{NMR}\left(400 \mathrm{MHz}, \mathrm{CDCl}_{3}\right): \delta=7.54(\mathrm{~s}, 8 \mathrm{H}), 7.46(\mathrm{~d}, 4 \mathrm{H}, \mathrm{J}=8.2 \mathrm{~Hz}), 7.35(\mathrm{~d}, 4 \mathrm{H}$, $\mathrm{J}=8.2 \mathrm{~Hz}), 3.12(\mathrm{~s}, 2 \mathrm{H}), 2.19(\mathrm{ddt}, 12 \mathrm{H}, \mathrm{J}=11.0,7.4,4.0 \mathrm{~Hz}), 1.34-1.09(\mathrm{~m}, 18 \mathrm{H}) .{ }^{31} \mathrm{P}\left\{{ }^{1} \mathrm{H}\right\} \mathrm{NMR}$ $\left(162 \mathrm{MHz}, \mathrm{CDCl}_{3}\right): \delta=11.07(\mathrm{~d}, \mathrm{~J}=2367.2 \mathrm{~Hz})$. 


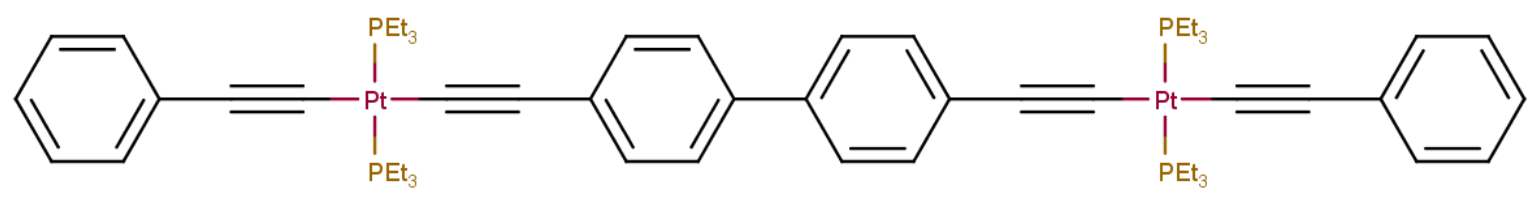

Biphenyl-4,4'-diethynylbis[bis(triethylphosphine)iodoplatinum] $(50 \mathrm{mg}, 38 \mu \mathrm{mol}$ ) was dissolved in dry methylene chloride $(15 \mathrm{ml})$ in an aluminum-wrapped flask. Silver(I) nitrate (13 $\mathrm{mg}, 76 \mu \mathrm{mol}$ ) together with freshly distilled pyridine ( 2 drops) was added to the mixture and the slurry was stirred in the dark at room temperature overnight. The silver(I) iodide precipitate was filtered off with a Whatman $0.2 \mu \mathrm{m}$ syringe filter and the filtrate was evaporated to dryness. The residue was dissolved in dry methylene chloride $(10 \mathrm{ml})$ of and diisopropylamine $(0.2 \mathrm{ml})$ and phenylacetylene $(10 \mu \mathrm{l})$ were added. The solution was stirred approximately 20 minutes under argon atmosphere and Cul $(2 \mathrm{mg})$ was added. The reaction mixture was stirred at room temperature overnight and the the liquids were evaporated. The residue was purified by flash column chromatography $\left(\mathrm{SiO}_{2}\right.$, methylene chloride/hexane 100:1). Yellowish powder (49 mg, $100 \%$ yield). ${ }^{1} \mathrm{H} \mathrm{NMR}\left(400 \mathrm{MHz}, \mathrm{CDCl}_{3}\right): \delta=7.54(\mathrm{~d}, 4 \mathrm{H}, \mathrm{J}=$ $8.14 \mathrm{~Hz}), 7.38(\mathrm{~d}, 4 \mathrm{H}, \mathrm{J}=8.14 \mathrm{~Hz}), 7.29(\mathrm{~m}, 4 \mathrm{H}), 7.21(\mathrm{~m}, 4 \mathrm{H}), 7.12(\mathrm{~m}, 2 \mathrm{H}), 2.19(\mathrm{~m}, 24 \mathrm{H}), 1.26$ $-1.18(\mathrm{~m}, 36 \mathrm{H}) .{ }^{31} \mathrm{P}\left\{{ }^{1} \mathrm{H}\right\} \operatorname{NMR}\left(162 \mathrm{MHz}, \mathrm{CDCl}_{3}\right): \delta=11.38\left({ }^{1} \mathrm{JPt}_{\mathrm{P}}=2366.3 \mathrm{~Hz}\right)$. Anal. (\%) Calcd for $\mathrm{C}_{56} \mathrm{H}_{78} \mathrm{P}_{4} \mathrm{Pt}_{2}$ : C, 53.16; $\mathrm{H}, 6.21 ; \mathrm{Pt}, 30.84$. Found: $\mathrm{C}, 52.94 ; \mathrm{H}, 6.03 ; \mathrm{Pt}, 30.51$. 


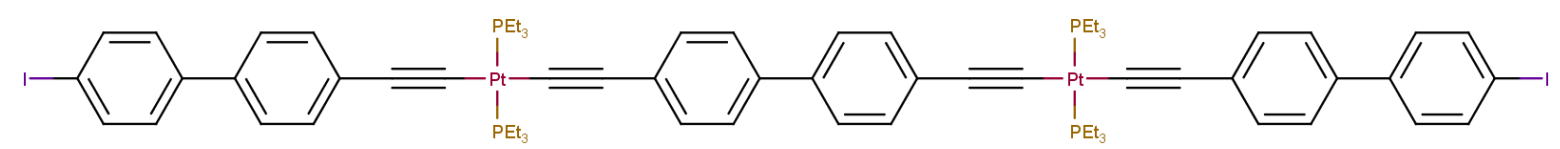

and $\quad 4,4^{\prime}$-bis(\{[4-(4'-phenylethynyl)biphenyl]ethynyl\}bis\{triethylphosphine\}platinum(II)ethynyl)biphenyl (13).

These complexes were prepared as described above for compound (11) starting from 4-(4'iodobiphenyl)acetylene and [4-(4'-phenylethynyl)biphenyl]acetylene, respectively, instead of phenylacetylene in $80 \%$ and $83 \%$ yield, respectively. Yellowish powders. Data for $(\mathbf{1 2}):{ }^{1} \mathrm{H}$ NMR $\left(400 \mathrm{MHz}, \mathrm{CD}_{2} \mathrm{Cl}_{2}\right): \delta=7.82-7.66(\mathrm{~m}, 4 \mathrm{H}), 7.52-7.40(\mathrm{~m}, 8 \mathrm{H}), 7.40-7.28(\mathrm{~m}, 12 \mathrm{H})$, $2.20(\mathrm{~m}, 24 \mathrm{H}), 1.40-1.04(\mathrm{~m}, 36 \mathrm{H}) .{ }^{13} \mathrm{C}\left\{{ }^{1} \mathrm{H}\right\} \mathrm{NMR}\left(101 \mathrm{MHz}, \mathrm{CD}_{2} \mathrm{Cl}_{2}\right): \delta=141.0,138.4,137.9$, $136.8,131.8,131.7,129.1,126.9,126.7,109.8,109.7,92.9,17.0(\mathrm{~m}), 8.7 .{ }^{31} \mathrm{P}\left\{{ }^{1} \mathrm{H}\right\} N M R(162$ $\left.\mathrm{MHz}, \mathrm{CD}_{2} \mathrm{Cl}_{2}\right): \delta=11.44\left({ }^{1} J_{\mathrm{Pt}-\mathrm{P}}=2360.5 \mathrm{~Hz}\right)$. Anal. (\%) Calcd for $\mathrm{C}_{68} \mathrm{H}_{84} \mathrm{I}_{2} \mathrm{P}_{4} \mathrm{Pt}_{2}: \mathrm{C}, 48.93 ; \mathrm{H}, 5.07$; I, 15.2; Pt, 23.37. Found: C, 49.21; H, 5.10; I, 14.35; Pt, 22.76. Data for (13): ${ }^{1} \mathrm{H}$ NMR (400 MHz, $\left.\mathrm{CD}_{2} \mathrm{Cl}_{2}\right): \delta=7.60(\mathrm{~d}, 8 \mathrm{H}, \mathrm{J}=2.4 \mathrm{~Hz}), 7.58-7.43(\mathrm{~m}, 12 \mathrm{H}), 7.42-7.25(\mathrm{~m}, 14 \mathrm{H}), 2.20(\mathrm{dtq}, 24 \mathrm{H}$, $J=12.3,8.2,4.6 \mathrm{~Hz}), 1.25$ (dt, 36H, J=15.9, 7.7 Hz). ${ }^{13} \mathrm{C}\left\{{ }^{1} \mathrm{H}\right\} \mathrm{NMR}\left(101 \mathrm{MHz}, \mathrm{CD}_{2} \mathrm{Cl}_{2}\right): \delta=140.70$, $137.26,136.45,131.93,131.48,131.20,131.09,128.60,128.40,128.30,127.79,126.53$, $126.42,126.12,123.25,121.70,109.99,109.14,89.85,89.25,16.40(\mathrm{~m}), 8.13 .{ }^{31} \mathrm{P}\left\{{ }^{1} \mathrm{H}\right\} N M R$ $\left(162 \mathrm{MHz}, \mathrm{CD}_{2} \mathrm{Cl}_{2}\right): \delta=11.44\left({ }^{1} \mathrm{JPt}_{\mathrm{P}}=2358.9 \mathrm{~Hz}\right)$. Anal. (\%) Calcd for $\mathrm{C}_{84} \mathrm{H}_{94} \mathrm{P}_{4} \mathrm{Pt}_{2}: \mathrm{C}, 62.37 ; \mathrm{H}$, 5.86; Pt, 24.12. Found: C, 62.15; $H, 5.89 ; \mathrm{Pt}, 23.84$. 